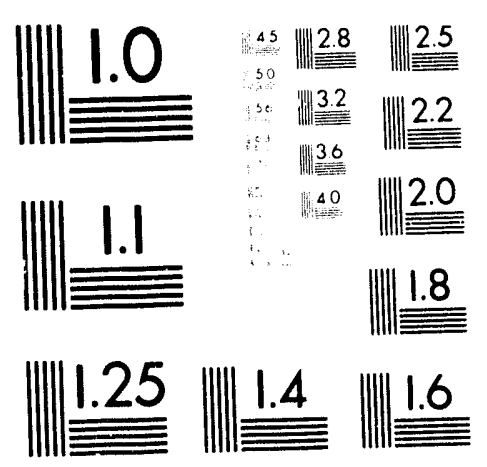



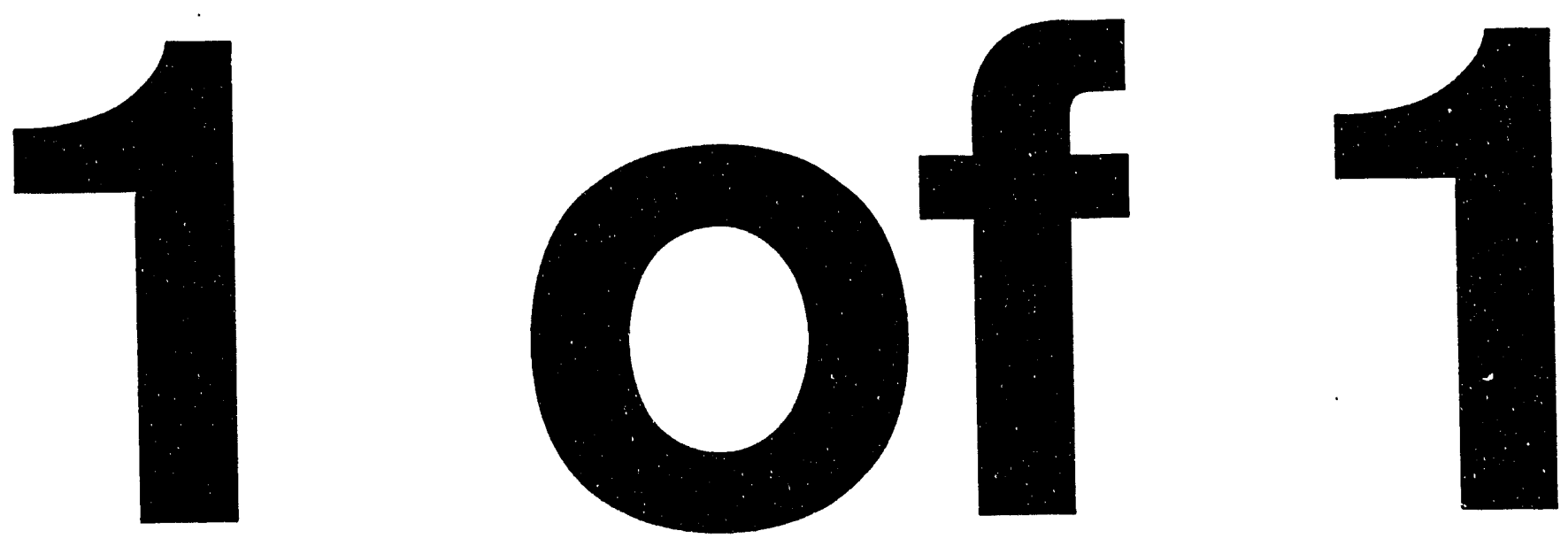


\title{
A Combined Physical/Microbial Process for the Beneficiation of Coal
}

\author{
Graham F. Andrews \\ Carol J. Stevens \\ Karl S. Noah \\ Michael E. Mcllwain
}

Published September 1993

\author{
Idaho National Engineering Laboratory \\ EG\&G Idaho, Inc. \\ Idaho Falls, Idaho 83415
}

Prepared for the

U.S. Department of Energy

Assistant Secretary for the Office of Fossil Energy

Under DOE Idaho Operations Office

Contract DE-AC07-76ID01570 


\begin{abstract}
A large-laboratory scale physical/microbial process was demonstrated for the removal of pyritic sulfur from coal. The process took place in an aerated-1rough slurry reactor with a total slurry volume of $150 \mathrm{~L}$. The reactor was divided into six sections. each of which acted as a physical separator and a bioreactor. The process objective was to physically remove the larger pyritic inclusions and to biodegrade the small inclusions (micropyrite). The process was continuously operated for 120 days, treating approximately 1 ton of Illinois \#6 coal. Ninety percent pyrite removal was achieved at a $20 \%$ slurry concentration and a reactor residence time of 5 days. Additional research should be performed to find the optimum values for reactor residence time, slurry concentration, and process hydraulic residence time (or recycle ratio). Finding these optimum values will enable a process to be developed that will maximize the amount of coal that can be processed per unit reactor volume per unit time with the desired level of pyritic sulfur removal.
\end{abstract}




\section{SUMMARY}

A combined physical/microbial process for the removal of pyritic sulfur from coal was demonstrated at the large-laboratory scale. The physical/ microbial process consisted of an acrated-trough slumy reactor with a lotal slurry volume of $150 \mathrm{~L}$. divided into six sections, each of which acted as both a physical separator and a bioreactor. The process ohjective was physical removal of the larger pyritic inclusions, which would take many days to hiodegrade, and hiodegradation of the many small inclusions (micropyrite). which are difficult to separate physically. This combination should give high (up to $9(0 \%)$ pyrite removals without the excessively fine grinding needed for a purely physical process. because hiodegradalion does not require that an inclusion first be liberated from the coal. only that it be exposed to microbial allack somewhere at the coal particle surface.

The process flowshee includes liquid recycle to provide the backeriat, acidity, and ferric ion needed to initiale the microbial activity on the feed coal, as well as biosurfactants that aid in slurrying the coal. The coal is fed into section 2. and solids settling out in Sections 2-6 are drained and recycled to Section 1. Besides acting as at second-stage physical separator (i.e., rougher seclion), growth of bacteria on the pyrite concentrated in Section 1 is another important source of acclimated bacteria for the process.

The process was operaled continuously for 4 months. treating nearly 1 ton ol an industry recognized hard-to-clean Illinois \#6 coal supplied by the Monterey Coal Company and ground to $80 \%-100$ mesh. A mixed culture consisting mainly of Thiobacillus ferenes: lams, but with some Thiobacillus thionovidams and Leptospiritlum fermenidems. was provided at startup, and a microbial consortium developed from this and the indigenous microbes on the feed coal. The concentration of free-swimming cells was on the order of $10^{x}$ per $\mathrm{mL}$., hut showed considerable variation due manly to atlachment to the coal. The only nutrient adeded was small amounts of ammonium sulfate. the other requirements (c.g... phosphate) apparenty being salisfiod hy minerals from the coal and the feedwater. The temperature was maintained at $24.5+3.1 \mathrm{C}$ and the pll kept between 1.8 and 2.2 by the addition of sulfuric acid. The process variables were the slurry concentration in Section 2 of the reactor $w$, the reacfor residence time $\tau$. and the process hydraulic residence time, $\tau_{H}$ (the ratio $\tau_{H} / \tau$ is a measure of the liquid recycle).

Ninety pereent reduction of pyritic sulfur was obtained at $\tau=5$ days, $w=20 \%$ (w1/wt), with a recovery of $90 \%$ of the heating value in the feed coal. Of this total pyrite removal. $16 \%$ was separated physically and appeared in the solid waste drained from Section 1 and the remainder was oxidized microbially. Forty pereent of the ash was also removed, although only $10 \%$ appeared in the solid waste from Section 1, the other $30 \%$ being pyrite and basic minerals that dissolve under the acidic conditions of the process. When coal loading was increased $(\tau=3$ days and $w=35 \%)$. American Society for Testing and Malcrials (ASTM) pyrite analysis of the product continued to show good $(70 \%)$ removal, but this was not confirmed by analysis of total sulfur. This is probably caused by the partial oxidation of pyrite to elemental sulfur. and by a shortage of sulfuroxidizing bacteria. which tend to be removed from the process attached to the product coal at this coal loading.

Because of the long lime needed to reach steady state, only four combinations of the process variables were studied. Future work needed for process optimization will include several improvements. The aterated trough was originally designed purely as a bioreactor and its geometry needs to be optimized for physical separation. Losses of water, coal, and bacteria with the mist in the air leaving the process must be reduced. Finally, the washing step needed to remove sulfate from the product coal before combustion must be incorporated into the process to recover and recycle sufficient sulfur-oxidizing bacteria. 


\section{CONTENTS}

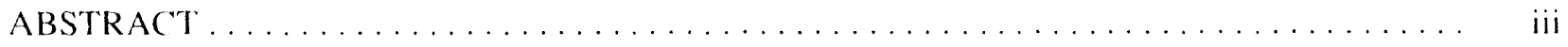

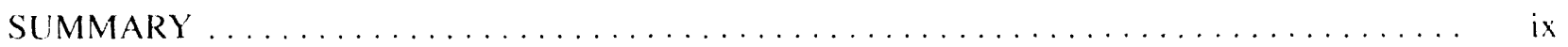

1. INTRODUCTION $\ldots \ldots \ldots \ldots \ldots \ldots \ldots \ldots \ldots \ldots \ldots \ldots \ldots \ldots \ldots \ldots \ldots$

1.1 Combining Physical and Microbial Processes $\ldots \ldots \ldots \ldots \ldots \ldots \ldots \ldots \ldots \ldots$

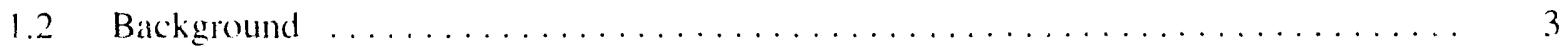

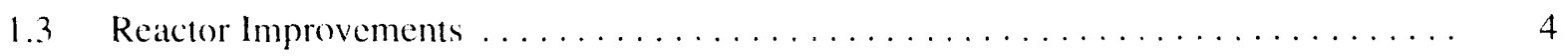

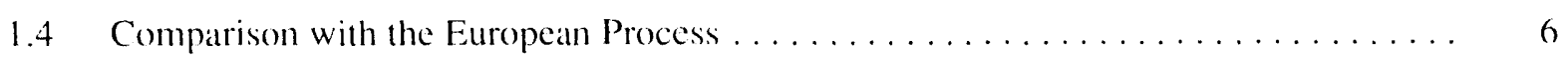

2. GOVERNING EQUATIONS AND PERFORMANCE CRITERIA $\ldots \ldots \ldots \ldots \ldots \ldots$

2.1 Mass Balances and Measures of Performance $\ldots \ldots \ldots \ldots \ldots \ldots \ldots \ldots \ldots \ldots$

2.2 Ash Balances and the Solids Drain Strategy $\ldots \ldots \ldots \ldots \ldots \ldots \ldots \ldots \ldots \ldots$

3. EQUIPMENT AND PROCEDURES $\ldots \ldots \ldots \ldots \ldots \ldots \ldots \ldots \ldots \ldots \ldots \ldots \ldots \ldots$

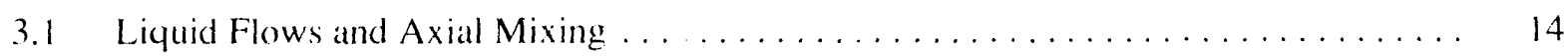

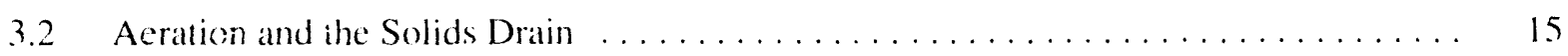

3.2.1 Physic: Ash Separation . . . . . . . . . . . . . . . . . . . . 17

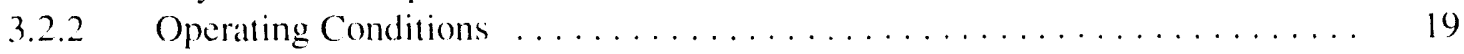

$3.3 \quad$ Water Loss and Temperature Control . . . . . . . . . . . . . . . . . . . 23

3.4 Startup, Operational, and Analytical Procedures $\ldots \ldots \ldots \ldots \ldots \ldots \ldots \ldots \ldots$

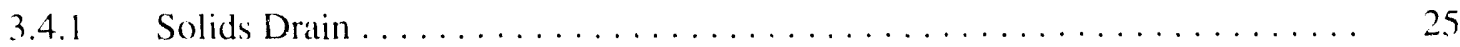

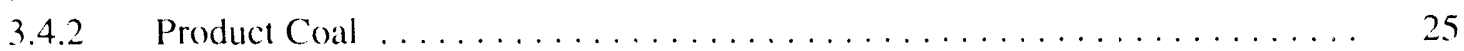

3.4 .3 Other Measurements . . . . . . . . . . . . . . . . . . . . . 25

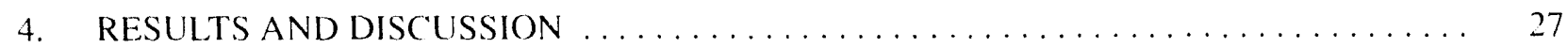

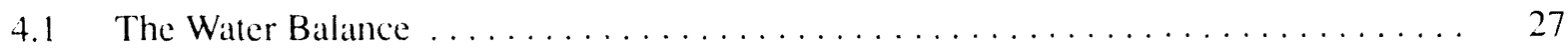

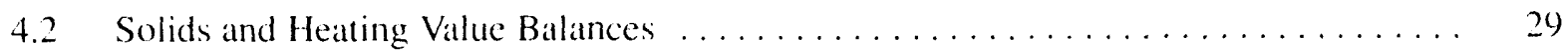

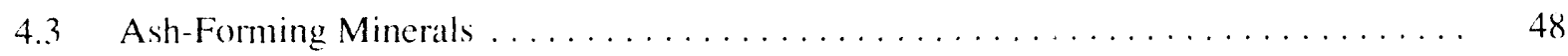

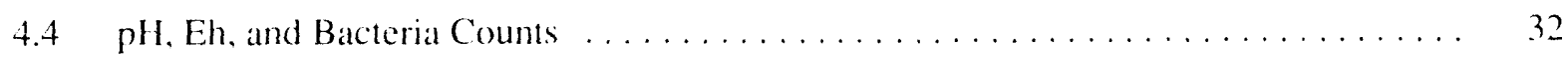

4.5 The Sulfur Balance and Pyritic Sulfur Removal $\ldots \ldots \ldots \ldots \ldots \ldots \ldots \ldots \ldots \ldots$

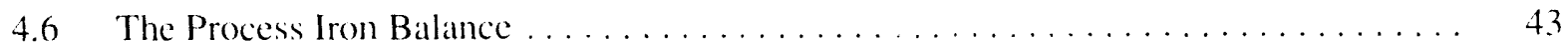




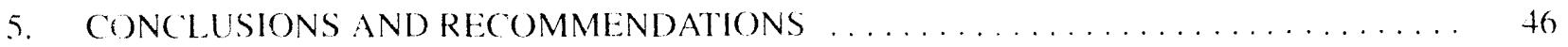

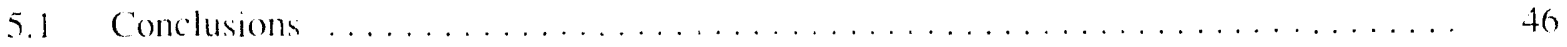

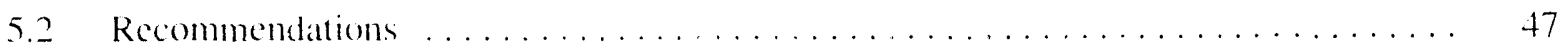

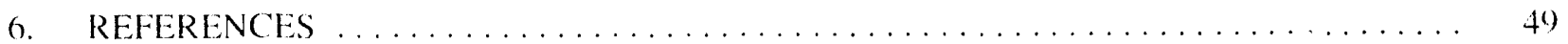

Appendix A-Solution To The Ash Removal Equations $\ldots \ldots \ldots \ldots \ldots \ldots \ldots \ldots \ldots \ldots$ A-1

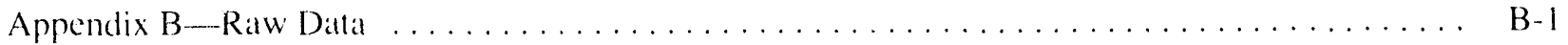

\section{FIGURES}

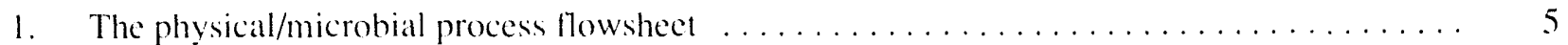

2. Solids flow model: coal and liquid feed rates $\ldots \ldots \ldots \ldots \ldots \ldots \ldots \ldots \ldots \ldots \ldots \ldots \ldots$

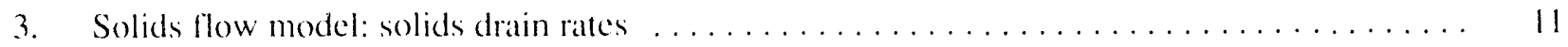

4. Solids flow model: ash in drained solids $\ldots \ldots \ldots \ldots \ldots \ldots \ldots \ldots \ldots \ldots \ldots \ldots \ldots$

5. Solids flow model: solids concentration in reactor $\ldots \ldots \ldots \ldots \ldots \ldots \ldots \ldots \ldots \ldots \ldots, 12$

6. Solids flow model: fractional ash removal and Btu loss $\ldots \ldots \ldots \ldots \ldots \ldots \ldots \ldots \ldots \ldots$

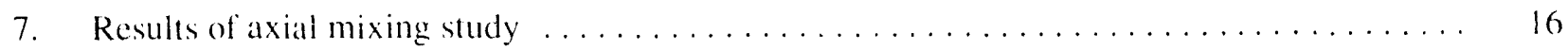

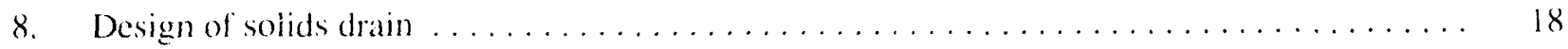

9. Results of physical separation study for porous polyethylene tubing $\ldots \ldots \ldots \ldots \ldots \ldots \ldots$ 2)

10. Results of physical separation study for silicone covered rigid tubing done on $11 / 15 / 91 \ldots \ldots$. 21

11. Results of physical separation study for silicone covered rigid tubing done on $11 / 27 / 91 \ldots \ldots 22$

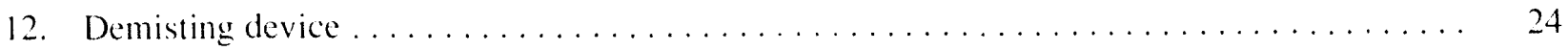

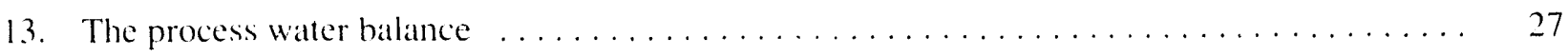

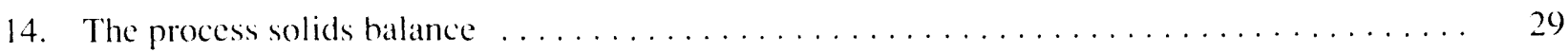

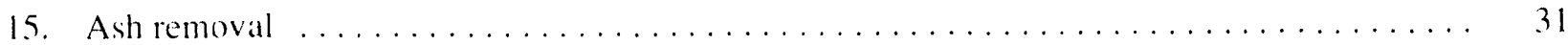

16. Size distributions of feed, drain, and product coal $\ldots \ldots \ldots \ldots \ldots \ldots \ldots \ldots \ldots \ldots \ldots \ldots$

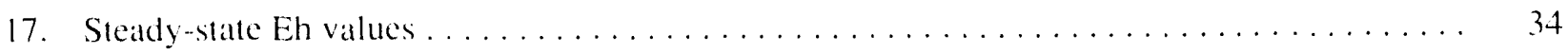

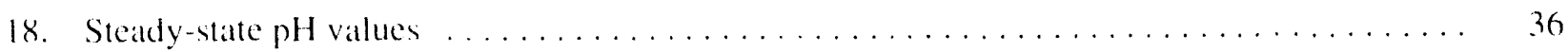

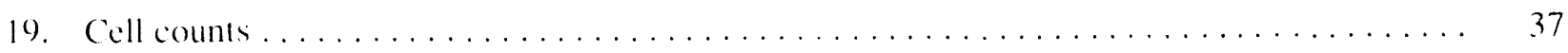

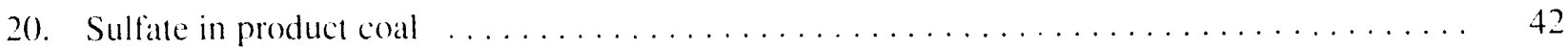




\section{TABLES}

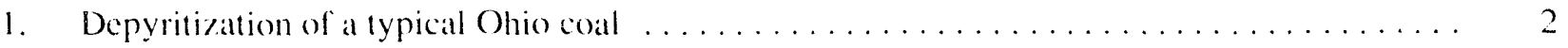

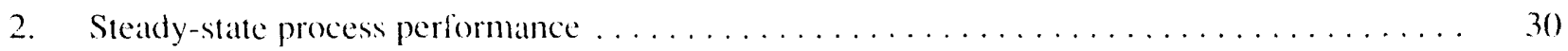

3. Measurements of product coal and solid waste $\ldots \ldots \ldots \ldots \ldots \ldots \ldots \ldots \ldots \ldots \ldots \ldots$

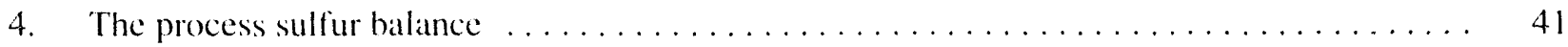

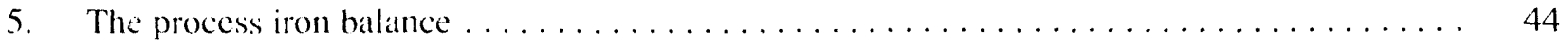




\section{A COMBINED PHYSICAL/MICROBIAL PROCESS FOR THE BENEFICIATION OF COAL}

\section{INTRODUCTION}

\subsection{Combining Physical and Microbial Processes}

The overall objective of coal beneficiation is to produce a product low in sulfur and ash at the lowest possible cost and with minimum wastage of heating value. DOE's Coal Preparation Program has set a target of $90 \%$ removal of pyritic sulfur, but found that this can only be achieved for most coals by physical processes (i.e., flotation, agglomeration) if the coal is ground extremely fine.' Besides being expensive in itself, grinding coal to a top size of $10-100 \mu \mathrm{m}$ complicates the downstream processes of coal separation and drying.

The requirement for fine grinding can be traced back to the fact that pyrite exists in coal as discrete inclusions with a wide distribution of sizes. The bulk of the pyrite in most coals is in the form of few, relatively large inclusions. However, there are also millions of very small inclusions (micropyrite) that make cleaning difficult for coals that contain them as a significant fraction of the total pyrite mass. It follows that the sensible way to clean coal is to remove the few large inclusions first, and then to achieve higher levels of depyritization by removing ever smaller inclusions. Table 1 shows the results of this hypothetical ideal procedure for a typical Ohio coal? (actually the average of 2.3 coals for which the inclusion size distribution has been measured and fit to the log-normal distribution). Thirty percent pyrite removal can be achieved by eliminating all inciusions larger than $8.3 \mu \mathrm{m}$, of which there are $4,90()$ per $\mathrm{cm}^{3}$ of coal. This can readily be accomplished by a physical process. Grinding the coal to $160 \mathrm{um}$ provides sulficient liberation and the settling velocity of a particle this size is sufficient 10 provide adequate separation in a cyclone or similar process. Altempting to remove these large inclusions by a microbial process would be counterproductive, since bacteria would need at least 6 days to dissolve an inclusion of $8.3 \mu \mathrm{m}$.

Obtaining $9(0 \%$ removal is considerably more difficult. All inclusions larger than $8 \mu \mathrm{m}$, of which there are over three million per $\mathrm{em}^{3}$. must be removed. Floal/sink processes are now impractical because of the low settling velocities of such small particles (the $3.67 \mathrm{~h}$ given as time for float/sink separation in Table 1 is the time needed for an $8-\mu \mathrm{m}$ liberated pyrite inclusion to separate by 1 meter from a $8-\mu \mathrm{m}$ coal particle by differential settling in a liquid). Surface-area dependent physical processes such as flotation or agglomeration could be used, although the coal must be ground to approximately $14 \mu \mathrm{m}$ to provide sufficient liberation of such small inclusions. When dealing with these very small inclusions, a microbial process has $t$ wo advantages. First, much less time is necied to dissolve small inclusions: about 1 day for an $8-\mu \mathrm{m}$ inclusion depending on the fraction of its surface that is exposed to microbial attack. Second, a microbial process requires less coal grinding than a physical process. The reason for this is that liberation is no longer necessary; the inclusion need only be exposed to bacterial attack somewhere at the surface of the coal particle. The $30 \mu \mathrm{m}$ given in Table 1 as the coal size for microbial access is the coal size al which sufficient inclusions are exposed, if the inclusions are atssumed to be randomly distributed through the coal. In fact, when coal is ground, it tends to fracture along planes weakened by the presence of inclusions, exposing more pyrite to direct microbial attack. Therefore, 30 $\mu \mathrm{m}$ underestimates the coal size at which $90 \%$ removal is possible. Experiments on microbial depyritization have shown $90 \%$ pyrite removal from many different coals in the size range 10()-20) mesh $(75-150 \mu \mathrm{m})$. $^{3}$ 


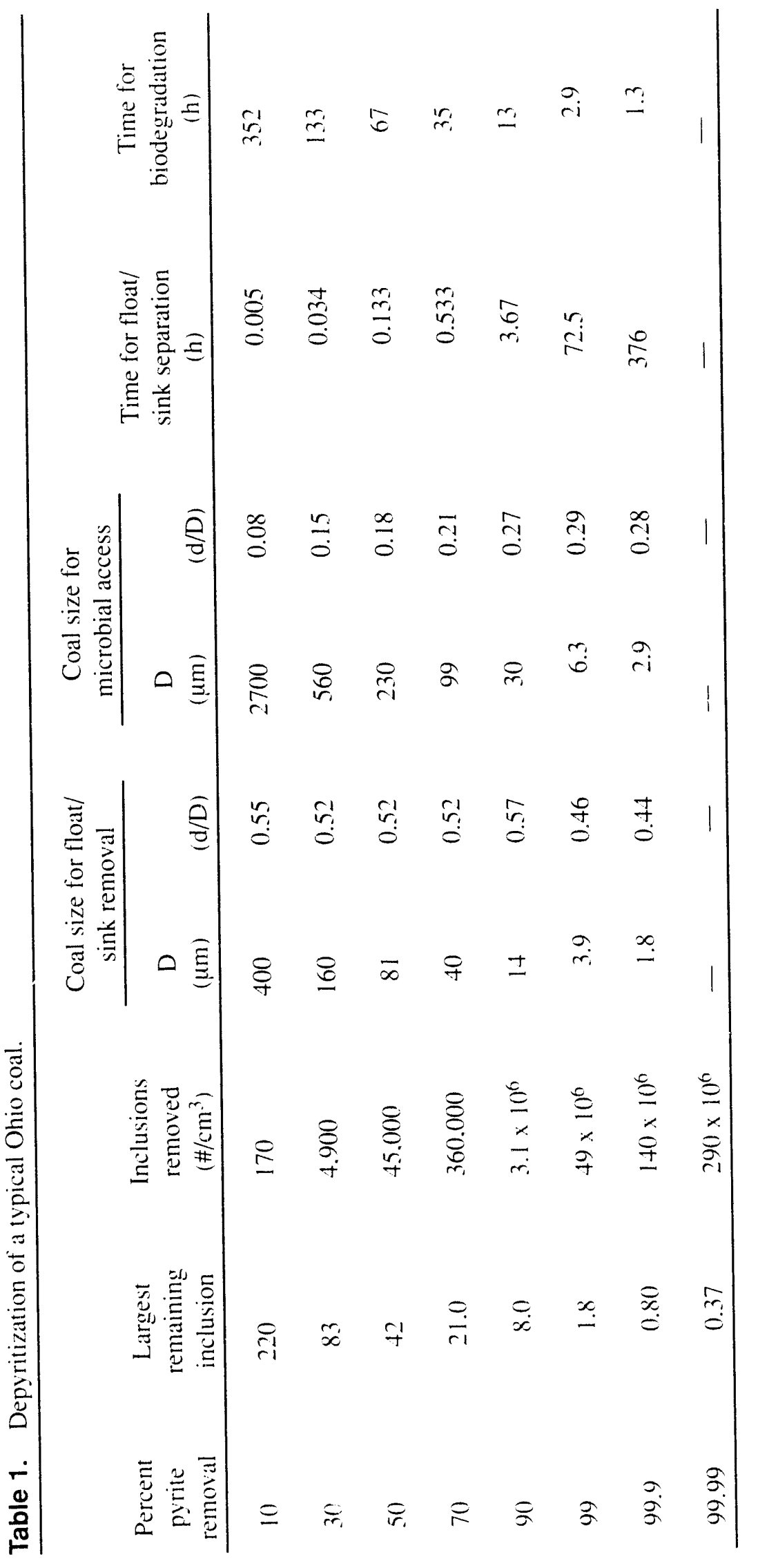


Although the calculations that lead to the results in Table 1 are only approximate, the ronclusions are considered qualitatively correct. Increasing pyrite removal meams removing more and more inclusions of ever smaller sizes. I becomes increasingly difficult to do this physi. cally without very fine grinding and/or considerable loss of heating value in the reject stream. On the onher hand, a micenbial process works hest on the very small inclusions because ks grinding is necled and their high surface/volume ratio means that small inclusions need less time for biodegratdation. The work described in this report follows from these conclusions. The objective is to create a process in which the latge pyrite inclusions are separated physically while the small inclusions are dissolved by microbial activity. This process is demonstrated on an Illinois \#6 coal known to contain signaficant micropyrite, making it diflicult to clean hy conventional methods.

A combined microbial/physical process should also give improved removal af other ash-forming minerals in coal. The hasic minerals (carbonates) will be dissolved in the acidic ( $\mathrm{pH} 2$ ) conditions of the microbial process, even if they are fincly dispersed through the coal. However, a purely microbial process would not affect the insoluble. yuarty-type minerals. which are relatively casy (o) remove physically.

Table 1 shows that both microbial and physical depyritization processes can potentially work betler as the coat is ground finer. The coal top size for this work was therefore chosen on economic rather than technological grounds. The argument is that if the coal is to be pulverized to a size of -10() mesh before being blown into a boiler. then grinding if to this size is a normal cost of doing business that can be charged to the combustion step. Grinding smaller than this is not only expensive, but the cost must be charged to the coal beneficiation step with severe consequences for ils economic feasibility. A coal top size of approximately - 100 mesh was therefore chosen for this work. and operating conditions capable of giving $90 \%$ pyrite removal at this size were sought.
This leaves several questions including:

- Can a slurry of coal al this size be dewatered and dried"?

- Can the physical/microhial process be carried out at the ulitity site or must postprocess pulverized coal he transported to the utility sitc?

- Should the process be carried out only on the lines stream of existing coal preparation plants'?

Some of these questions have been addressed in a previous report. ${ }^{3}$ Others remain for luture work.

\subsection{Background}

The Earth, Environmental, and Life Sciences Group of the Idaho National Engineering Laboratory (INEL, has previously developed a purely microbial process for the removal of pyritic sulfur from coal. This process employed a mixed microbial culture based on the genus Thiobarillus, and an acrated-trough slurry reactor, with a long channel with a V-shaped bottom along which ran porous acration lubes. The air bubbles kept the coal particles in suspension and provided oxygen and carbon dioxide needed for microbial metabolism. This type of hioreactor was chosen becaluse it would be relatively inexpensive to build on a large scale. ${ }^{3}$ A large-laboratory scale (200-L) reactor was operated for several months during 1990. The results were described in previous reports 4.5 and are summarized here as a starting point for the present work.

Nincty pereent of the pyrite was removed from an Illinois \#6 coal ground to $74 \%$ - 100 mesh, at a coal residence time $\tau$ of 7 days and a slurry concentration of $20 \%$ (wt/wt). Only onc-half of this removal was accounted for by microhial pyrite oxidation with the consequent appearance of sulfate in solution. The remainder was calused by setlling of large liberated inclusioms to the bottom of the bioreactor. Settled solids removed at the end of the operating period contained $61 \%$ ash and $26 \%$ sullur. The process also produced slight reductions in ash $(\sim 10 \%)$ and heating value $(\sim .3 \%)$ in the product coal. 
Liquid recycle was found to be critical to process pe1, mance. It provides the bacteria, ferric ion, and acidity needed to initiate pyrite oxidation in the feed coal and biosurfactants that facilitate coal wetting and the production of a uniform slurry. Recycling a fraction of the liquid leaving the bioreactor also reduces the volume of wastewater generated by the process. The recycle was quantified in terms of a hydraulic residence time.

$\tau_{H}=\frac{\text { Water in the Process }}{\text { Flow of Water out of Process }}$

With $\tau_{H}$ much greater than $\tau$ (i.e., a high cycle ratio) some unknown product apparently accumulated in the process to levils that inhibited microbial metabolism. The best overall process performance was achieved with $\tau_{H}=14$ days (i.e., recycle ratio of approximately 1 ).

The main operating problem was found to be corrosion-erosion caused by the combined effects of mechanical abrasion, microbial activity, and the aerobic. acidic chemical environment. Corrosion of the aeration tubes was particularly serious hecause it led to nonuniform acration and settling of the coal at some points in the reactor. The baffles originally installed to control axial mixing in the reactor aggravated these problems and were removed. The reactor then acted as a completely mixed tank. and the theoretical advantages ${ }^{t}$ of plug flow operation were not realized.

\subsection{Reactor Improvements}

The same large-laboratory scale plexiglass bioreactor $(8 \mathrm{ft}$ long $x 10 \mathrm{in}$. wide with a base halfangle of 30 degrees) used in the previous experiments was employed in the work described here. It was. however extensively modified in light of the experience described in Section 1.2 and the analysis described in Section 1.1. The objective was to produce a reliable process that represented an optimum combination of physical separation of large pyritic inclusions and bicdegradation of small ones. The modifications are shown in Figure 1 and described in more detail in Section 3.
The reactor was divided into six equal sections by baffles bolted firmly in place. Slurry overflow from one section to the next was through a single 1/4-in. hole, which greatly reduced axial mixing. Each section had its own aeration tube, airflow control, and flow meter. The reactor also had a conical solids collector in the center of the base of each section, and a ball valve through which the settled solids could be drained periodically.

The dry feed coal was added to Section 2 , where it formed a slurry caused by the agitation provided by the air bubbles and the effect of the biosurfactants. Bacteria were able to act on the pyrite as the slurry flowed through Sections 2-6 and out onto the dewatering screen. In each section, some of the larger, denser particles tended to settle out. They were removed through the solids drain and added to Section 1: the latter served two important functions. In physical separation terms, Section 1 was a roughing section, where the rejected solids underwent a second separation step. Particles high in organic matter, that may have been collected inadvertently in the solids drained from the other sections, would stay in suspension and be recovered by flowing out with the slurry into Section 2. Only truly high density particles containing much pyrite and other minerals should have settled in Section 1. These solids were drained and constituted the solid waste from the process. In microbiological terms. Section 1 can be thought of as a continuous inoculum generator. The solids in Section 1, having undergone one physical separation, were enriched in pyrite and the degradation of this pyrite was accompanied by microbial growth. These microhes were added to those flowing into Section 1 with the liquid recycle stream, and they flowed out into Section 2 to inoculate the feed coal.

There are two areas of uncertainty in this process operation that would benefit from further research. The first concerns the role of what may be loosely called flotation effects in the physical separations. No frothers or other flotation chemicals were added (they are expensive and inhibit microbial activity) and no froth forms on the slurry surface. Nevertheless, the organic fraction of the coal is more hydrophobic than the pyrite and other 


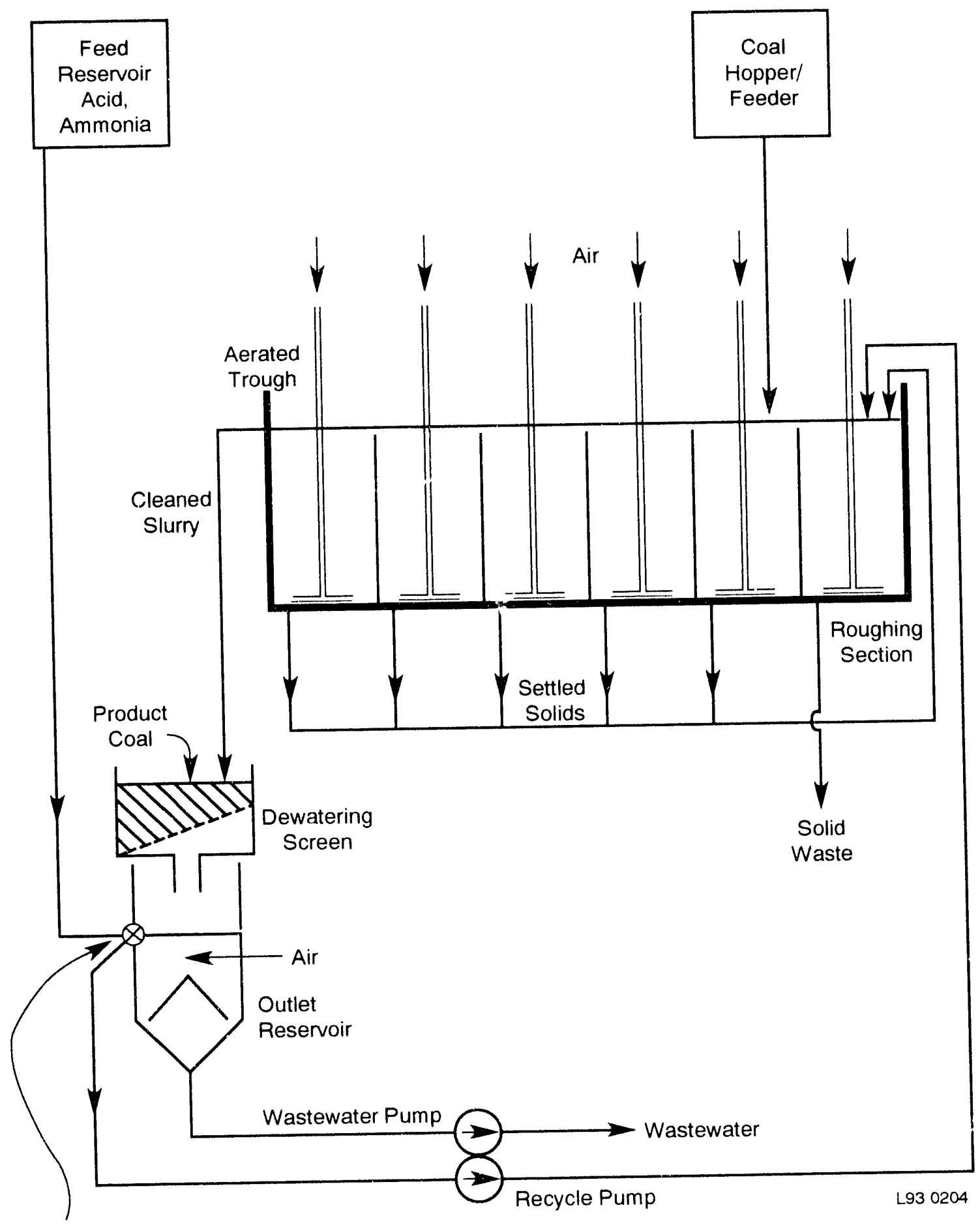

Float Valve

Controls Feed

Flow into Recycle Line

Figure 1. The physical/microbial process llowsheet. 
mineral matter, and there is some evidence that the difference is increased by the presence of Thiobacillus bacteria or perhaps the biosurfactants they produce. ${ }^{7}$ It follows that organic coal particles are more likely to attach to the bubbles and be transported up to the surface of the slurry, from where they flow into the next section. The relative importance of these hydrophobic effects and density effects in keeping the high mineral particles down at the bottom of the reactor is unknown. It may be possible to greatly improve the physical separation by simply changing the shape of the section (e.g.. increasing the depth).

The second uncertainty concerns the importance of the continuous inoculation function of Section 1 . The cell concentration in the reactor is fixed by the balance between the number of cells that grow on the available pyrite, and the numbers that leave the process either in the liquid waste or adsorbed on the product coal. The growth yields for the autotrophic bacteria Thiobacillas and Lepospririllam on pyrite are quite low and their affinity for attaching to coal surfaces is quite high, so this balance may not produce a sufficiently high cell concentration to maximize the rate of pyrite biodegradation. Liquid recycle and the microbial growth in Section 1 all help this balance, but it remains a concem when dealing with low-pyrite coal. This question is difficult to resolve experimentally. Even if the total attached biomatss on the product coal could be measured reliably (this remains a topic for research), there would still be a concern that the microbial culture was becoming deficient in specific critical classes of bacteria (e.g. those like Thiobacillus thiendidans that are responsible for sulfur oxidation).

\subsection{Comparison with the European Process}

The European Economic Community (EEC) is currently huilding a $1 \mathrm{kon} / \mathrm{d}$ pilot plant for the purely microbial depyritization of coal in Sardinia. Italy. Details of this pilot plant are now available. "and can be compared with the process proposed here.

The EEC process also consists of six equal tanks in series. However, there is no liquid recycle and thus no input of biomass to the first reactor except what is attached to the feed coal. This limits the flow through the process because if the dilution rate ( 1 /residence time) in the first tank exceeds the biomass specific growth rate then all the microbes will be washed out. The absence of recycle also wastes biomass unnecessarily from the process, requires a separate mixing tank to produce a uniform slurry, and produces a large volume of dilute wastewater for treatment. A process with recycle generates a smaller volume of more concentrated waste that is easier to treat.

In the INEL proposed process, the large, dense mineral particles are deliberately allowed to settle out. This reduces the energy required for mixing to keep the slurry in suspension. The EEC process recently switched from airlift, Pachuca lank reactors 10 mechanically agitated reactors in an attempt to reduce the energy cost of keeping the dense particles in suspension for the long times needed by a purely microbial process. Based on our experience. corrosion of the agitators is likely to be severe.

The coal separation and washing steps in the EEC process use gravity settlers for slurry dewatering. The process we have proposed ${ }^{3}$ uses pressure filters. The relative merits of these two methods are unknown, but it is certain that efficient washing of the coal to remove the sulfate produced, and to recover the bacteria, will be critical. The amount of water needed for washing must be kept 10 a minimum, again in order 10 reduce the volume of wastewater that must be trealed. 


\section{GOVERNING EQUATIONS AND PERFORMANCE CRITERIA}

\subsection{Mass Balances and Measures of Performance}

The prosess shown in figure I has lwo inlets. the feed coal (subseript f) and the acid/mutricm stream from the reservoir (subscript $\mathrm{r}$ ), and three outlets, the watstewater (subscript w), the product coal (subscript p) and the solids drained from Section I subscript 1). Each of these flows contains water (flow $=\mathrm{F} \mathrm{kg} / \mathrm{d}$ ), coal (flow = G kg dry coal/d), and various forms of sulfur and minerals. The steady-state water balance over the process is:

$r_{1}+r_{r}=F_{n}+F_{p}+F_{1}+E$

The actual values of the terms in this equation are given in Appendix B1. On a typical day, over $10 \mathrm{~kg}$ of water $(\mathrm{Fr})$ and $4 \mathrm{~kg}$ of coal flowed through the process. The waste solids from Section I were screened, the liquid being returned to the reactor. 'The water remaining in solids was of order (1.1 $\mathrm{kg} /$ day and can be ignored. All the other liquid flows are measured and Equation (1) is used to calculate the water loss rate E. This loss was caused by a combination of evaporation and a mis! generated by the vigorous acration of the slurry that passed through the demisting filters on the air effluent from the reactor. Only two flows in the process are directly controlled. The recycle pump controls the flow into the reactor $F_{(1}$. and thus the reactor esidence fime $\left(\tau=W / F_{0}\right)$. where $W=$ mass of water in the reactor. The waste pump controls the wastewater flow. Fi, which fixes the process hydraulic residence lime, defined as the mass of water in the reactor divided by the rate at which the water flows out of the process.

$\tau_{H}=\frac{W}{F_{l}+F_{1}+F_{n}+E}=\tau \frac{F_{1}}{F_{1}+F_{1}}$

Note that the mosisture in the product coal. Fp, is fixed by the efficiency of the dewatering process, which means that $\tau_{1}$ has a finite maximum value when $F_{11}=0$. The process was actually operated all this no waskewater limit for much of the time. An alternative a $\tau_{11}$ would be to think in terms of a recycle matio defined hy $F_{0}=F_{r}(1+R)$. It is cleat from fyltation (2) that if the moisture in the feed coal, $F_{1}$ is negligible, then $\tau_{f 1}=\tau(l+R)$. It there is no liquidrecyck then $F_{1}=F_{1}$ and $\tau=\tau_{11}$.

The steady-state sulfur mass balance for the process can be wrilten:

$$
\begin{aligned}
& \left(\frac{F S}{3}+(i x)_{1}+\left(\frac{1 S S}{3}\right)_{1}=\left(\frac{r S}{3}+(i x)_{n}+\right.\right. \\
& \left(\frac{F S}{3}+(i X)_{1}=\left(\frac{F S}{3}+(i X)_{n}+\left(\frac{F S}{3}\right)\right. \text {. }\right.
\end{aligned}
$$

$S$ is the mass fraction of sulfate in the water, $D_{1}$ is the mass flow of (dry) solid waste, $X$ is the mass fraction of pyritic sulfur in the coal (dry basis) and the 3 is a conversion factor from sulfur (atomic weight $=32$ ) to sulfate (molecular weight $=96)$. The contribution of pyritic sulfur in the fines that appear in the wastewater. $(C X)_{w}$, wats found to be negligible. $E_{m}$ is the rate of water loss from the reactor caused by misting, and $S_{m 1}$ is the sulfate concentration in the mist. This term was found to give a surprisingly large contribution to the overall sulfur balance. The $(\mathrm{FS} / 3)$, term results from the addition of sulfuric acid and ammonium sulfate to the feed reservoir for the purposes of pH control and mutriem addition. Sulfate is used here because other anions added to the process maty either inhibit microbial activity $(\mathrm{Cl}$, citrate), leave undesirable elements in the product coal ( $\mathrm{Cl} . \mathrm{NO}_{3}$ ), or cause the fomation of undesirable precipitales $\left(\mathrm{PO}_{4} \cdots\right)$.

For the streams labelled $f, p$, and 1 , it is important to realize that $S$ is not an actual sulfate concentration, but an operationally defined parameter. Besides dissolved sulfate, a slurry sample may contain hydroxysulfate precipitates in the liquid or attached to the coal, and sulfate sulfur from the coal itself. The convention is adopted that all of these forms of sulfate are actually in the liquid. 'Thus, $S_{f}$ is the concentration that would result if all the sulfate sulfur in the feed coal were actually dissolved in the coal moisture. To measure $S$ in a slurry siample, all the forms of sulfate are first dissolved in hydrochloric acid, and the coal is filtered out and 
dried to determine its moisture content. The mass of sulfate in the filtrate is then measured. and $S$ determined by dividing this mass by the liquid in the original sample. Although this definition of $\mathrm{S}$ is convenient for microbial desulfurization processes, it does require some care. For example, it is reasonable to suppose that dissolved sulfate concentration in the water leaving the reactor is the same as that in the wastewat $r$ and in the interstitial water in the product coal on the dewatering screen. However, it does not follow that $S_{6}=S_{W}=$ $S_{p}$, because of the effect of the other forms of suliate. $S_{6}$ is the sulfate concentration in the water leaving the reactor (Section 6).

Two different measures are used to define the performance of the process in removing sulfur. The product quality, $y$, is defined by the fractional reduction of pyritic sulfur:

$y=1-\frac{X_{1}}{X_{1}}$

The fraction of the pyritic sulfur that is oxidized to sulfate by the microorganisms is defined by the fractional pyrite oxidation, $r_{0}$, which is the ralce of appearance of sulfate sulfur divided by the rate that pyritic sulfur is fed into the process.

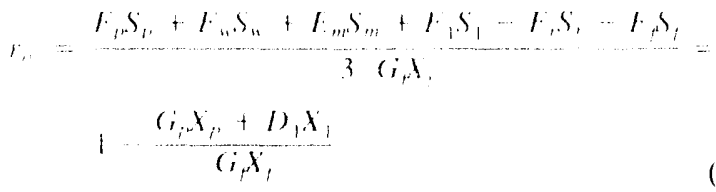

The difference between $y$ and $r_{0}$ is a measure of the physical removal of pyrite in the process, which is the fraction of the pyrite in the feed coal that appears in the solid waste. Note however, that if the $D_{1} X_{1}$ term was zero (i.e., no physical separation), $r_{0}$ would be slightly larger than y hecause $\mathrm{G}_{p}<\mathrm{G}_{\mathrm{f}}$. Some of the effects that result in this incomplete recovery of the coal mass (e.g., dissolution of pyrite and other minerals) are beneficial, while others (e.g., loss of fines to the wastewater and oxidation ol the coal organic mat ter) are not. The best measure of this aspect of process performance is therefore the heating value recovery
$H V R=\frac{((i / H)}{((i A H)}$

Where $\Delta H$ is the heating value of coal.

\subsection{Ash Balances and the Solids Drain Strategy}

Operation of a complex process like that shown in Figure 1 raises a number of related questions. What is meant by coal residence time or slurry concentration and how is the mass of solids to be drained from each section determined? We could, for example, choose to remove an amount equal 10 $1 / 2)^{\text {th }}$ of the coal feed from each of Sections 2 through 6 and add it to Section 1, and then remove $1 / 5^{\text {th }}$ of this (i.e. $\frac{5}{20} \times \frac{1}{5}=\frac{1}{20}$ of the feed) as solid waste. This would create a uniform decrease in the slurry concentration in Sections 2 through 6. and a low slurry concentration in Section 1 (this low concentration may be desirable fo facilitate oxygen transfer into a slurry that contains high levels of pyrite)."

The above procedure would be arbitrary because it takes no account of the ash concentration in the particular coal at any point in the process. A more sophisticated operating strategy must first recognize that the ash-forming minerals in coal can actually be divided into three callegories according to their behavior in the process. Basic minerals such as carbonates will dissolve in the acidic ( $\mathrm{pH} 2$ ) conditions in the reactor. Some of the insoluble minerals are fincly dispersed throughout the coal and have not been liberated by grinding to the coal top size used in the process (this is the ash in the float fraction in a float/sink test minus the basic minerals). Physical separation can affect neither of these categories. The physical part of the process is designed only to remove the third category, insoluble minerals (including pyrite) that have been sufficiently liberated by grinding. For the purposes of this section, ash refers only to these insoluble, liberated minerals. 
The analysis is based on the concept of a separation factor delined by:

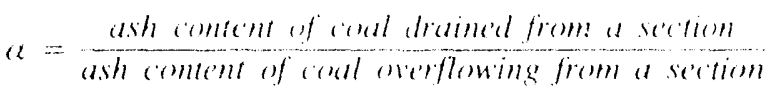

If this is assumed te be a constant, mass balances for lotal solids and ash can be written for each section and the entire reactor. Back mixing between sections is ignored, as is the slight reduction of total solids mass caused by the dissolution of pyrite and soluble minerals.

For $\mathrm{i}=3$ through 6, where $\mathrm{i}$ is the reactor section

$G_{i-1}=G_{i}+D_{i}$

$\left(i_{i-1} A_{i-1}=\left(j_{i} A_{i}+D_{i}\left(2 A_{i}\right.\right.\right.$

$A_{i}=$ ash in coal in slurry leaving section $i$

$G_{1}=$ coal flow rate in slurry leaving section $i$

$D_{i}=$ coal flow rate in drain from section $i$.

For Section 2:

$i_{1}+i_{1}=i_{2}+I_{2}$

$\left(i_{1} A_{1}+C_{1} A_{1}=\left(i_{2} A_{2}+b_{2} l_{2} A_{2}\right.\right.$

For the entire reactor:

$i_{i}=i_{0}+D_{1}$

$G_{f} A_{f}=G_{6} A_{6}+D_{1} \alpha A_{1}$

To complete the analysis a strategy must be specified for defining how much solids should be removed from each section. It is reasonable to make this proportional to the amount of ash entering the section. Since the amount of ash entering any section $\mathrm{i}$, is equal to the amount leaving $\left(\mathrm{G}_{\mathrm{i}} \mathrm{A}_{\mathrm{i}}\right.$ $+D_{j}\left(\ell A_{i}\right)$, this can he written:

$D_{1}=\beta A_{i}\left(G_{i}+(\alpha)_{i}\right)$ for $1 \leq i \leq 6$

where $\beta$ is a process variable sel by the operator and is defined as the solids drained from a section divided by ash being fed into a section. (iven perfect ash liberation and separation $(\alpha=\infty)$, setting $\beta=1$ would make all the ash in the feed appear in the drain from Section 2 and hence in the solid waste from Section 1. D3 through $D_{0}$ would be zero because no ash would ever reach these sections. In the real world of impertect separations these drains are needed. Setting $\beta>1$ lends to give intproved ash rejection at the expense of decreased heating value recovery.

Equations (7) $10(10)$ constitute 18 equations that can be solved (see Appendix $A$ ) for the 18 unknowns $A_{i}, D_{i}$, and $G_{i}(i=1$ through 6$)$. This leaves only the problem of specifying the relationship between the coal feed rate, $\mathrm{G}_{\mathrm{f}}$, the slurry volume in the reactor, $\mathrm{V}$, and the liquid flow rate into the reactor, $F_{0}$. Note that $F_{0}$ is assumed constant through the reactor, which implies that the effects that increase the liquid mass flow rate addition of moisture with the coal and dissolution of coal minerals) are balanced by those (evaporation and misting) that tend to reduce it. Two process variables must be specified. The slurry concentration is specified in Section 2 because this is where it is highest. As a mass fraction it is:

$w=\frac{G_{2}}{G_{2}+F_{1 \prime}}$

The reactor residence lime $(\tau)$ was defined in the previous section as $W / F_{0}$ where $W=$ mass of liquid in the reactor. Since the slurry concentration is different in each section this must be related to the total slurry volume, $\mathrm{V}$, by:

$W=H_{1} \tau=\frac{\varrho_{1} l^{\prime}}{6} \sum_{i=1}^{6} \frac{1}{1+\frac{\varrho_{1}}{\varrho_{1}} \frac{i_{i}}{l_{i}}}$

The results of these calculations serve two purposes: (1) they provide a guide to process operalion (i.e., how much solids should be drained from each section?; what are the coal and liquid feed rates needed to give a certain residence time and slurry concentration?) and (2) they also provide a baseline against which the performance of the actual process can be judged (i.e., what should be the asticontent of the product coalt?; what is the vartation of the coal slurry concentation hetween sectionis?'s 
Figures 2 through 6 show the results as functions of the separation factor for conditions that approximate one set of experimental conditions. The parameters are $\tau=5$ dalys, $w=20 \%, A_{f}=.5 \%$ (the feed coal was $9.5 .5 \%$ total ash, but $2.5 \%$ was soluble basic minerals and an estimated $2 \%$ was fincly dispersed ) $\beta=1, \rho_{c}=1.35 \mathrm{~kg} / \mathrm{L}$. and $\mathrm{V}=$ $150 \mathrm{~L}$. Figure 2 shows the feed rates of coal $\left(i_{i}\right)$ and water $\left(F_{0}\right)$ needed to achieve the specified residence time $(\tau)$ and slurry concentration in reactor Section 2 (w). As the separation factor increases the ratio $G_{f} / F_{0}$ actually increases slightly from ().214 with no separation $(\alpha=1)$ to 0.237 at $\alpha=10$. Clearly as the physical separation improves, we can make better use of the available reactor volume.

Figure 3 shows the mass of solids that must be removed from each section. The amount removed from Section 2 is considerably higher than that from Section 6, becatuse the feed to this section contains far more ash that is likely to settle out.
D2 initially increases with the separation factor, because Section 1 receives more ash and some of it is washed through to Section 2, increasing the ash loading on this section. However, for $x>4$. the improved separation in Section 1 reduces this effect, and D decreases with increasing $\alpha$ for Sections 2 through 6 . The solids drained from Section 1 increase slightly with $(\ell$, in line with the increase in the coal feed rate (see Figure 2).

The quality of the coal drained from each section is shown in Figure 4, which shows the great advantage of the two-stage physical separation. Even if a very high separation factor $(\alpha=10)$ could be achieved, the solids drained from Sections 3 through 6 would still contain only $15-25 \%$ ash. Discarding them would represent a considerable waste of heating value. However, after the second separation step in Section 1, the drained solids would (with $\alpha=10)$ contain over $7(0 \%$ ash.

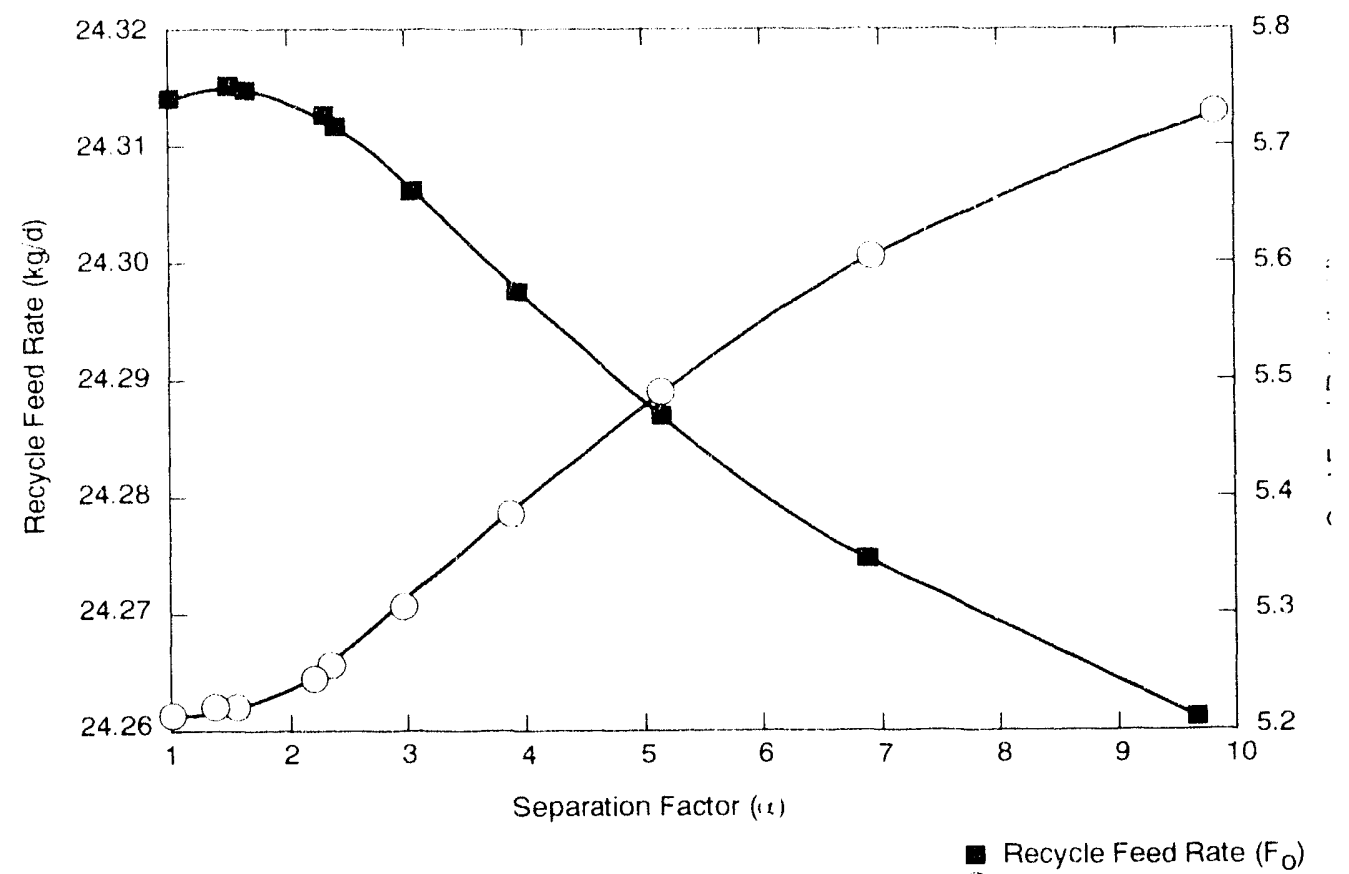

Coal Feed Rate $\left(G_{f}\right)$

L930205

Figure 2. Solids flow model: coal and liquid feed rates. Variables were fixed all $W=20 \%, A_{f}=5 \%$. and $\tau=.5 \mathrm{~d}$. 


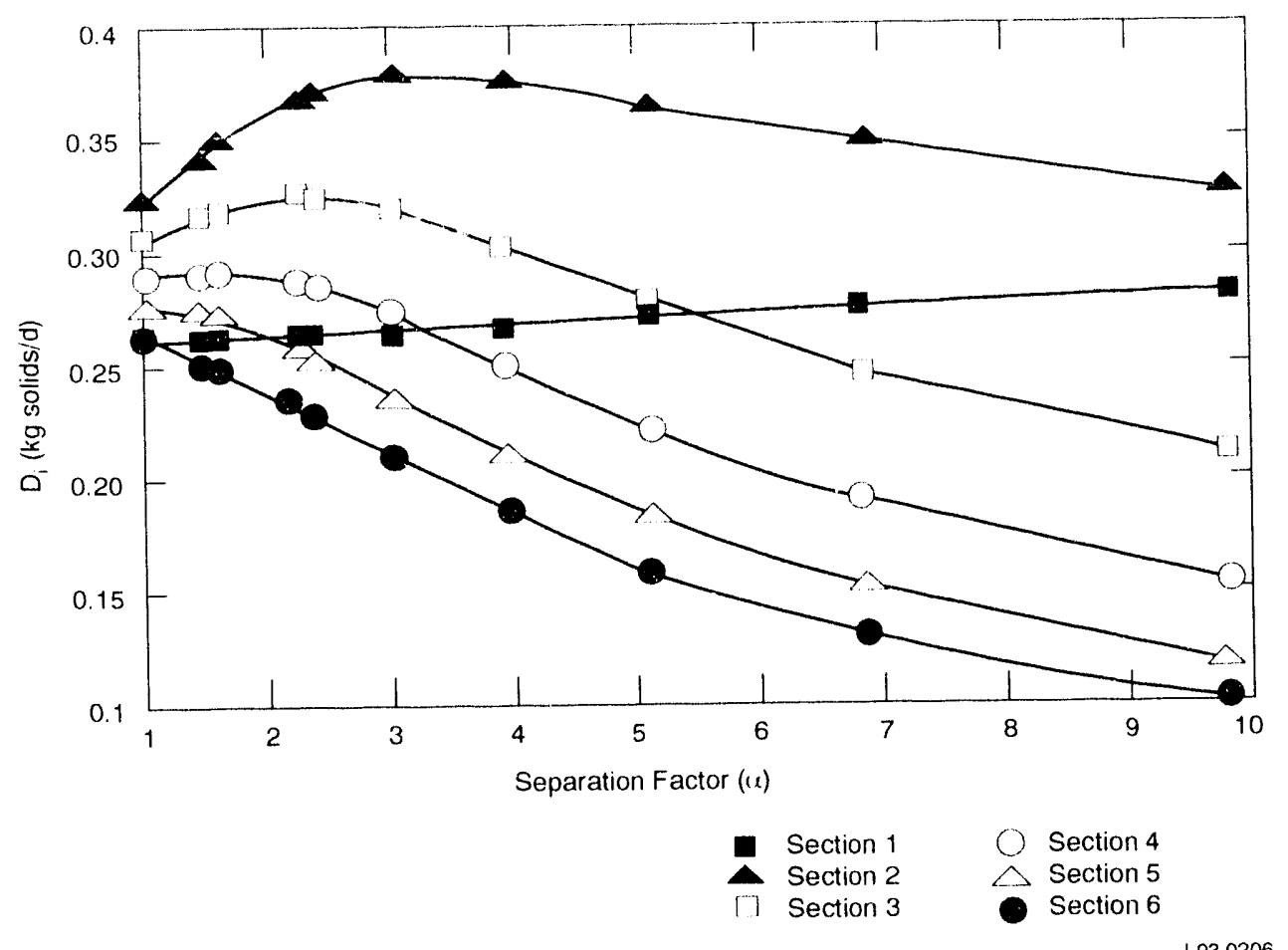

Figure 3. Solids flow model: solids drain rates. Variables were fixed at $\mathrm{W}=20 \%, \mathrm{~A}_{\mathrm{f}}=5 \%$, and $\tau=5 \mathrm{~d}$.

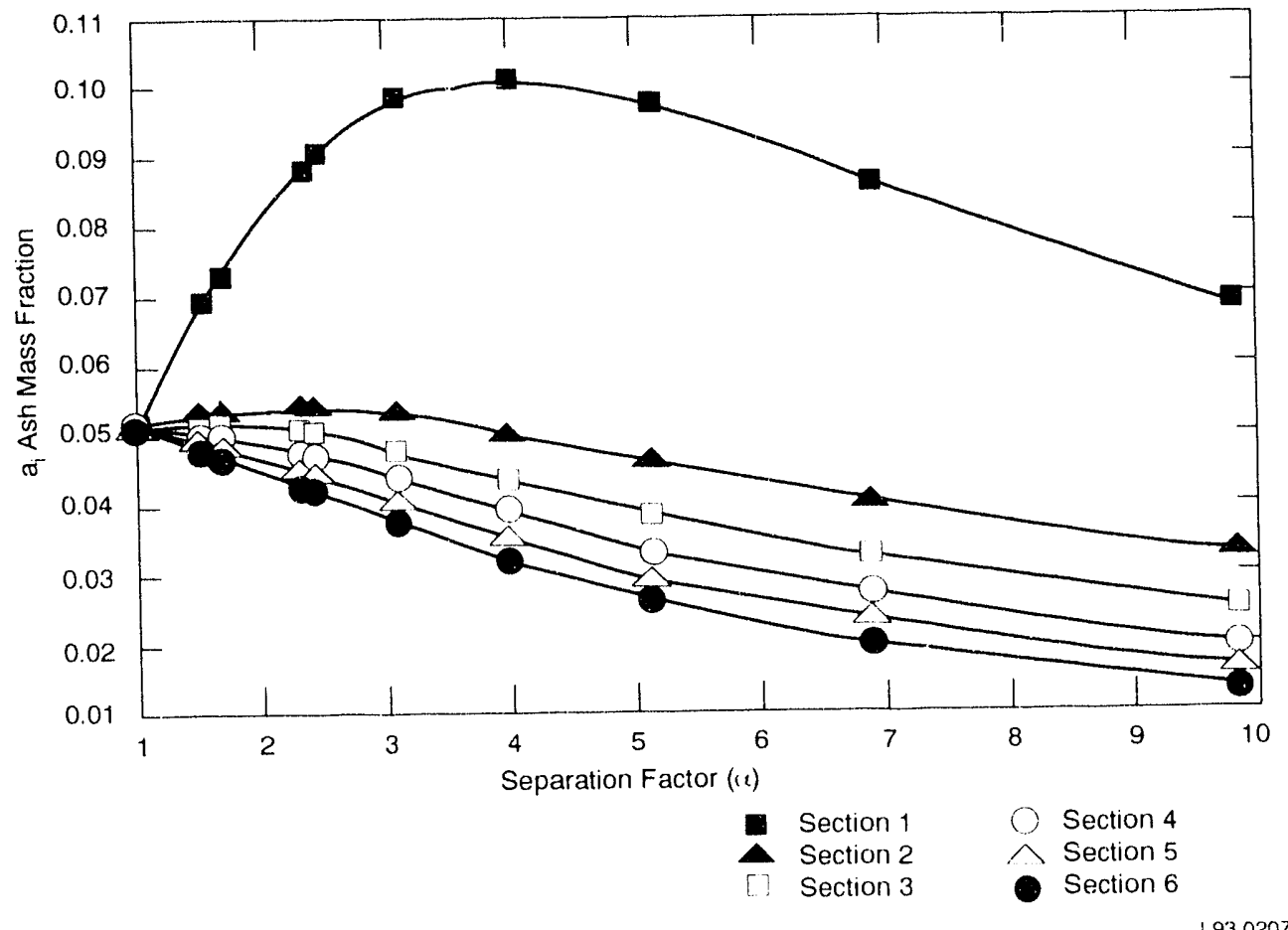

Figure 4. Solids flow model: ash in drained solids. Variables were fixed at $\mathrm{W}=20 \%, \mathrm{~A}_{\mathrm{f}}=5 \%$, and $\tau=5 \mathrm{~d}$. 

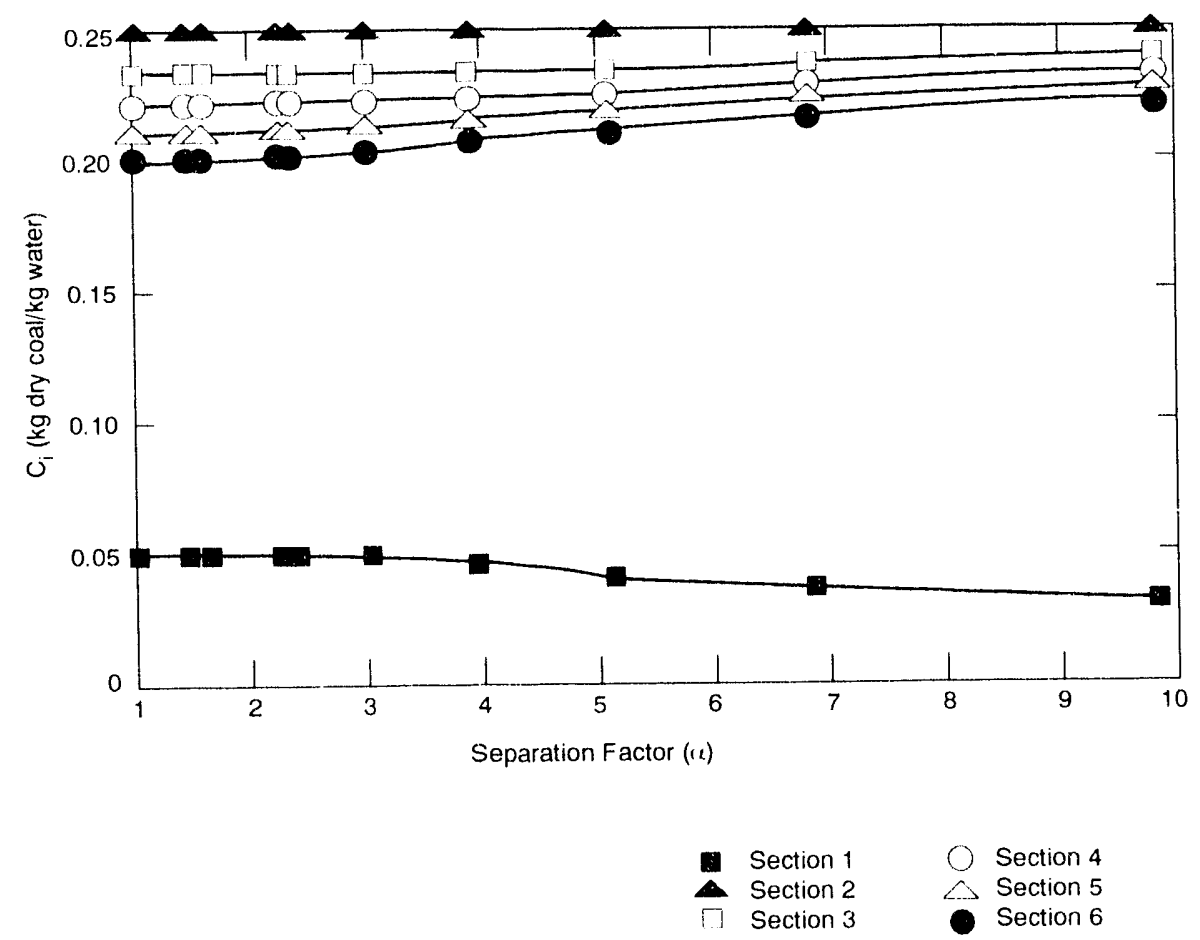

L93 0208

Figure 5. Solids flow model: solids concentration in reactor. Variables were fixed at $\mathrm{W}=20 \%, \mathrm{~A}_{\mathrm{f}}=5 \%$, and $\tau=5 \mathrm{~d}$.

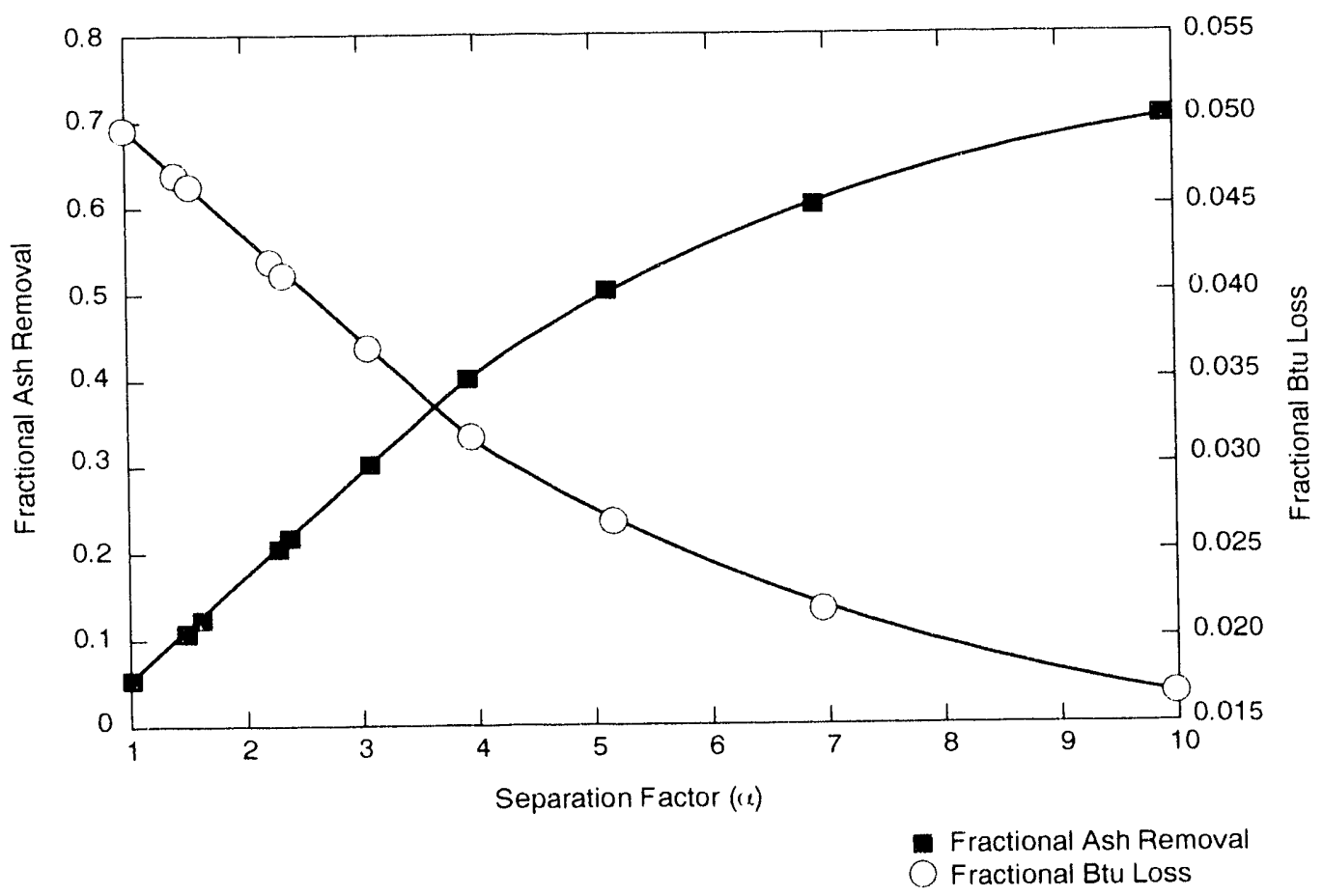

L.930209

Figure 6. Solids flow model: fractional ash removal and Btu loss. Variables were fixed at $\mathrm{W}=2(0 \%$, $A_{f}=5 \%$, and $\tau=5 \mathrm{~d}$. 
Figure 5 shows how the movement of solids between sections controls the slurry concentration $\left(\mathrm{G}_{\mathrm{i}} / \mathrm{F}_{\mathrm{i}}\right)$ in each section. The concentration in Section 2 is fixed at $0.25 \mathrm{~kg} / \mathrm{kg}$. corresponding to a slurry mass fraction [see Equation (11) | of $w=$ 0.2. There is a steady decline in concentration through Sections 2-6, although the decline is less at higher separation factors because fewer solids are drained (see Figure 3). It can be seen that the proposed operating strategy produces a low slurry concentration in Section 1. This may be beneficial because the high pyrite concentration in this section produces a higher demand for oxygen by the microorganisms, and oxygen transfer rates are lower in dense slurries." On the other hand a dilute slurry does represent wasted bioreactor volume. An improved operating strategy would be to remove more solids from Sections 2-6 (e.g., set $\beta=2$ for these sections) while keeping the amount drained from Section 1 the same to avoid excessive loss of heating value in the solid waste. This was, within certain practical constraints, the strategy followed during the experir.dents.

Figure 6 summarizes the expected performance of the phy acial pration process as a function of the separation factor. With no separation $(\alpha=1)$, removing $5 \%$ of the feed coal as solid waste simply removes $5 \%$ of the ash and $5 \%$ of the heating value. Increasing a to 10 gives over $70 \%$ ash removal with only $1.5 \%$ loss of heating value.

The actual value of separation factor that can be achieved in the reactor was measured before startup (Section 3.3) and later refined based on process operation (Section 4.3). Combining this measurement with Figures 2-6 (or their equivalent for other values of $\tau$ and $w$ ) allows all the solid and liquid flows around the reactor to be fixed. 


\section{EQUIPMENT AND PROCEDURES}

The equipment and procedures used for these experiments were similar to those described previously. ${ }^{4}$ This section discusses the improvements made for the present set of experiments and the reasons for them.

\subsection{Liquid Flows and Axial Mixing}

The same plexiglass laboratory reactor, $8 \mathrm{ft}$ long $x 10$ in. wide with a 30-degree half-angle at the base was used. The slurry level was fixed by outlet tubes, $3 / 8$ in. ID $\times 4$ in. long. Three tubes, corresponding to slurry volumes of 100,150 , and $200 \mathrm{~L}$. were available but only the 1.50-L level was used.

Previous experience had shown that trying to operate a continuous, small-scale slurry reactor at conditions approximating plug flow produced a number of scale-down problems involving plugged lines and settling of coal in the reactor. ${ }^{4}$ The reactor had therefore been operated essentially as a continuous stirred tank and the potential advantages of plug flow coupled with cell re :ycle had been lost. Several improvements were made to rectify this situation.

During previous experiments the process hydraulic residence time was fixed by removing a certain volume of liquid from the outlet reservoir (see Figure 1) each day, and replacing it with fresh water containing the desired nutrients. The resulting diurnal variation in the composition of the feed to the reactor was effectively damped out by the mixing in the reactor. This would not be acceptable in a plug-flow reactor. The wastewater pump shown in Figure 1 was therefore added to pump waste continuously from the system to a reservoir that sat on a weighing scale so that the wastewater flow could be monitored. The : wastewater was removed from the bottom of the outlet reservoir to maximize the removal of fines and precipitates from the system. However, the concentration of solids in the wastewater never exceeded 2\% except during process upsets caused by failure of the slurry dewatering screen (a $41-\mu \mathrm{m}$ nylon mesh that was replaced monthly). As the wastewater flow rate was decreased, the hydraulic residence time of the process was increased [Equation (2)] up to some upper limit corresponding to zero wastewater flow (i.e., the only significant liquid effluents from the process are the water in the product coal cake and evaporation and mist losses). The process was usually operated at this limit.

The liquid level in the outlet reservoir was maintained by a float valve. When the level dropped, water containing nutrients flowed from the feed reservoir into a side chamber connected to the outlet reservoir by tubes. This chamber acted as a mixer where fresh feed was mixed with an appropriate amount of recycled liquid from the outlet reservoir before being pumped out to the reactor by the recycle pump. This arrangement of float valve and side chamber was necessary to automatically make up water losses from the process, while not allowing short-circuiting of the fresh feed directly to the wastewater. The feed reservoir also sat on a weighing scale so that the flow could be monitored. The feed consisted of dechlorinated tap water containing $0.49 \mathrm{~g}$ $\left(\mathrm{NH}_{4}\right)_{2} \mathrm{SO}_{4}$ per $\mathrm{kg}$ of coal fed and enough $36 \mathrm{~N}$ $\mathrm{H}_{2} \mathrm{SO}_{4}$ to keep the $\mathrm{pH}$ in Section 2 below 2.2. The amount of ammonium sulfate was based on a cell yield of $0.04 \mathrm{~g}$ cells/g pyrite ${ }^{10}$ and this coal having $1 \%$ pyritic sulfur. The amount of sulfuric acid varied between 5.5 and $7.5 \mathrm{~mL}$ per $\mathrm{kg}$ of coal fed.

Axial mixing in the reactor was reduced by the addition of solid baffles, dividing it into six equal sections, each with its own aeration system. Flow between sections was through single 1/4-in. holes, countersunk to a sharp edge to prevent coal from settling and plugging them. Each baffle had three holes, corresponding to the slurry levels of 100 . 150 , and $200 \mathrm{~L}$, but the 100 -L holes were plugged and the 2(0)-L holes were above slurry level. This arrangement maximizes physical separation, because only solids near the slurry surface, which should be enriched in the light, hydrophobic organic fraction of the coal, can flow into the next section. 
Tracer studies were conducted to assess the success of these measures to control axial mixing The system was first filled with tap water. A concentrated salt solution was added to Section 1 (inlet end) and the electrical conductivity measured in Section 6 (ontlet end), while water was pumped from the outlet reservoir into the reactor at a rate $F_{0}=V / \tau$. where $V=$ liquid volume in reactor and $\tau=$ nominal residence time.

With such long residence times and the high aeration rates needed to ensure complete mixing in each section |0.5 standard cubic feet per minute (SCFM) to each section/, the loss of water caused by evaporation and misting complicated these experiments and the analysis of the data. The syslem was run basically as in Figure 1 with no wastewater flow, and the recycle pump feeding the reactor from the outlet reservoir. Inflow of tap water from the feed reservoir via the float valve maintained the level in the outlet reservoir and compensated for evaporation. With this arrangement, if the reactor is operating as a series of $n$ stirred tanks, the entire system can be considered as a series of $(n+1)$ lanks with continuous recycle of liquid from $(n+1)$ (the outlet reservoir) back to 1. The theoretical solution for the concentration in the nth tank of such a series is avalable for comparison with the data, but care is needed in defining the residence time for each tank. The volume of each of the $n$ theoretical tanks is fixed at $\mathrm{V} / \mathrm{n}$, but the flow into each is progressively decreasing because of the evaporative losses. If the total loss rate is $\mathrm{E}$, the average liquid flow rate is $\left(F_{0}-E / 2\right)$ and the residence time of a theoretical tank can best be defined as:

$$
\tau_{n}=\frac{1}{n\left(F_{1}-\frac{V_{2}}{2}\right)}=\frac{\tau}{n\left(1-\frac{r_{1}}{2 \Gamma_{n}}\right)}
$$

This procedure contains another inexactitude. Without knowing $\mathrm{E}$ and $\mathrm{n}$ in advance, it is impossible to give the external tank, (i.e., outlet reservoir), a residence time equal to $\tau_{n}$. However, this has no effect on the results up to a time of about $1.4 \tau$. The exact configuration of the external tank only influences the results after about $2 \tau$, when an element of the tracer has a chance to flow com- pletely around the system and trigger the conduclivity detector for a second time. Note that the evaporation rate can be measured during the experiment by the rate at which the level drops in the feed reservoir.

The results are shown in Figure 7 as conductivity in Section 6, normalized by the conductivity corresponding to (added tracer)/(total water volume in system) versus time/n $\tau_{\mathrm{n}}$. (Note that $n \tau_{11}=\tau /\left(1-E / 2 F_{0}\right)=$ residence time corrected for water loss]. Also shown are the theoretical results for $n=4,5$, and 6 . In comparing the data with the theory, it must be remembered that there is some uncertainty on the $y$-axis because of unresolved questions about the nature of the water loss. If the loss is caused by misting, then salt is being lost as well and the average salt concentration in the system decreases with time. If water loss is caused by evaporation, then no salt is lost and average tracer concentration would remain constant. With this effect in mind, the reactor appears to be operating functionally as a series of five stirred tanks. While this is still far from the ideal of plug flow, it represents a considerable improvement over the previous experiments.

The fact that a reactor divided into six sections behaves like five tanks in series, indicates that at these very long residence times, backmixing between sections through the small (1/4-in.) holes in the baffles is significant. This backmixing can be avoided in the future by not putting all of these holes (and the reactor outlet tube) on the same level. Arranging the holes to give a slightly lower level in each succeeding section would force water in section i to flow uphill to get back into section ( $\mathrm{j}-1)$.

\subsection{Aeration and the Solids Drain}

Each section of the reactor had its own aeration tuhe, pressure gauge, flow control valve, and airflow meter feeding an aeration tube that ran along the bottom of the trough for the entire length the section. The aeration lubes must give good bubble dispersion, not leach anything inhibitory 


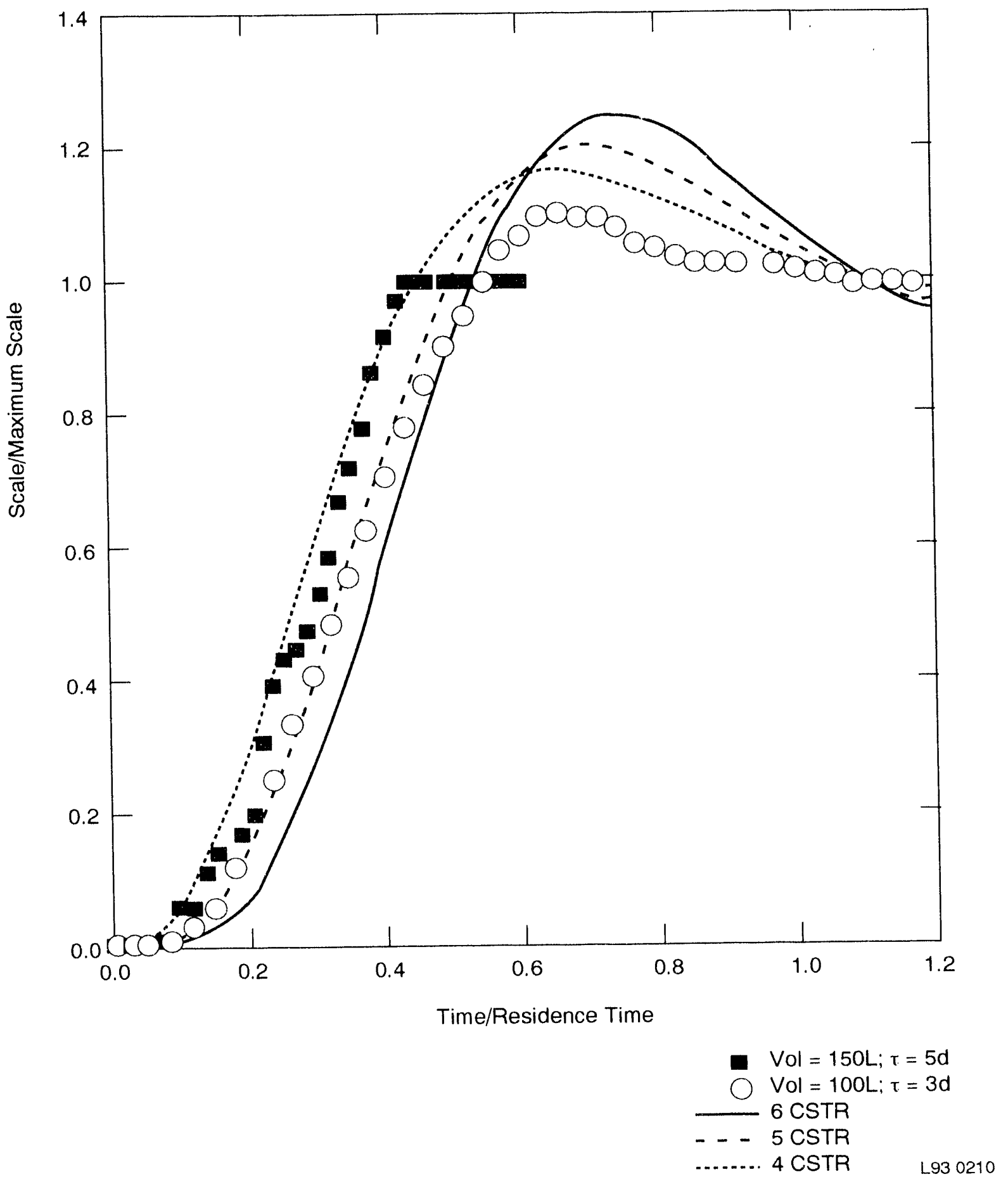

Figure 7. Results of axial mixing study. 
to the bacteria, and not plug, abrade, or corrode in the low pH conditions surrounded by liberated quartz and pyrite particles. They must also have a reasonably low pressure drop to minimize air compression costs in a commercial-scale operation. Two hasic types of acration tubes were evaluated.

The first were hollow, rigid tubes, $5 / 8 \mathrm{in}$. or $3 / 4 \mathrm{in}$. OD, to fit into the base of the trough, and of various plastics (butyrate, polycarbonate, polyethylene, and acrylic). The ends of the tubes were plugged and small holes were drilled in two rows 60 degrees apart so that the bubbles would emerge parallel to the trough walls. (Bubbles impinging on the trough walls have been found to cause rapid corrosion of the plexiglass). The holes were uniformly spaced except over the central 3 in. of tube, which had no holes. Hole sizes were specified in terms of the drill bit used to make them. The 81 bit (0.010-in.) holes were found to require excessive pressure drop and plug quickly, so most investigations used 73 bit (0.()24-in.) or 66 bit (0.033-in.) holes.

The second type used two lengths of silicone rubber tubing, 3/32-in. wall thickness, stretched over hollow rigid plastic formers of $1 / 2$-in. OD. The formers had their ends plugged and slots cut along the side to permit airflow. Holes were punched in the silicone rubber tubing in the same configuration described above using an 18-gauge needle.

Figure 8 shows a cross section through the solids drain in the base of the reactor at the center of each section. These drains consist of a cone with a 15-degree half-angle tapering down to a 1/2-in. nipple pipe thread (NPT) line containing a PVC ball valve to remove the accumulated solids. There was no aeration directly above these drains, so Figure 8 shows only the rigid former of the aeration tube, the tube bringing the air down into it, and a small tube that directed some air down into the cone in an attempt to keep the accumulated solids there loose and free-flowing. The latter was not successful, and the accumulated solids would only flow out some lime after the valve was opened, unless they were dislodged in some manner. This aspect of solids handling needs improving in future designs.

One objective in designing the reactor sections was to maximize the physical separation of mineral matter. A pattern of mixing and recirculation must be created that keeps the organic coal particles in suspension while the denser and more hydrophilic particles settle out into the solids drain. Each section must contain regions where water and light hydrophobic particles are entrained with the rising swarm of bubbles; the upflow here being balanced by downward flow of licpuid and solids in other regions (mainly near the walls). Having no aeration inmediately above the solids drain was a deliberate decision; a downflow region here should deposit denser particle: in and around the solids drain while the lighter particles follow the liquid streamlines and get reentrained in the surrounding upflow regions.

In some early tests, a shallow bed of coarse particles $(20 \times 40$-mesh sand or $(0.5$-mm glass beads) was added to the bottom of the trough, filling the conical drain and just covering the aeration tube. The aeration kept this bed ebullient, and it was hoped that the settled pyrite and mineral particles would mix with it while the coal particles were kept away from the aeration tube. Solids removed from the drain could be wet sieved to separate the sand for return to the trough. Although this idea worked and high-ash solids could be separated from the sand, long-term operation showed no improvement in tubing life and had a tendency for the sand to cement together, plugging the drain. The idea was therefore abandoned.

\subsubsection{Physical Ash Separation}

Complete optimization of the design for physical separation was not possible within the time and funding constraints of the project. Only short experiments could be done to investigate the variables most likely to affect the physical separation of ash and pyrite; the airflow rate and the number and size of holes in the aration tube. 


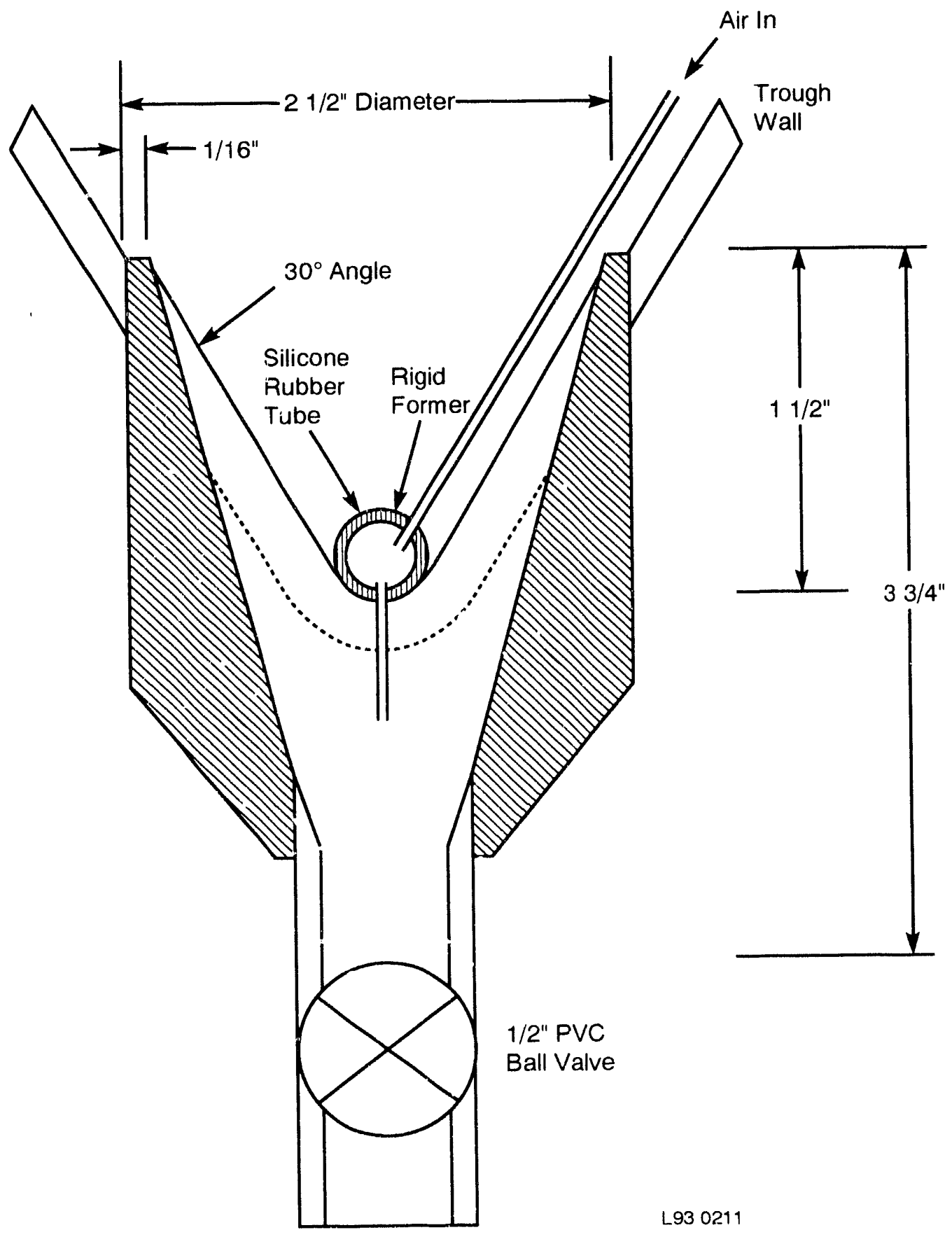

Figure 8. Design of solids drain. 
Figure 9 shows the results obtained with rigid polyethylene aeration tubes containing various configurations of holes. (This tubing was actually microporous but previous testing had shown that the pores quickly plugged with coal fines and precipitates, so holes were drilled in it). In these experiments, a reactor section contained $3.5 \mathrm{lb}$ of $20 \times 4()$-mesh silica sand, $4.4 \mathrm{lb}$ spent $T$. ferrororidans medium to facilitate wetting of the coal, $12.2 \mathrm{lb}$ coat, and sufficient water to fill the section. Sand was added before turning on the airflow. This slurry was aerated for 15 minutes at 2 SCFM after which one plug volume (the volume of the conical drain shown in Figure 8: $91 \mathrm{~cm}^{3}$ ) of solids was drained and returned to the section. After an additional 15 minutes acration, another plug volume was drained, wet sieved to separate the sand, and the remaining solids were dried and analyzed for ash via ASTM Procedure D3174. This procedure was repeated at airflows down to 0.5 SCFM.

It was anticipated that more holes would generate a larger number of smaller bubbles and thus more efficient acration. as well as a lower pressure drop through the acration tube. The results (see Figure 9: the raw coal contained $9.55 \%$ ash) confirmed these expectations. The 12- and 2()-hole lubes gave optimum separation at an airflow of 1.5 SCFM, while the 10-hole tube required a flow greater than 2 SCFM. The reason for the maximum separation is that at airflows less than 1.5 SCFM, there is insufficient turbulence to keep all the organic coal particles in suspension. so that they settle out along with the mineral particles. At higher flow rates there is so much turbulence that even the dense mineral particles stay in suspension, so separation is again reduced.

The data shown in Figures 10 and 11 for silicone rubber covered ateration tubes were obtained during the startup period when the aerated trough was run as a batch reactor and each section contained a $20 \%$ slurry of coal in a mixed culture of Thiohacillus and Leptospirillum bacteria, with no sand or glass beads. The $\mathrm{pH}$ had been equilibrated at 2.0 so that the basic minerals in the coal had dissolved, reducing its total ash content to approximatlely 6\%. hut leaving its insoluble, liberated ash (see Section 2.4) the same. Eatch sec- tion had a slightly different aeration tube, although those in Sections 1, 2, and 4 were sufficiently similar $(44,40$, and 38 holes respectively) to be considered identical. The airflows were set at the desired level and one plug volume of solids was drained and returned to the section. After 2 hours aeration, a further plug volume of settled solids was drained and analyzed for ash. For the 20-hole aeration tube in Section 3, the complete range of airflows was studied, with 15 minutes aeration being allowed at a given airflow rate before solids were drained and analyzed.

Figures 10 and 11, duplicate experiments done 12 days apart, show similar results. With 20 holes, gas dispersion was poor and there was no physical separation except at the highest airflow in Figure 10. Doubling the number of holes to the 38 to 44 range produced a sharp maximum in the physical separation at an airflow of 1.5 SCFM, exactly as in the previous experiment (see Figure 9). The drop between Acration Tubes 4 and 5 was probably caused by a combination of fewer holes and lower airflow.

\subsubsection{Operating Conditions}

All the rigid aeration lubes were found to plug quickly. Typically one-half of the holes would be totally plugged after one week's operation, producing nonuniform aeration, higher pressure drops, and seltling of coal over the plugged regions of the tube. Forty-hole silicone covered aeration tubes were therefore adopted. They resolved most of the difficulties of corrosion and settling experienced previously ${ }^{4}$ at the expense of a higher pressure drop. which translates into higher air compression costs. This pressure is needed to expand the lubing to open the holes to the point where air can flow out, and is not significantly reduced by increasing the number of holes (decreasing the tube wall thickness deserves investigation). At a constant airflow of 1.5 SCFM, the pressure would fall from $15 \mathrm{lb}_{\mathrm{f}} / \mathrm{in} .^{2}$ to around $8 \mathrm{lb} /$ in. ${ }^{2}$ over a period of weeks as the lubing fatigued and corrosion widened some of the holes. After approximately a month ail the air would be nowing out of one or two large holes and the tube was replaced. 


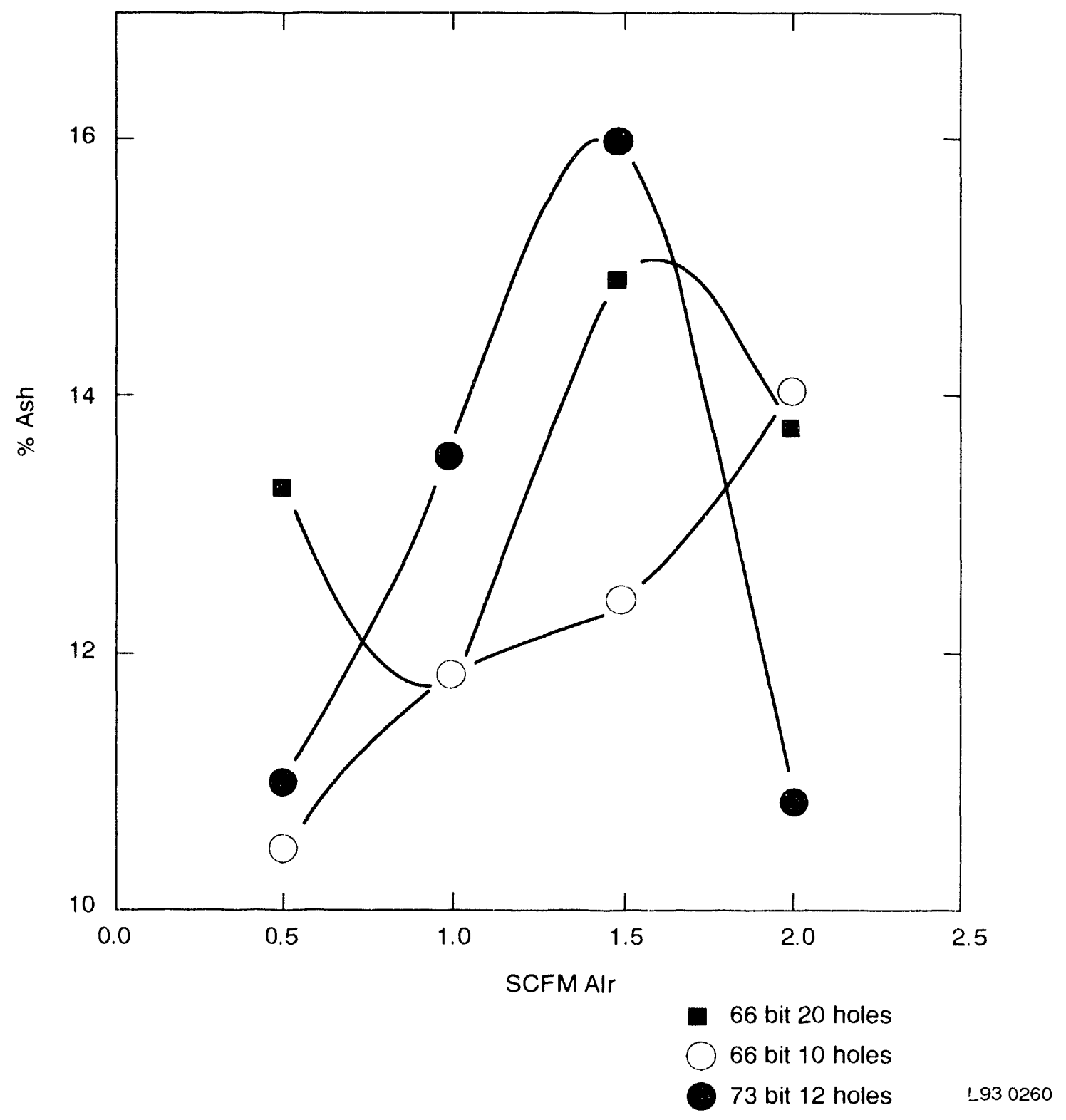

Figure 9. Results of physical separation study for porous polyethylene tubing. 


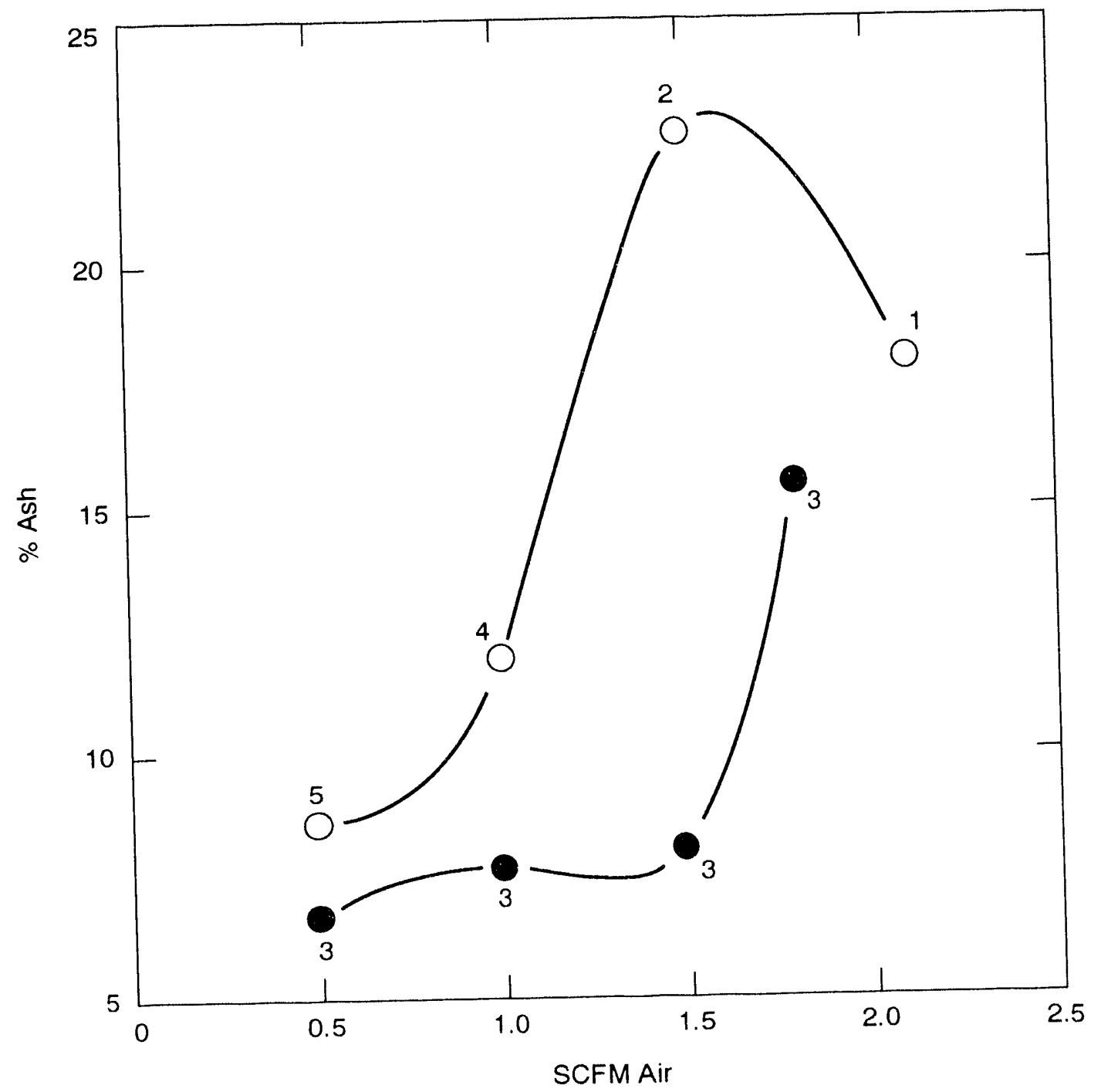

$1=$ Polycarbonate 44 holes
$2=$ Polycarbonate 38 holes
$3=$ Acrylic 20 holes
$4=$ Polycarbonate 40 holes
$5=$ Acrylic 32 holes

L93 0212

Figure 10. Results of physical separation study for silicone covered rigid tubing done on $11 / 15 / 91$. 


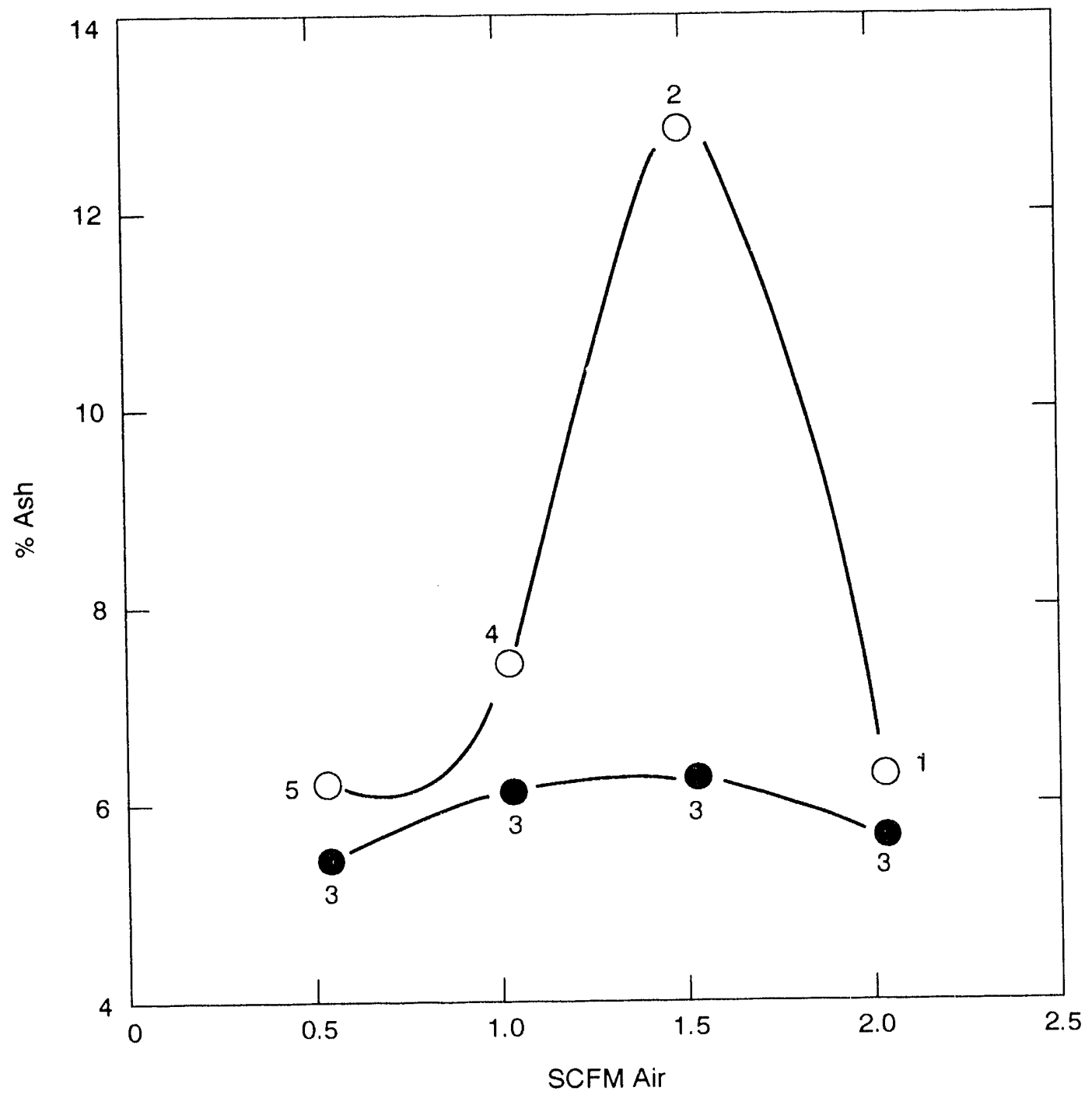

$1=$ Polycarbonate 44 holes

2 = Polycarbonate 38 holes

$3=$ Acrylic 20 holes

$4=$ Polycarbonate 40 holes

$5=$ Acrylic 32 holes

L.93 0213

Figure 11. Results of physical separation study for silicone covered rigid tubing done on 11/27/91. 
Figures 9 t!rough 11 show the importance of kecping the airfow all 1.5 SCFM in cach section. This arflow is high enough o keep the organic particles in suspension, yet low enough on allow settling of the liberated minerats. This equals 1.4 on a gas volume per slurry volume per minute basis. and represemts farly intense acration. It is three limes that used previously and, hased on that experience. oxygen transter to the microorganisms should not be limiting even al the higher slurry concentralions. The corresponding air velocity (airflow/slurry surface area) is $1.4 \mathrm{li} /$ min. This velocity is proportional to the agitation power inpul per unit slurry volume and should be kept constant during scale-up in geometricallysimilar reactors.

Values of the separation factor defined in Seetion 2.2 can be calculaled from the data shown in this section at an arrflow of 1.5 SCFM. It varies from 3.5 in ligure 10 10 2 in Figure 11 ; the difference arising hecaluse the bacteria were growing and generating biosurfactants between those two experiments, allering the gas dispersion and the hydrophobic interactions. The data in Figure 9, after correcting for the soluble basic minerals, suggest a similar value of $a=2.2$. This approximalle value was used with figures 2 - 6 from Section 2.2 to fix the initial flows of liquid and sotids around the reactor.

\subsection{Water Loss and Temperature Control}

The combination of long liquid residenec limes and intense acration in the reactor produces an obvious potemtial problem of evaporation. If the reactor is matmatined at 2.4" $\mathrm{C}$ and the inlet ais is totally dry, then the total airflow of 9 SCT.M call evaporate up $108.8 \mathrm{~kg} / \mathrm{d}$ of waller, which is on the order of one-third of the liguid feed rate. Such inlense evaporation would aller the slurry concentration and its conting effeces need ob be commerateded by comsiderable heating if the temperature is to be kepl in the correct range for microbial metabolism.
In these experiments, the inlet air was humidilied by a custom-built, steam-injection humidifier. It consisted of 11 fl of $1-1 / 8-i n$. diameler lubing giving an air residence lime of 0.5 seconds. Steam was injected into the inflow through a melering needle valve, and exeess condensale was removed through a trap at the outled end. Tests showed that this consistently produced a humidity more than 8()$\%$. The addition of this humidilier facilitated temperature control by greatly reducing evalporative cooling. The $1 \mathrm{~cm}$ perature throughout the reactor could be maintained al $24.5+3.1^{\circ} \mathrm{C}$ by three $100 \mathrm{~W}$ aquarium heaters localled in Sections 1, 3, and 5.

It became apparent during the experiments that the majority of the waller loss was due not to evaporation but 10 mist in the air leaving the reactor. This amounted to 6-7 kg/d (see Section 4.1). The losis calused by evaporation from the coal on the dewatlering screen is unyuantifiable and maty contribute to this total. There was one demister/filter on the roof of each section except Section 2. Their design is shown in Figure 12 . They were origimally filled with glass wool, but this quickly hecame sallurated and plugged, forcing the air to find alternative exits. This was replaced with a coarse plastic screen malerial, which drained well and would operate for several days belween watshings to remove accumulated coal lines (daily washings were needed with a $35 \%$ coal slurry in the reacter). Air demisting is another areat requiring allention in fulure designs.

\subsection{Startup, Operational, and Analytical Procedures}

These experiments were done on the same coal as used previously. ${ }^{4}$ It was an Illinois \#6 supplied by the Monterey (oal (ompany, with $9.5 .5 \%$ atsh. $4.04 \%$ lotal sulfur. 1.(2) pyritic sulfur, a healling value of $12.7(1) \mathrm{BH} / \mathrm{lb}$, and a moisture contem (after grinding) of $2.9 \%$. The coal was ground 10 $80 \%-100$ mesh at the Mountain Stalles Energy (MSti) Ince facility in Butle. Montana and shipped to the INEL, ander nitrogen in 5.5-gal drums. 


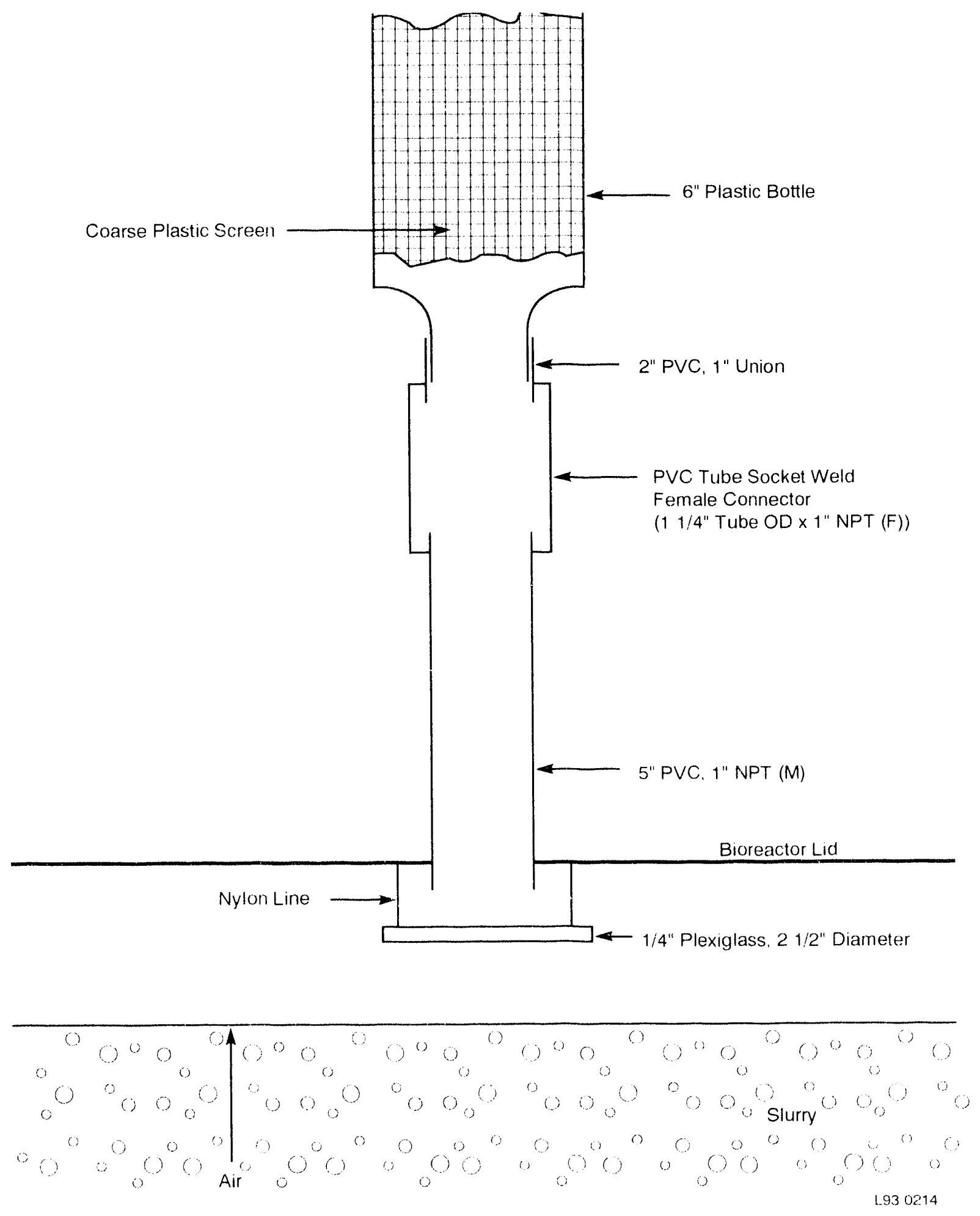

Figure 12. Demisting device. 
Details of the process statup procedure have been described previously. the reaclor was lilled with microbial medium containing $1.2 \mathrm{~g} / \mathrm{l}$. $12.2+$ as the energy source, and inceulated with a mixed culture of Thobarillus and lephospirillum from previous experiments. The medium was periodically recycled through an electrolytic cell to regencrate the lact and allow continued micro. bial growth. When the microbial eell concentralion reached $1.4 \times 10^{6}$ cells per mL. coal was added. The resulting $20 \%$ slurry was aleraled for 29) days in batch mode. and the coal and licpuid feeds were lumed on at the start of Day 30. An additional 30 days of comlinuous operallon allowed the microbial colture of become properly adapled to the coal before any stcady-state measurements were taken.

The daily procedures during the operating period were as follows:

\subsubsection{Solids Drain}

The solids were removed from the drains of Sections 1 through 6 on a datly basis. Since the concial drains (sec ligure 8 ) could each hold a voltume of approximately $100 \mathrm{ml}$, and the dratin strategy (sec rigure 3) reguired removing a volume of $3(1) .5()(0) \mathrm{ml} / \mathrm{section}$ drain/day, the solids were removed repealledly, allowing 20 - 30 minutes for the drains lo refill with sellled solids. Alter the initial solids were removed from each dratio, we allowed a 20 - 30 minute wating period for the drains lo refill with sellled solids. This procedure was repeated until $3000.500 \mathrm{ml}$. of solids was removed from each section. Note that the amount of solids thall can be drained in this way is necessarily imprecise, but ean be kept consistent when averaged over the reater residenes lime (3-5 days). The solids dratined from Sections 2-6 were wet sieved fo remove the liquid, which was returned to the section from which it came. The sieved solids were weighed and added lo section 1.

The solids dratined from section I were also wet sieved. the liquid heing distributed between Sections 20 to make up the volume lost with the drained solids. The sieved solids were weighed. and samples taken for ash and (during certain scatly statc perinds) pyrite analysis.

\subsubsection{Product Coal}

The wel coall cake that had atecumulated on the dewallering sereen was weighed and spread on a drying traly. The we coal was mixed and a repre. sentallive sample was laken by fillome a $5(0)(1)-m$. beatier. The dry product coal was analyaed for lotal sulfur, heating value, pyritic sulfur, and atsh. Before these meatsurements were taken, the coal wals washed fo remove the sulfate sulfur, which comsisted of precipitate, sulfate sulfur in the coal, and that dissolved in the interstitial water. To measure sulfalle sulfur and to prepare the coal for lotal sulfur and heating analysis, the following wash procedure was adopled. Approximaltely 3()$-4() \&$ from the $5(0)-m l$. heaker was added to $3.50 \mathrm{ml}$, of $1.2 \mathrm{~N} \mathrm{HCl}(10 \mathrm{ml}$. I.2 N HCl $101.0 \mathrm{~g}$ of wel coal cake) and stired for 30 minutes, then fillered. The solids were washed two more limes following the salme procedure. The lillates were analyad for iron by Alomic Absorption Speciroscopy and the sulfalles by a harim chloride lubbidimedric method (ASTM D)-516-82). After the third wash, the extracted residuc was atr dried. then analyzed for ash, folal sulfur, and heating value. MSt: Inc., Butle, Montana pertormed the total sulfur and heating value analysis. To measure pyritic sulfur, 10 gof we coal cake from the 50()-ml beaker wats driced, from which 5 got dried coal was used lo dederminc pyritic sulfur by ASTM 1)-24(9)-(9).

The trays were allowed to dry in the laborallory for lo days. They were then weighed and the coal on them mixed, and a representative sample was taken for analysis of the residual moisture. This allowed calculation of the masses of dry coal and moisture in the original catke.

\subsubsection{Other Measurements}

The wastewalle reservoif was weighed and its comlents mixed to suspend the coat fincs. A 10(1-ml sample was laken with a graduated cylinder and allowed lo sedtk in order to measure the fince concentration. A separate t mo sample

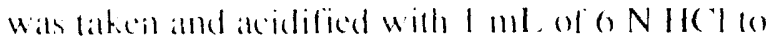


dissolve any precipitates. Alter at leass I hour, the fines were liltered out and the fillate antalysed for iron and sulfate as above. The wastewaller reservoir was then emptied and replaced. During periods when the system was operated with no wastewaler flow. samples were taken of the sturry from the reactorefliluent, and analyzed in the same waly. These measurements were used mainly to indicate when steady-state operation had been reached.

The weight of the feed reservoir was also noled. If necessary, it wals refilled with tap water that had been passed through an activated carbon filter to remove any free chlorine. Ammonium sullate and $36 \mathrm{~N}$ sulfurie acid were also added at a rate of $(1.49 \mathrm{~g}$ and $5.5107 .5 \mathrm{ml}$. per $\mathrm{kg}$ of coal trealed.

The pH, temperature, and oxidation/reduction potential (bh) in each reactor section were also measured. Several checks were conducted. including the liquid llow rate into Section 1 and the reactor effluent slurry concentration (measured by collecting the effluent in a graduated cylinder and allowing it to settle overnight). Samples were also taken daily from the outlet reservoir and the reactor inlet liquid for direct microscope counts of total bacterial numbers. 


\section{RESULTS AND DISCUSSION}

\subsection{The Water Balance}

The cumulative flows of water around the process during the 120 days of comtinuous operation are shown in ligure 1.3. The moisture in the feed coal is seen to be a small factor, increasing stowly during the experiment as the coal feed rate was increased. The water loss with the drained solids was always negligible. The dominant terms in the water halance are fresh liquid feed. the water in the wel product coal cake from the dewatering screen, the wastewater flow, and the loss by evaporation and misting foalculated from Equation (1)]. After Day 107. the wastewaler flow was lumed off to achieve the desired hydraulic and reactor residence times $\left(\tau_{11}\right.$ and $\tau$ ) and slurry concentration in Section 2 of the reactor $(w)$.

Figure 13 shows that the flow rates (the slopes of the lines) were steady and consistent when averaged over the long time scales the reactor residence times) involved in the experiment (the discomtinuity at Days 79 and 80 is caused by the flows nol being measured on these days). However, the raw data (latile B-1. Appendix B) show that there was considerahle variation hetween days. There are several reasons for this. The only flows that were actually fixed by pump controllers were the reactor inlet flow and the wastewater flow, both being calculated from the equations in Section 2 to give the desired values of $\tau_{\eta} . \tau$, and $w$. The occasional large variation in the other flows resulted from process upsets such as sticking of the reservoir float valve or plugging of the reactor outlet tube. Smaller fluctuations resulted from fatcors such as wear of the pump lubing and inevitable variations in the effectiveness of the dewatering sereen from day 10 day. Another reason for the fluctuations was revealed by careful measurements of the slurry flow, made by collecting the reactor effluent for consecutive periods of I hour These measurements showed llow surges as if the reactor was slowly overfilling over an 8 - 12 hour period and then returning 10 a lower level relatively quickly. These changes in level

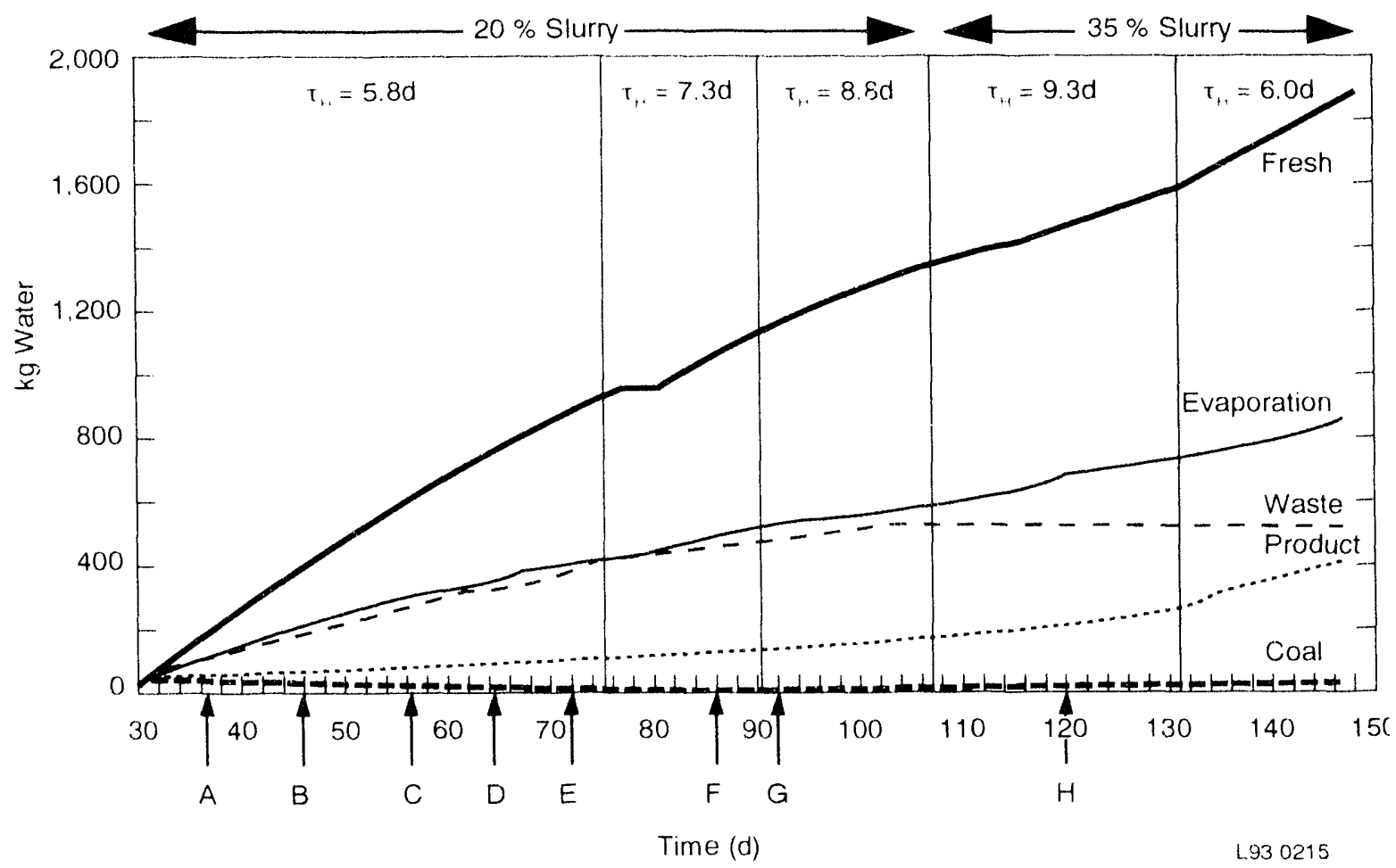

Figure 13. The process waller balance. 
were not visible but, becatuse of the large size of the reactor, they could involve a signilicant fraction of the datily flow (a $1 \mathrm{~mm}$ change in level in the reactor requires approximately $0.65 \mathrm{~kg}$ of slurry). These fluctuations will be eliminated in the future by changes in the design of the outlet tube and the holes in the baffles.

The most unexpected result from the water bal. ance was the large loss of water from the process, which was an average of $7.8 \mathrm{~kg} / \mathrm{d}$ over the 120 days of the experiment. It was originally thought that this loss was caused by evaporation. At the operating temperature of $24^{\circ} \mathrm{C}$, the vapor pressure of water is $3 \mathrm{kPa}$, so at the airflow rate of 9 SCFM (2.54 L/min), the maximum possible evaporative loss (if inlet air is totally dry) is $3 \times$ $254 \times 6() \times 24 \times 0.018 / 10) 1 \times 22.4=8.8 \mathrm{~kg} / \mathrm{d}$. The letters $A$ through $F$ in Figure 1.3 indicate a progressive series of improvements to the inlet air humidifier, altempting to reduce this water loss. The humidifier reached the final form described in Section 3.3 at $F(86$ days) and measurements of inlet air humidity showed that it exceeded $80 \%$. making the evaporation hypothesis untenable. In fact, the water loss was due mainly to mist droplets in the outlet air stream. The outlet air filters had reached the form described in Section 3.3 at $\mathrm{E}$ (72 days). They were originally filled with glass wool, which removed mist efficiently and, in conjunction with the air humidilier, reduced the average water loss to $6.1 \mathrm{~kg} / \mathrm{d}$ between Fand $\mathrm{H}$. However, glass wool dres nof drain and quickly hecame saturated, loatling 10 plugging and atssociated operating problems when the air sought other ways out of the reactor. At H, the glass wool was replaced with a larger plastic mesh (actually from plastic pan scrubbers). While this was slightly less efficient at mist removal (the slope of the Evaporation line in Figure 1.3 increases slightly) it drained more readily and led to fewer operational problems. The mesh was rinsed every few days to remove the accumulation of coal fines.

\subsection{Solids and Heating Value Balances}

The raw data on the flow rate of dry solids around the process is shown in Table B-2. and is summarized on a cumulative basis in Figure 14. Once again. there is considerable datily variation, but the flows are steady over the time scale of interest. Nearly one ton of coal was treated over the 120 days of continuous reactor operation. The loss of coal fines with the wastewater was always negligible.

The process was operated under four different sets of operating conditions, the periods being marked by the vertical lines at 75, 107, and 132 days in Figures 13 and 14 (the line at $9($ ) days marks a very slight increase in feed rate). At each condition, approximately four reactor residence times were allowed for the process to reach steady state. There followed a steady-state period of slightly over one residence time during which all readings were taken daily. These readings were averaged and summarized in Table 2. Note that the solids wasted from Section 1 were kept between $4 \%$ and $6 \%$ of the feed coal.

During the first two steady states, the mass of feed coal was closely matched by the sum of the product coal and the drained solids. This may seem unusual, since the dissolution of the basic ash and pyrite should reduce the total mass of solids. However. the product coal and solid waste were not washed before drying and weighing, so their meatsured weight included dissolved salts and precipitates from the interstitial water. This apparently canceled the loss of mincral matter. During the two final steady states, both at $3.5 \%$ slurry concentration, there was a definite loss of solids. amounting to approximately $1.6 \mathrm{~kg} / \mathrm{d}$. Some of this coal accumulated in the bioreactor; there was a noticeable increase in the deposition of solid clumps on the walls and lid of the reactor at the higher slurry concentration. Some coal also apparently left the reactor in the mist: the filters in the laboratory air conditioning system showed a surprisingly rapid accumulation of coal dust. It is also possible that some of the coal organic maller was being solubilized. After the experiments described here were completed and the system was refurned to operating at $\tau=7$ days and $w=$ $20 \%$, a grab sample of slurry was laken from the reactor. filtered, and tested for dissolved carbon. It was found to contain 1,400 parts per million 


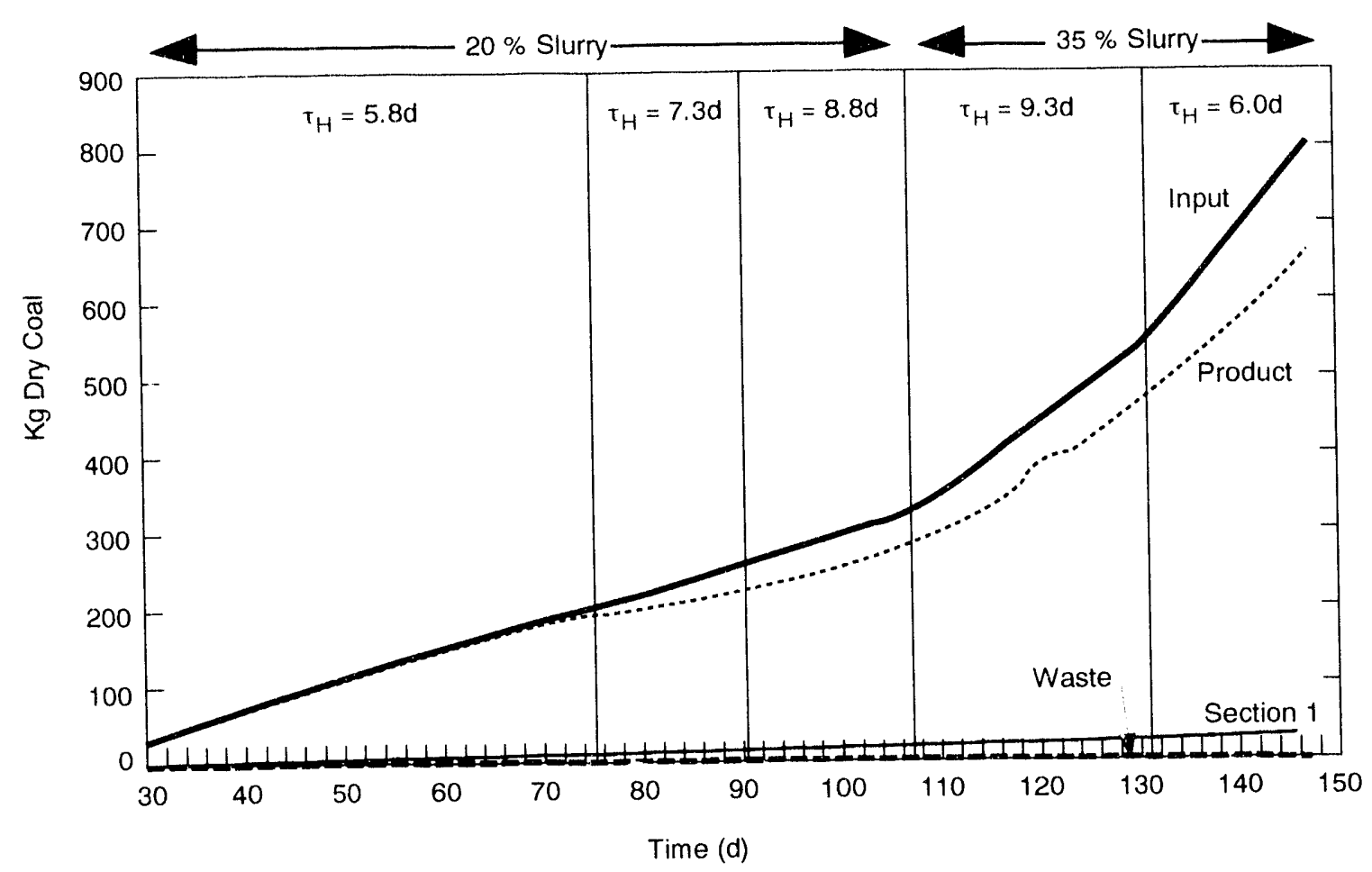

L93 0216

Figure 14. The process solids balance.

(ppm) of organic carbon suggesting that there was some solubilization of the coal, due either to chemical or microbial reactions. This merits further study, although it probably does not account for the observed loss of solids because there is no reason why it should be so much more intense in a $35 \%$ slurry than in a $20 \%$ slurry.

More important than the recovery of the mass of the feed coal is the recovery of its heating value. The heating value of the product coal, on a Btu/lb basis, shown in Table 2, was found to be consistently $5-7 \%$ less than that of the feed coal, despite its lower mineral content. This is consistent with previous results ${ }^{4}$ and may be caused by microbial oxidation of some part of the coal structure, which could also cause the solubilization discussed above. This loss, and the loss of heating value to the solid waste are combined in the heating value recovery defined by Equation (6). It is found to be in the range $80-90 \%$ for all the steady-state conditions (see Table 2).

\subsection{Ash-Forming Minerals}

The raw data on the ash content of the product coal and solid waste are given in Table B-3 and summarized as kilograms of ash per day in Figure 15. The ash flow with the product coal and the solid waste do not add up to that in the feed coal because some of the ash-forming minerals (including pyrite) are dissolved out of the coal during the process. Typically, $10 \%$ of the ash in the feed coal appeared in the solid waste, $60 \%$ appeared in the product coal, and $30 \%$ was solubilized. An ash removal of $40 \%$ in a process designed primarily to remove pyrite was an encouraging result, but the fact that most of it was dissolved rather than physically separated leaves considerable room for improvement. One way to assess the physical separation is the separation factor analysis given in Section 2. The data for the steady-state periods (see Table 2) show that the ash content of the solid waste was remarkably 


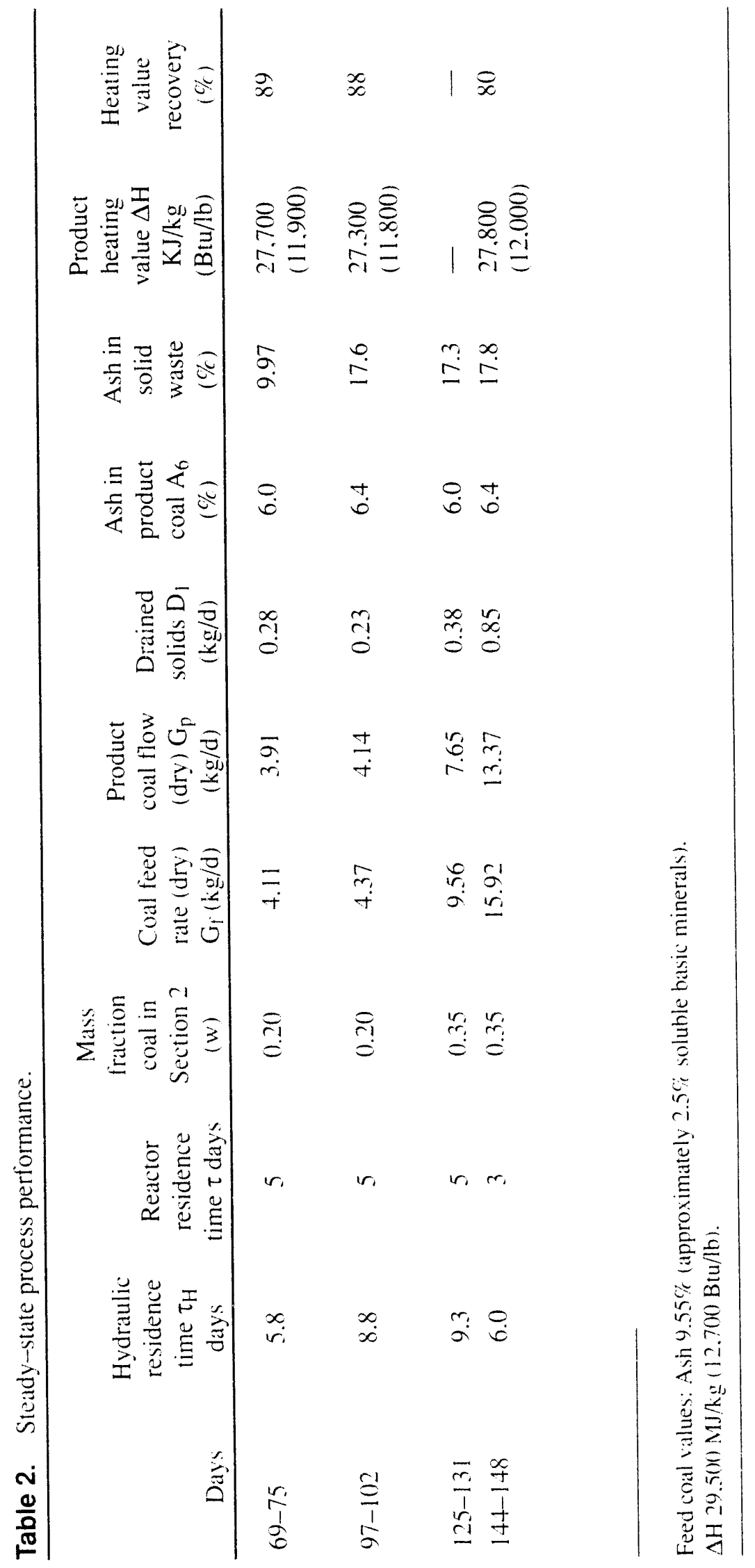




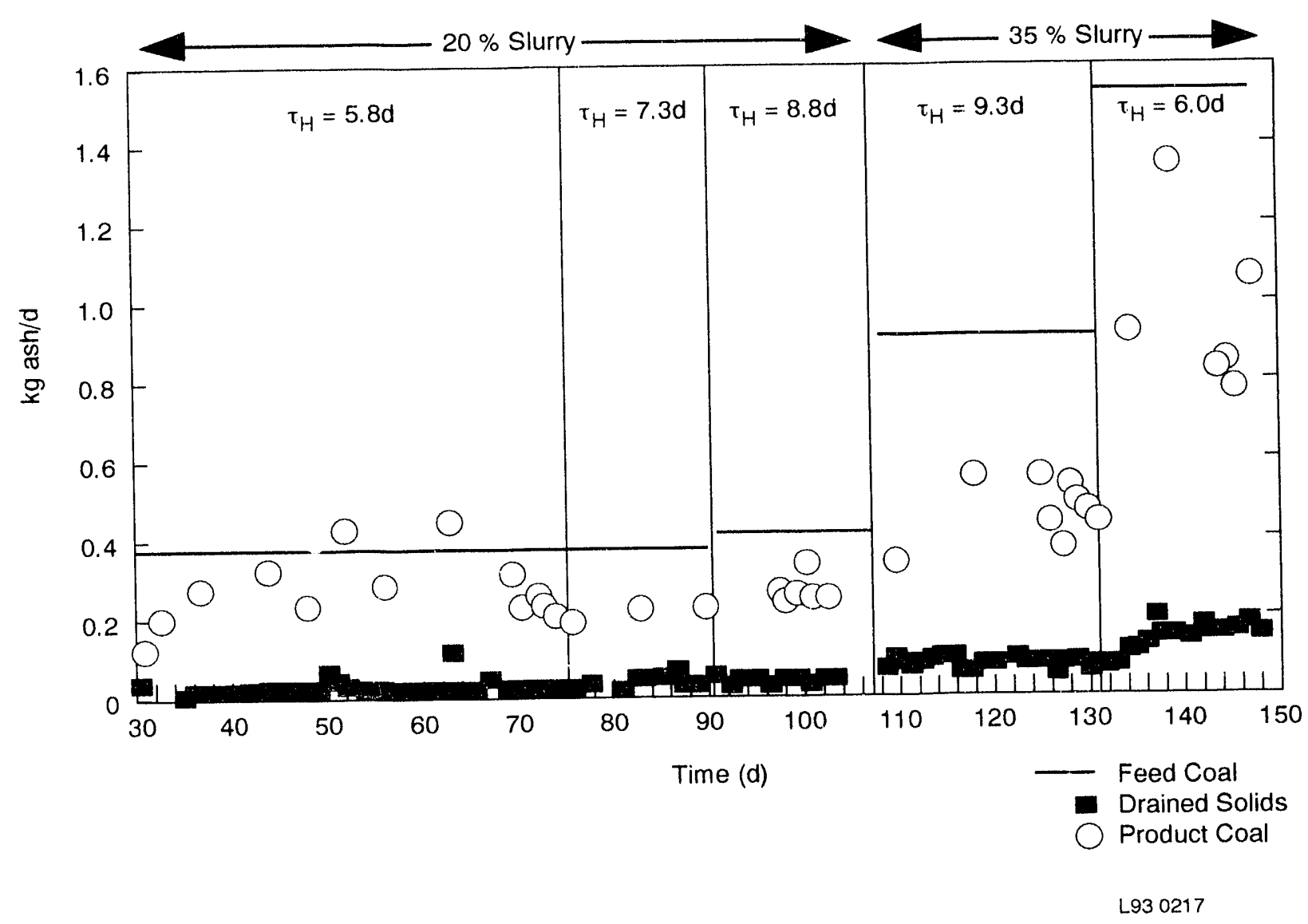

Figure 15. Ash removal.

constant at close to $17.6 \%$ (the lower value early in the experiment was probably caused by an inferior procedure for draining the solids). If it is considered that the $2 \%$ finely-dispersed, nonremovable ash assumed to be in the feed coal is still in this solid waste (see Section 2), this leaves $15.6 \%$ removable ash. Examination of Figure 4 shows that this corresponds to a separation factor $\alpha=1.9$, close to the value of 2.2 determined in Section 3.3. The value $\alpha=1.9$ was subsequently used, in conjunction with the Figures 2-6 in Section 2, to determine the feed rates and solids drain rates from the system.

The main reason for the low value of the separation factor is that Illinois \#6 coals are difficult to clean physically. The float-sink curve for our particular coal, as ground, was not determined because of time and funding constraints, the diffi- culties of the measurement for finely ground coal, and the fact that ash removal was not the primary objective of the process. Our estimate of $2 \%$ nonremovable ash may be conservative.

A second reason for the low separation factor concerns the mechanisms of physical separation. Mineral particles concentrate at the bottom of the trough because they are less hydrophobic and thus less likely to be carried upwards by the bubbles, and because of gravity settling. If gravitational effects dominate, then the critical quantity is the particle settling velocity. But settling velocity depends not only on the density, which is much higher for a mineral particle, but also on the particle size. A $150-\mu \mathrm{m}$ organic coal particle has a similar settling velocity to a $50-\mu \mathrm{m}$ liberated mineral particle, and thus a similar probability of appearing in the solid waste. To study this effect, 
grab samples of feed coal. product, and solid waste were taken on Day 119 and subjected to particle size analysis on a Coulter Laser Particle Size Analyzer. The resulting particle volume distributions are shown in Figure 16. The feed coal had a mean size of $140 \mu \mathrm{m}$ with a standard deviation of $105 \mu \mathrm{m}$. All the particles larger than $300 \mu \mathrm{m}$ appeared in the wasie stream, which had a mean of $214 \mu \mathrm{m}$ and a standard deviation of $161 \mu \mathrm{m}$. The product was enriched in the fine particles with a mean of $1(1) \mu \mathrm{m}$ and a standard deviation of $73 \mathrm{\mu m}$ (although this may reflect reduction in particle size caused by mechanical abrasion and microbial activity. as well as the physical removal of the larger particles).

There appears to he considerable room for improvement in the physical separation performance of the process. The geometry of the reactor sections (particularly the depth) needs to be conidered, and the arrangement of the aeration tube and solide drain optimised. Finally, a coal that contain more liherated ash and that has not been preckeaned athe fines straan from a coal preparattion plant for examples would provide a better test of this aspect of the process.

\section{4 $\mathrm{pH}$, Eh, and Bacteria Counts}

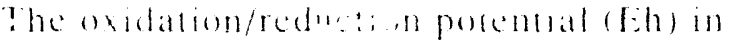

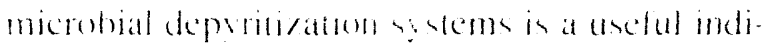

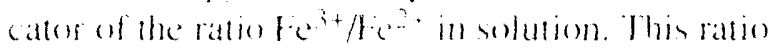
secreased by the comsunption of ferre ion for the chemical axidation of pyrite:

$F C S+2 F C^{3} \rightarrow 3 F C^{2}+2 S$

It is increased hy the subsequent oxidation of ferrous ion hy the iron-oxidizing begreria Thoha cillus ferrosidems and Leprosprillum ferresidems.

$F^{2}+H^{2}+\frac{1}{4} O_{2} \rightarrow H^{2}++\frac{1}{2} H_{2} O$

A high the show s than there is sufficient micro bial atelivity in the ysem we kep strtually all the

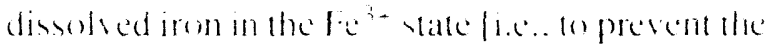
reactun presented in Equation (1 th from heom ing rate limiaingl.
The variation of Eh along the reactor during the foursteady-state periods is shown in Figure 17. As expected, there is a sharp drop in Section 2 because the feed coal is added there, increasing the amount of tresh pyrite and accelerating the reaction presented in Equation (13). Thereafter, microbial iron oxidation dominates and the Eh increases along the reactor. The Eh also decreases with increasing slurry concentration and decreasing liquid recycle $\left(\tau_{H} \rightarrow \tau\right)$. This is also as expected; less recycle means less $\mathrm{Fe}^{3+}$ in the reactor feed and more coal means that $\mathrm{Fe}^{3+}$ is consumed more rapidly by the reaction presented in Equation (13). Nevertheless, even under the most extreme conditions tested $1.35 \%$ slurry, $\tau=3$ days, and $\tau_{H}=6$ days), the Eh never fell below $500 \mathrm{mV}$, indicating that better than $90 \%$ of the dissolved iron was in the Fe ${ }^{3+}$ state.

An unusual feature of the coal used in these experiments is that it contains a high ratio of basic mineral matter 10 pyrite $2.6 \%$ of the $9.5 .5 \%$ total ash was found lo be soluble in HCl). During microbial depyritization, the dissolution of these basic mincrals produced a nee increase in $\mathrm{pH}$ despite the acid formed by the oxidation (by calla-

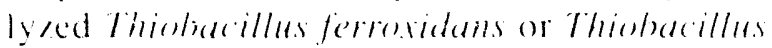
theseviderts of the sulfur generated by the reaction presented in Fyuation (1.3).

$S+\frac{3}{2}()_{2}+H_{2}() \rightarrow 2 H+H^{\prime}+S_{4} 2$

Note that much nore acid could be generated hy the formation of ferric hydroxysulfate precipilates. e.g. geotithe.

$\mathrm{He}^{3+}+2 \mathrm{H}_{2} \mathrm{O} \rightarrow \mathrm{FoO}\left(\mathrm{OH}+3 \mathrm{H}^{+}\right.$

(16)

However, such precipitales interfere with the process by coating the pyrite surfaces and complicating the washing of the product coal. A major process control objective is to keep the dissolved metal concentration and the $\mathrm{pH}$ within the lolerance of the microorganisms and low enough to prevent the formation of precipilates. The pll is kept within the desired range by adkling sulfuric acid to the liquid leed reservoir. Nole that there would be theoreticat advantages to replacing this with phosphoric aced. which provides an essential 


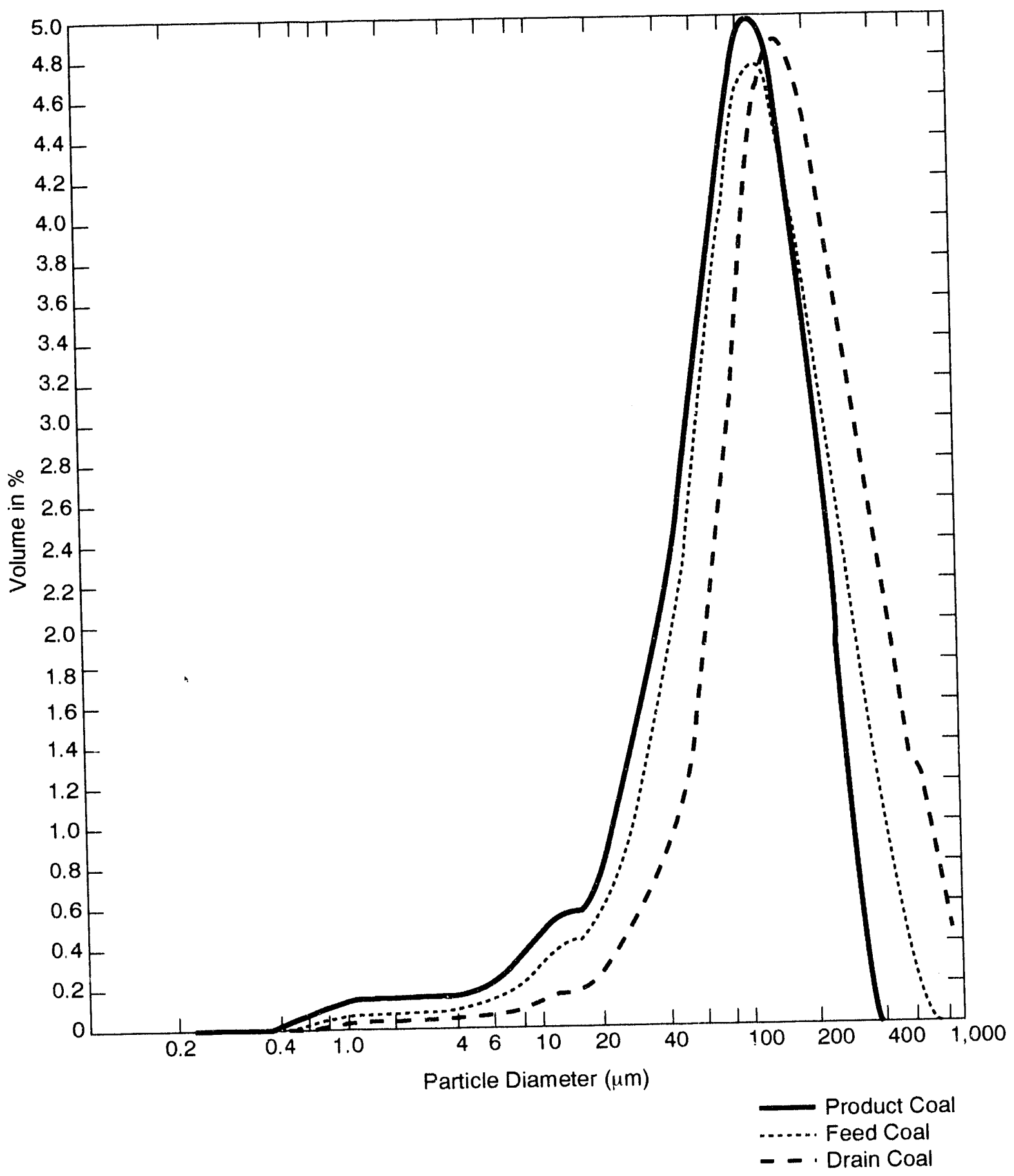

L93 0218

Figure 16. Size distributions of feed, drain, and product coal. 


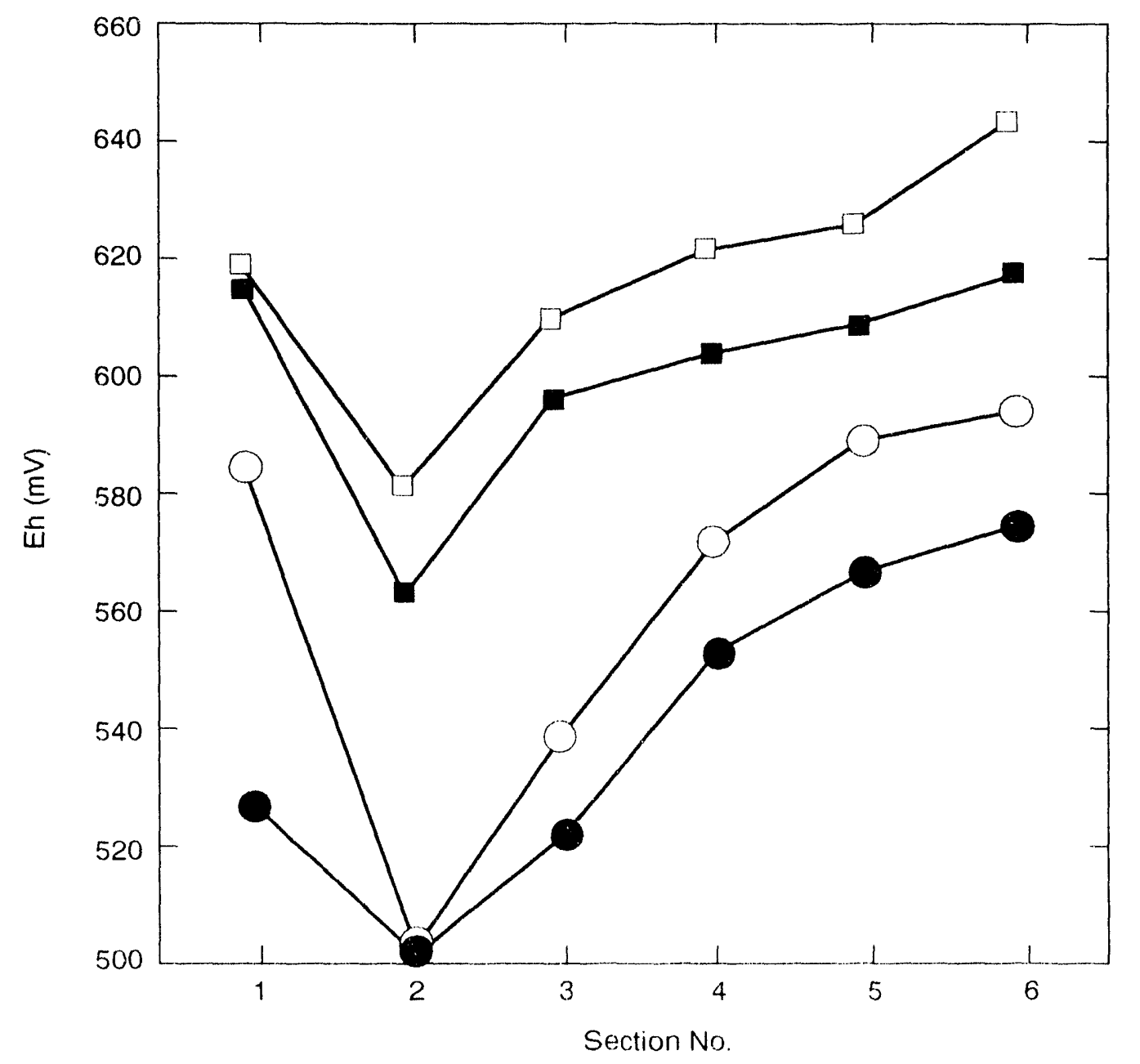

$w=20 \%, \tau_{H}=5.8 d$
$w=20 \%, \tau_{H}=8.8 d$
$w w=35 \%, \tau_{H}=9.3 d$
$w=35 \%, \tau_{H}=6 d \quad \angle 930219$

Figure 17. Steady-state Eh values. 
microbial nutrient. However, ferrous phosphate and other phosphates have very low solubilities, which would aggravate the formation of precipitates. The bacteria appear to obtain sufficient phosphate from the feedwater and coal.

The variation in $\mathrm{pH}$ along the reactor at the four steady-state conditions is shown in Figure 18. The sharp increase between Sections 1 and 2 was caused by the basic minerals in the feed coal. With a $35 \%$ slurry, the increase continued into Section 3, showing that the dissolution of these minerals was not instantaneous, or perhaps that there was an imbalance between the iron- and sulfur-oxidizing microbial activity in the system. Sulfur oxidation /reaction shown in Equation (15) I requires that the bacteria be altached to the pyrite surface, so many of the sulfur-oxidizing bacteria are lost from the system attached to the product coal. Iron oxidation / reaction shown in Equation (14) I can be caltalyzed by bacteria in the liquid since $\mathrm{Fe}^{2+}$, unlike $\mathrm{S}$, is soluble. Thus, the recycled liquid probably contains a disproportionate number of iron-oxidizing bacteria and it lakes time for the population of sulfur-oxidizing bacteria to grow to comparable levels. Since iron oxidation consumes acid / reaction shown in Equation (14)| while sulfur oxidation produces it |reaction shown in Equation (15)|, this sequence of events may contribute to the rise in $\mathrm{pH}$ between Sections 2 and 3. In Sections 3 through 6, the $\mathrm{pH}$ drops steadily becatuse of the microbial oxidation of pyritic sulfur.

In operating the process, the control objective wats to add sulficient acid to the feed reservoir to keep the pH ctose to 2 throughout the reactor.

This pH is high enough to allow microbial metabolism and low enough to prevent the formation of precipitates. With a $3.5 \%$ slurry and $\tau_{11}=$ 9.3 days, this strategy preduced a sharp increase from pH $=1.84102 .14$ between Sections 1 and 2 . 11 is not known whether this sudden change affected microhial metabolism. However, this change is due solely to the high basic mineral contern of the particular cenal. and would non be at problem with most coals.
The Eh and $\mathrm{pH}$ provide excellent indirect measures of the health and activity of the microbial population. Obtaining more direct measures is difficult. Many of the bacteria attach to the coal making them almost impossible to enumerate. Also, it is difficult to distinguish between the various categories of bacleria; the autotrophic iron and sulfur oxidizers $t$ al oxidize the pyrite, the acidophilic heterotrophs that live symbiotically with them, and other heterotrophs that may be oxidizing the organic fraction of the coal. More research and lesting are needed in this area. The only direct measure used in this experiment was direct microscope counts of the total bacterial concentration in the liquid in the reservoir under the product coal dewatering screen, and in the liquid fed to the reactor. The results are shown in Figure 19. The measurements are difficult and imprecise because of the presence of coal fines. and they show considerable daily variation around an average on the order of magnitude of $10^{x}$ cells per $\mathrm{mL}$. The liquid feed to the reactor consists of a mixture of feedwater and reservoir water, so the inlet data in Figure 19 is consistently lower than the reservoir data. The difference between them is consistent with the amount of liquid recycle, being high when the recycle ratio was low (Days 5()-75) and low when recycle wats high later in the experiment.

A disconcerting feature of the data in Figure 19 is that the cell counts appear to decline through the experiment as the coal feed rates to the process were increasing. This suggests that more cells attached to the product coal are lost from the process than can grow on the pyrite it contains, and demonstrates the importance of paying attention to the process cell balance as we seck to optimize the process by increasing the coal loading. Some important factors in this balance are as follows:

- Cell growth on the physically separated pyrite in Section 1 is essential

- Loss of pyrite in the solid waste stream means loss of eell production and may need to be reduced at the coal loading is increased 


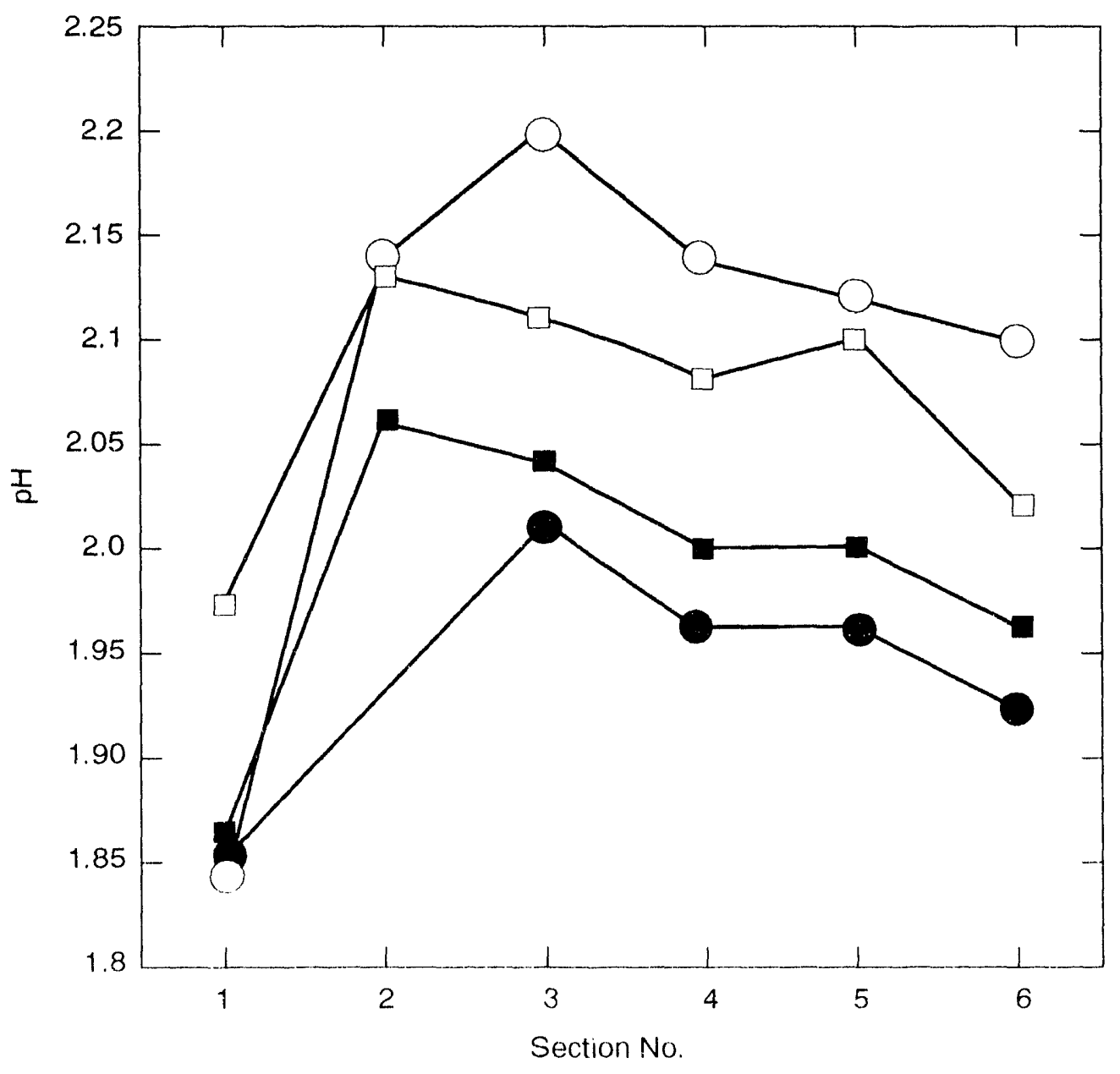

a $w=20 \%, \tau_{H}=5.8 d$

[.] $W=20 \%, \tau_{H}=8.8 \mathrm{~d}$

$\bigcirc w=35 \%, \tau_{H}=9.3 d$

$W=35 \%, \tau_{H}=6 d \quad L 930220$

Figure 18. Steady-state $\mathrm{pH}$ values. 

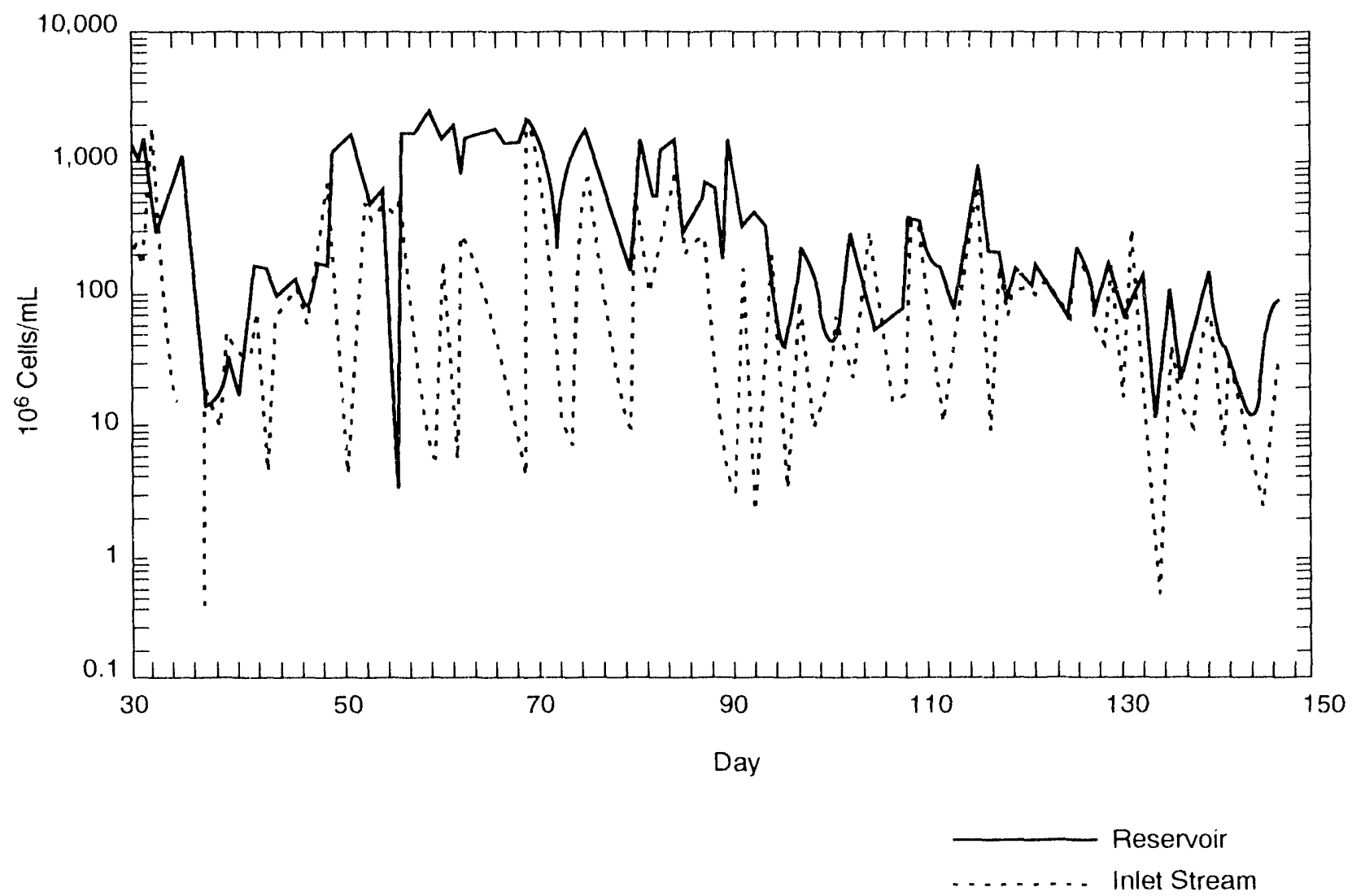

L93 0283

Figure 19. Cell counts.

- Wastewater flow needs to be minimized to reduce cell loss.

Eliminating the wastewater flow from the process at Day 107 appeared to halt, Kemporarily, the decline in cell counts. There must also be a large loss of eells in the mist leaving the hioreactor with the outlet air, another reason for reducing this water loss. The overall process flow sheet includes a washing step for the product coal that was not studied in this experiment. The washing is designed to remove dissolved and precipitated sulfate from the wet pooduct coal before it is burned, but il will also remove altached cells. Recycling this washwaller into the process will make an important contribution to maintaining at high cell concentrattion.
Another important factor in the cell balance is maintaining the correct amounts of mutrients essential for cell growth. One nutrient of concern wats the (O) needed for growth of the autotrophic backeria." A grab sample of the slurry was therefore taken, littered through a $0.2 \mu \mathrm{m}$ filter and ested in a Total Organic Carbon Analyzer. It was found 10 contain $94 \mathrm{ppm}$ of dissolved inorganic carbon. a surprisingly high number that is more than adequate to maintain microbial growth. The sample also contained $1.400 \mathrm{mg} / \mathrm{L}$ of organic carbon. The most likely explanation is that heerotrophic microorganisms atre oxidizing and solubilizing part of the organic fraction of the coat, resulting in a slight loss of heating value (Section 4.2). a large increase in dissolved organic carbon. and high level of dissolved carbon dioxide. The lwo important research guestions are how to 
minimize this activity, and why the high concentration of organics does not inhibit the atutetrophic, pyrite- oxidizing bacteria that are normally extremely sensitive to dissolved organic matter.

One reason for doing daily microscope examinations of the microbial culture was to check that acidophilic protozoa did not appear in the system. These protozoa did appear in an adjacent experiment on the depyritization of coal in heaps. The protozoa devastated the performance of this process by grazing on the Thiobacillus and Leptospirillum responsible for pyrite oxidation. However, the protozoa never appeared in the aerated trough system, presumably because it could not survive the intense mechanical agitation and abrasion in the slurry. This is an important factor in the long-term stability of the proposed process.

\subsection{The Sulfur Balance and Pyritic Sulfur Removal}

The results of the daily sampling of the product coal during the four steady-state periods are shown in Table 3. Measurements of pyritic sulfur by the ASTM procedure. modified as described in section 3.t. and of the total sulfur using a l le(c) analyer were comsintent during each period. showing that true steady blates hald heeds achicred. With a $20 \%$ burry and 5 daly reator residence time, pyritic sulfur was reduced by 8()$^{2} \%$ with a hydratulic renidence time of $\tau_{11}=5.8$ days (D)ays 69 7.51 and $87 \%$ with $\tau_{11}=8.8$ days (Days 97-102). This confirms previous resulst that showed the benefits of liquid recyele and suggested that a recycle ratio around $i$ (i.e.. $\tau_{11}=$ $2 \tau)$ was best. This was adopted as the operating strategy for the remainder of the experiment.

For the $w=20 \%$ and $\tau=5$ day conditions (the first two steady states in Table 3), lotal sulfur measurements confirmed the removal of pyritic sulfur. If the product coal contains the $3.12 \%$ organic sulfur in the leed conal and the $0.21 \%$ latl $\tau_{11}$ $=5.8$ datys) or 0.136 (at $\tau_{11}=8.8$ (dalys) pyritic sulfur measured in the product then the total sulleur should be $3.23 \%$ and $3.15 \%$. respectively. These are close 10 , although consistently higher than the measured values of $3.11 \%$ and $3.10 \%$ (note that the pyritic sulfur reduction rate calculated from the total sulfur measurements is consistently over $9(1 \%)$. However, at the most extreme conditions tested ( $\tau=3$ days and $w=35 \%$ ), the situation is very different. Although the pyritic and total sulfur measurements are both consistent through the steady-state period (Days 144-148), the pyrite measurement suggests a total sulfur of $3 .(02+0.38$ $=3.40 \%$, well below the measured value of $3.89 \%$. The pyrite reduction would be $6.3 \%$ based on the pyritic sulfur measurements, but only $1.5 \%$ based on the total sulfur measurements. The most likely explanation for this involves the reaction mechanism discussed in the previous section. There is no reason to believe that the biodegradation of coal pyrite proceeds stoichiometrically: indeed there is experimental and theoretical evidence that it does not. ${ }^{11}$ Iron oxidation / reaction shown in Equation (14) and sulfur oxidation |reaction shown in Equation (15) | are catalyzed by two different sets of hacteria (although T. fermoxidans can do both, it does not necessarily do both at the same times. The sulfur exidizing bacteria must be attached to the solid surfice. which makes them more likely to be lose from the process with the product conal or the solid waste stream. Thus. even though the Eh data hour an active iron-exidisme population. Here mat be a deficiency of sulfur-esidising batereria. In conventional bioprocess colgeinerering terminstegy. Whe mean cell residenee time for the sulfur oxidizing bacteriat has fallen below the reciprecal of their specific growth rate and they have been washed out. The net result is that the elemental sulfur is produced by the reaction shown in Eyuation (1.3) faster than it can be oxidized by the reaction shown in Eylation (15), and it accumulates in the system. It does not show up as pyritic sulfur because the ASTM procedure actually measures pyritic iron. the sulfur value being based on the stoichiometry of pyrite. However, elemental sulfur does appear in the total sulfur measurement. accounting for in high value. The solution is 10 maintain a higher population of sulfur-oxidizing bacteria by washing them off the product coal and returning them to the process. 
Table 3. Measurements of product coal and solid waste.

\begin{tabular}{|c|c|c|c|c|c|}
\hline \multirow[b]{2}{*}{ Date } & \multirow[b]{2}{*}{ Day } & \multicolumn{2}{|c|}{ Product coal } & \multirow[b]{2}{*}{$\mathrm{Btu} / \mathrm{lb}$} & \multirow{2}{*}{$\begin{array}{c}\text { Solid waste } \\
\text { percent } \\
\text { pyritic } \\
\text { sulfur }\end{array}$} \\
\hline & & $\begin{array}{c}\text { Percent } \\
\text { total sulfur }\end{array}$ & $\begin{array}{l}\text { Percent pyritic } \\
\text { sulfur }\end{array}$ & & \\
\hline Raw coal & - & 4.04 & 1.02 & 12.700 & - \\
\hline $1 / 21 / 92$ & 69 & 3.14 & 0.218 & 11,840 & - \\
\hline $1 / 22 / 92$ & 70 & 3.04 & 0.213 & 11.768 & - \\
\hline $1 / 2.3 / 92$ & 71 & & & & \\
\hline $1 / 24 / 92$ & 72 & 3.08 & 0.205 & 11,481 & - \\
\hline $1 / 25 / 92$ & 73 & 3.19 & 0.210 & 12.039 & - \\
\hline $1 / 26 / 92$ & 74 & 3.07 & 0.212 & 12.183 & - \\
\hline \multirow[t]{2}{*}{$1 / 27 / 92$} & 75 & 3.15 & 0.20 .3 & 12,162 & - \\
\hline & Average & $3.11 \pm .06$ & $0.210 \pm 0.005$ & $11,912 \pm 270$ & - \\
\hline $2 / 18 / 92$ & 97 & 3.16 & 0.116 & 11,864 & 3.82 \\
\hline $2 / 19 / 92$ & 98 & 3.11 & 0.123 & 11,884 & 2.15 \\
\hline $2 / 20 / 92$ & 99 & 3.14 & 0.131 & 11,817 & 3.65 \\
\hline $2 / 21 / 92$ & 100 & 3.10 & 0.157 & 11,808 & 4.46 \\
\hline $2 / 22 / 92$ & 101 & 3.10 & 0.124 & 11,580 & 3.49 \\
\hline \multirow[t]{2}{*}{$2 / 23 / 92$} & 102 & 3.00 & 0.126 & 11,586 & 3.19 \\
\hline & Average & $3.10 \pm .06$ & $0.130 \pm 0.014$ & $11,756 \pm 1.37$ & $3.46 \pm .77$ \\
\hline $.3 / 17 / 92$ & 125 & $\ldots-$ & 0.244 & - & 2.88 \\
\hline $.3 / 18 / 92$ & 126 & - & 0.184 & $\ldots$ & 2.72 \\
\hline $3 / 19 / 92$ & 127 & $\ldots$ & 0.216 & - & 4.50 \\
\hline $3 / 20 / 92$ & 128 & $\cdots$ & 0.214 & $\ldots$ & 4.01 \\
\hline $3 / 21 / 92$ & 129 & -- & $(0.250$ & $-\ldots$ & 3.49 \\
\hline $.3 / 22 / 92$ & 1.30 & -... & 0.222 & $\cdots-$. & 4.97 \\
\hline \multirow[t]{2}{*}{$3 / 2.3 / 92$} & 1.31 & $\cdots$ & 0.249 & & 2.90 \\
\hline & Average & & $0.226 \pm 0.024$ & $\cdots$ & $3.64 \pm .88$ \\
\hline $4 / 5 / 92$ & 144 & 3.91 & 0.311 & 12.010 & $\ldots$ \\
\hline $4 / 6 / 92$ & 14.5 & 3.82 & 0.408 & 11,970 & \\
\hline $4 / 7 / 92$ & 146 & 3.78 & 0.382 & 12.020 & \\
\hline $4 / 8 / 92$ & 147 & $\cdots$ & $\ldots$ & & \\
\hline \multirow[t]{2}{*}{$4 / 9 / 92$} & 148 & 4.14 & 0.42 & $11,8.50$ & \\
\hline & Average & $3.89 \pm .12$ & $0.380 \pm(0.049$ & $11,962 \pm 78$ & \\
\hline
\end{tabular}


An obvious question is the frateden of the pyrite reduction that is alused by microbial oxidation as opposed lo physical separalion. Since microbially-oxidised pyritic sulfur appears as sullate in the liquid. this requires a complete sulfur balance for the process that evaluales all the terms in Equation (3). This is shown lat Table 4. all cerms being in grams of sulfur per day, averaged over the steady-state periods. The sulfate sulfur in the feed coal and the solid waste were found to be negligible and are not included. Summing the sulfur oulflow in the wastewaler, the product coal (pyritic and sulfate), and the drained solids (pyritic) and comparing this result with the lotal sulfur inflow always showed a large discrepancy. One reason for this discrepancy must be the loss of sulfate with the mist in the air leaving the reactor, a phenomenon whose significance had nol been anticipaled during plamning of the experiment. Its magnitude was estimated from the known water loss rate and atverage sulfate concentration in the reactor and included in Table 4. The addition of this teme closed the process sulfur halance within the expected limits of ererer $1+5 \%$ ) for the lirst lwo steady states. Howerer. in the last two beatly states. Whete the slury concentration

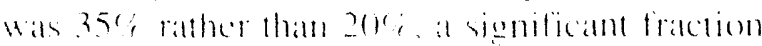

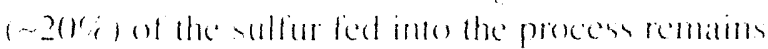

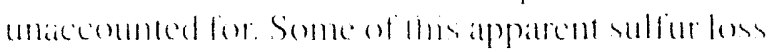
maly be callosed by the atcommulation of solids om

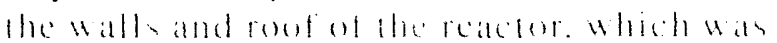

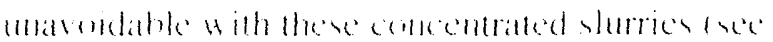
section +.2. Howerer mont al the sulfur loss must be callsed hy the partial oxidation of pyrike discussed aboves Some of the pyrtile sullur in the feed is converted fo elememal sullur rather than sullate and does not appear in any of the oullow measmomemts. This hypothesis is supported hy the pyrtic and total sulfur measurements from the founh steady stalle (sec lable 3). Which suggests that the product coal comtaids $(1 .+49+0.17 \%$ elemental sulfur. corresponding to a sulfur flow of helween 42.8 and $8 x .2 \mathrm{~g} / \mathrm{d}$. The low end of this range is the amount neceled to close the process sulfur balance. During the second and third skaty state periods, he prite in the solid waste

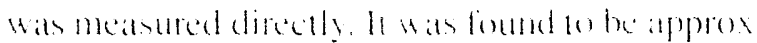

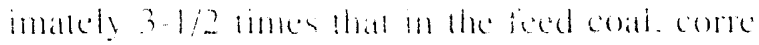

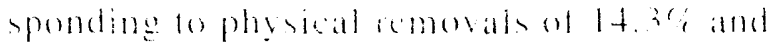
17.7\% (note that the draned prite numbers in
Table + for He first and last steady states, when these meatsurements were not made, come finm assuming an average value of $16 \%$ removal). This is a similat separation performance ats was found from ash measurements (Section 4.2 ) and is nol a good result from a lwo-stage process. This is partly caused by the nature of the Illinois \#6 coal, which is known to be difficult lo clean physically. However, it must not be forgotlen that the acrated trough was originally designed purely as a bioreactor, and has not been optimiecd for physical separation. Further development. particularly changes in the solids drain and increases in the slurry depth, should give much improved physical removal of hoth pyrite and ash.

The pereent removal of pyritic sulfur caused by microbial oxidation is calculated from the datta in Table + for the rate of appearance of sullate li.e. the first form of Eyuation $(5)$; the second form is not valid when elemental sulfur is being produced). As expected, the pereent oxidation decreases wible decreased reactor residence bime and increased coal stury concentration. from $6.5-70 \%$ with $\tau=5$ dalys and $w=20 \% 1020 \%$ with $\tau=3$ days and $u=35 \%$. This raises the ques. lion of the combination ol physical separation and microbial oxidation that would work hes in pracetice. Higher keds of microbial oxidation require

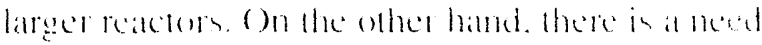

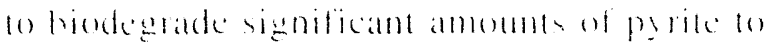

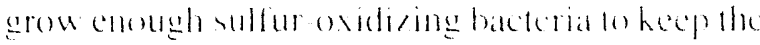
process going. A process that applomelese com plek prove oxidation also has all envirommental atvantage: the solid waste it profuces can no lomger produce any acid dratiage. These competing requirements maty best be med by combinatlioms of physical separation and hiodepyritization other than that shown in Figure I. One can, for example, envision a 7-stage reactor, with the coal fed into Section t. the solids dratined from Secetions 4 going to Section 2, and those dratined from Sections 2 and 3 going 101 . The focus should not be on the overall reacter residence lime, bet on the lime dilferent pantickes ypend in the reacerer. A pure arganic coal panticle will patss thromgh quickly, while a liberated pyrite inclu sion is lrapped in the syskem for sereral daly by the mechamisms of physical sepatration. 


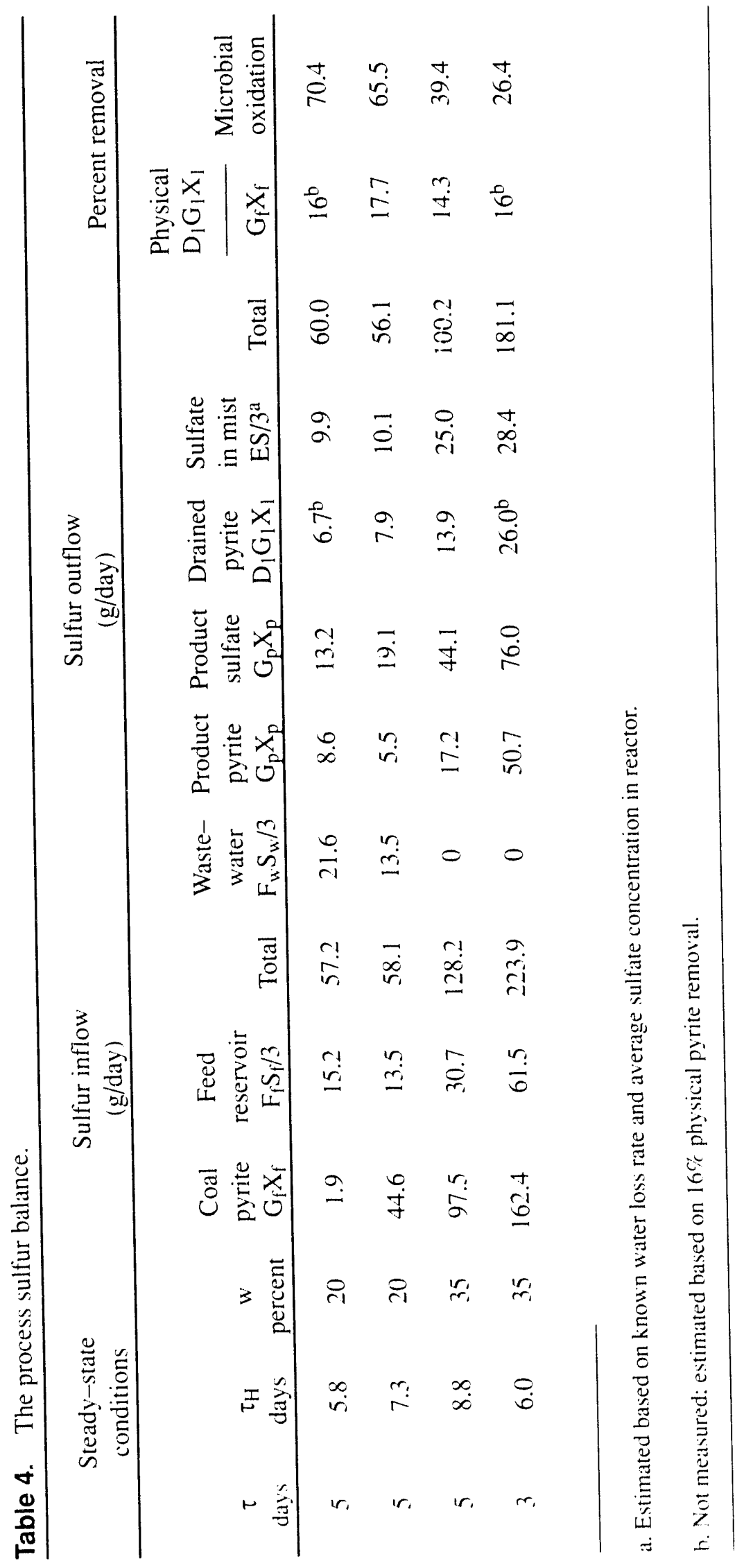


This work produced several impontant conclu

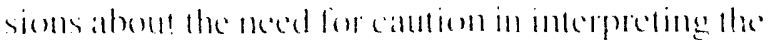
results of standard analy lical procedures for micontal coal depyritization. The literature conlaims clatims for very rapid apparent miconobial depyritization, hased on the disappearance of pyritic sulfur. Some of these are from slurry bioreactor systems and are caused by physical settling of the large pyrite inclusioms. ()ther clanims overlook the possibility of partial ox idation of pyrite to elemental sulfur and the lace that the ASTM pyrite procedure actually measures pyritic iron. Separate measurements of total or elemental sulfur in the coal or sulfate sulfur generated are essemtial to confirm the removal of pyritic sulfur. It was also found that the ASTM procedure for removing nonpyritic iron by boiling in HCl before a pyrite meatsurement is inadequate for samples containing ferric hydroxysullate precipilates gencrated by microbial aterivity. Repeated washings are neces- saly (1) mate the prite measurement aceurate. An

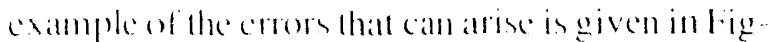
me 20) fl secmed reatsonable to suppose that the amomont of sulfale in the product coal removed daty from the dewattering sereen could be found by multiplying the amount of water it combaned by the concentration of sullate in the liquid in the slurry laaving the reactor (1) in Figure 2()). This effluent slurry appeared 10 contain no precipilates because a standard procedure adding $1 \mathrm{~mL}$ of $6 \mathrm{~N}$ HCl $10+$ ml of slurry, mixing for 1 hour, fillering and measuring sulfate in the filtrate produced no increase in the measurements ( in Figure $2(1)$ ). However, a direct measure of the sulfate in the wet coal catke using repeated washings in $1.2 \mathrm{~N} \mathrm{HCl.}$ consistently produced values that were 2 or 3 times higher ( $\bullet$ in figure 2()). Somce of the difference can be explained by evaporation of water from the coal cake on the dewatering sereen. Some of the difference however secms to be becallse the

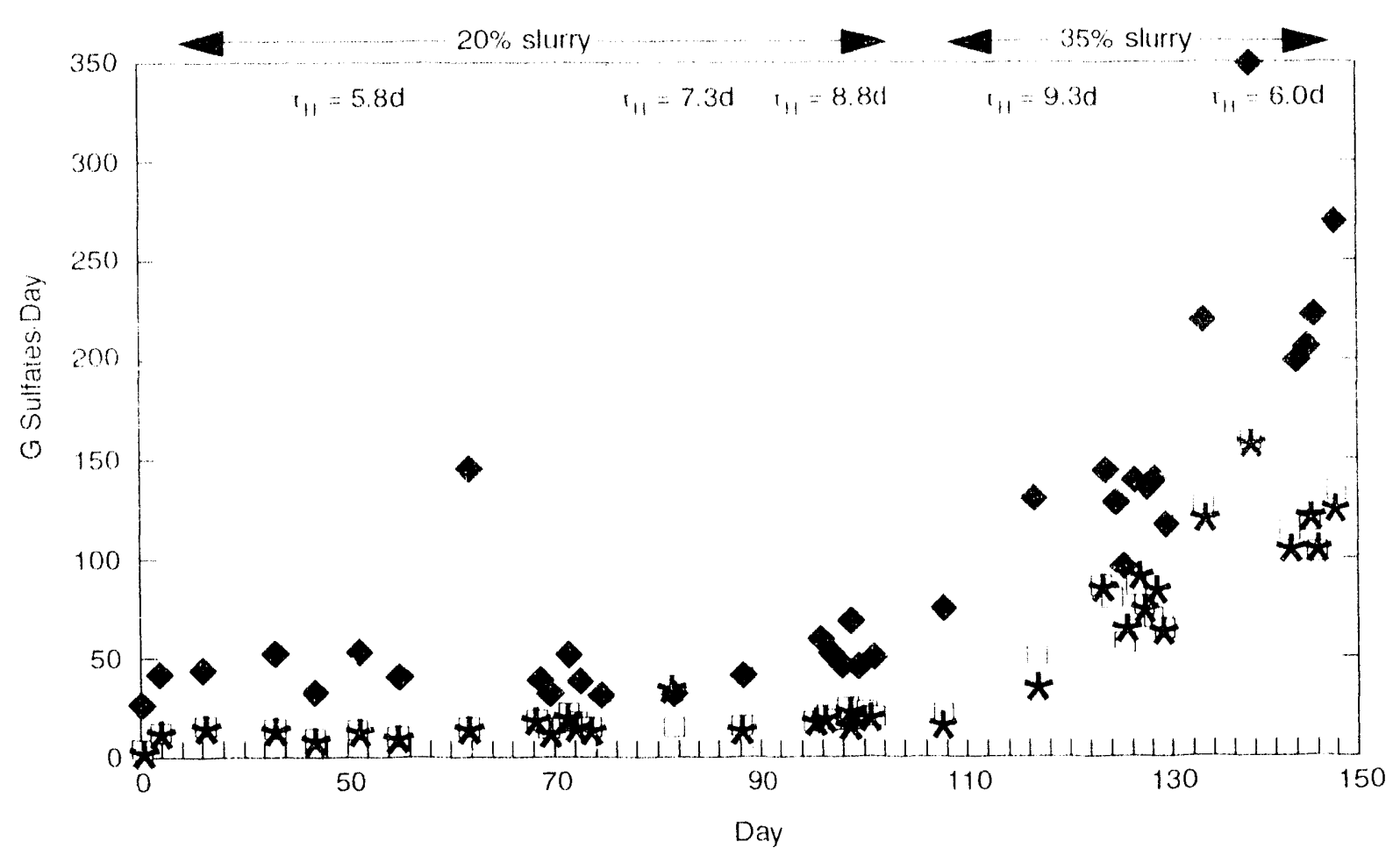

\footnotetext{
Product coal liquid, no $\mathrm{HCl}$ added * Product coal liquid, with HCL added - HCl washes

Figure 20. Sultalle in product coil. 
shury in the reactor eflluent does contain some precipitates that were not dissolved and detected by the standard procedure described above. Some of the difference remains unexplatined; the values in Table + are the higher values dekrmined by direct measurement.

\subsection{The Process Iron Balance}

The interpretation of the data in the previous sections is confirmed by measurements of the forms of iron entering and leaving the process. The data are given in Table B-4 and the averages over the steady-state periods are summarized in Table 5. Iron enters the process as pyrite in the feed coal and leaves as (a) pyrite in the product coal and solid waste, (b) dissolved and precipitated iron in the water associated with the product coal, (c) iron dissolved in the wastewater, and (d) iron in the mist leaving the reactor with the air. The solid waste flow for the first and last steady states, and the mist loss are estimated ats for the sulfur balance. The results show a slight surplus of outlow over inflow for the first three steaty states and a deficit for the last steady state that is less than expected from the sulfur and lotal solids balances (because of accumulation of solids on the walls and roof of the reactor). The most probable explanation for the imbalance is the presence of some nompyritic iron (e.g., $\left.\mathrm{FeCO})_{3}\right)$ in the soluble hasic mineral fraction of the feed enal.

The pereent removal of irom by physical separation is not shown in Table 5, but must be identical to the physical removal of pyritic sulfur in Table 4. Both are calculated from the pyrite meatsurements in the feed coal and solid waste where pyrite can salfely be assumed to be FeS2. More significant is the comparison between the pereentage of the pyritic sulfur oxidized to sulfate (Table 4) and the percentage of the pyritic iron that is solubilized and appears in one of the liquid effluents (Table 5). At a $20 \%$ slurry concentration, the iron solubilized is very similar to the sulfur oxidized: the slightly higher values for iron $(74$ and $81 \%$ vs. 70 and $66 \%$ ) probably being caused by the presence of mompyritic iron in the feed coal. Furthermore. adding the percent sulfur removals by physical and microbial means gives values 886 and $82 \%$ ) con- sistent with the pereent reductions calculated from the pyritic sulfur measurements $1(1.02-.21) / 1.02=$ $70 \%$ and $(1.02-.13) / 1.02=87 \%$ and independenty from the lotal sulfur measurements in Table $31(4.04-3.11) /(4.04-3.02)=91 \%$ and $(4.04-3.1(0) /(4.04-3.02)=92 \% 1$. It appears that the process is working well; there are plenty of both iron- and sulfur-oxidizing bacteria in the system, and the pyrite is being solubilized stoichiometrically. The rate limiting step is probably the purely chemical reaction shown in Equation (13).

Contrast this with what happens when the coal loading is increased $(w=35 \%, \tau=.5$ days, and 3 days). Both the percent sulfur oxidized and the percent iron oxidized are reduced, as expected, but the iron removal is now much larger (70) and $51 \%$ for iron vs. 39 and $26 \%$ for sulfur). This is again consistent with the numbers for percent reductions. The pyrite measurements for the feed and product, which are actually measurements of pyritic iron, give solutions of $(1.02-.226) / 1.02=$ $78 \%$ and $(1.02-.38) / 1 .(12=6.3 \%$, which agree reatsonably well with the total removals obtained by summing the iron solubilization and physical removal eflects $(84$ and $69 \%$ ). However, the lotal sulfur measurements for $\tau=3$ days (not available for $\tau=5$ days) give a reduclion of only $(4.04-3.89) /(4.04-3.02)=15 \%$. What these numbers suggest is that at the higher conal llows. sulfuroxidizing bacteri: attached to the product coal are being removed from the system laster than they an grow. The reaction shown in Equation (1.5) becomes ralle limiting and a passivating layer of clemental sulfur forms on the pyrite surface, slowing both iron and sulfur solubilization as shown by the lower removals in Tables 4 and 5 . However, sulfur oxidation is more seriously affecled because more iron than sulfur has been solubilized, which accounts for the values in Table 5 being higher than those in Table 4. The accumulated elemental sulfur does not show up in the ASTM pyrite measurements, which actually measure pyritic iron. However, it does show up in the total sulfur measurements, which accounts for the much lower reductions calculated from these measurements. The consistency of values calculated fuch as pyrite reduction) from independent measurements of dissolved iron, dissolved sulfate pyrite, and fotal sulfur is a useful test of the data. 


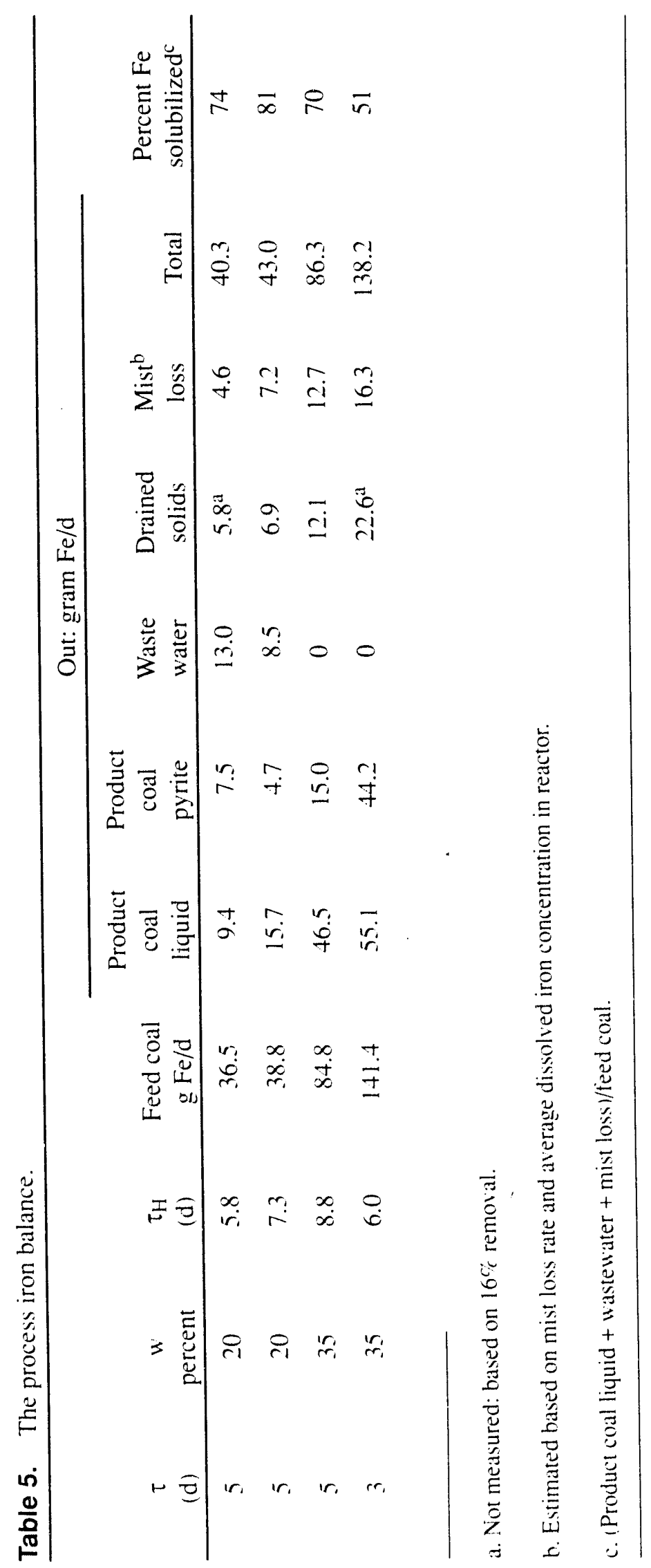


In summary. it is difficult to give a single figure for pyrite removal becaluse pyrite does not necessarily remain pyrite during the process. The best numbers are the reductions based on total sulfur measurements calculated above, and the physical and microbial removals shown in Table 4 . The latter removals do not add up to the former because reduction only compares the quality of the product and the feed coals, while a removal is calculated from the flows of sulfur in feed and product. These measures show that the goal of $90 \%$ removal of pyritic sulfur was reliably achieved with a slurry concentration of $w=x, \%$ and a reactor residence time of $\tau=5$ days. Increasing the coal loading by increasing $w$ or reducing $\tau$ reduced the removal primarily caused by the loss of sulfur-oxidizing bacteria. Changes in process configuration are expected to resolve this problem and achieve $90 \%$ reduction at higher loadings. 


\section{CONCLUSIONS AND RECOMMENDATIONS}

\subsection{Conclusions}

This work has given a first demonstration of the possibilities of combining physical and microbial processes for removing pyrite from coal. The process is based on two stages of physical separation, with the rejected solids from the first stage being transferred to the first reactor section, which acts as a rougher. Bacterial growth in this section, initiated by bacteria in the liquid recycle stream. serves to inoculate the feed coal (added to the second section) and maintain a large, active cell population. The objective is to pliysically remove the large pyritic inclusions, which would take too long to biodegrade, while biodegrading the many small inclusions, which are difficult to separate physically without very fine grinding. Theoretical considerations, based on typical size distributions of pyritic inclusions, suggest that 9()$\%$ of the pyrite could be removed from a coal ground to -100 mesh with a residence time of I day.

Considerable progress was made towards demonstrating this performance in a large-laboratory scale (150)-L slurry volume) process. The reactor wats operated continuously for 120 days, treating approximately 1 ton of an Illinois \#6 coal. Ninety percent pyrite removal was achieved at a $20 \%$ slurry concentration and a reactor residence time of 5 days: $16 \%$ attributed to physical pyrite sep:ration and the remainder to microbial oxidation: This was accompanied by $40 \%$ ash removal: approximately $30 \%$ being caused by dissolution of basic minerals and $10 \%$ to physical separation. Ninety percent of the heating value of the feed coal was recrovered: the loss being divided about equally between slight oxidation of the coal organic matter and loss of heating value with the solid waste from the physical separation.

At a three day residence time and $3.5 \%$ slurry. heating value recovery dropped to $80 \%$ (atthough the heating value per pound of product had increased and pyrite measuremen', using the ASTM Procedure D-2492-9(1 suggested a pyrite reduction o over $60 \%$. However, this is actually a measurerient of pyritic iron, and some of the sulfur was actually converted to elemental form rather than being oxidized to sulfate. This problem can be overcome by taking measures to retain sulfur-oxidizing bacteria in the process. These measures include incorporating washing of the product coal into the process and reducing mist losses from the reactor. By combining these measures with improvements in the physical separation process, further development should allow he process to meet the theoretical expectations with many coals.

The experiments reported here demonstrated solutions to many of the operational problems identifieit in previous work, and extended the results to higher coal loadings. The silicone rubber aeration tubes gave uniform aeration and, with the correct airflow rate, kept the organic fraction of the coal in suspension while allowing the denser mineral particles to settle out. They also corroded far more slowly than previous designs. The importance of liquid recycle was confirmed, and a recycle ratio close 101 was again found to give iac bost compromise between the need to inoculate the feed coal with bacteria and ferric iron, and the effect of high concentrations of inhibitory products that can accumulate around the recycle loop. When operating at this recycle ratio and at high slurry concentrations, a commercial process would generate relatively little, concentrated wastewater that would be treated and either recycled to the process or discarded and made up by clean water. The clean or recycled water would be used first for washing the product coal and the wash effluent. with all of its valuable bacteria, fed into the process. The wastewater treatment (probably by lime precipitation) and coal washing steps are essential parts of the process that must be studied in future work. The present laworatory-scale process actually generated no wastewater, but this is partially due to the high "mist" lonses which must be eliminated in the future. 


\subsection{Recommendations}

Research should continue to find optimum va!ues of the main process variables of reactor residence time, slurry concentration, and process hydraulic residence time (or recycle ratio). The objective must be to maximize the amount of coal that can be processed per unit reactor volume per unit time Iproportional to (slurry concentration)/(reactor residence time)/ with ihe desired level of pyritic sulfur removal. The main difficulty is simply that of time. In a process with hydraulic residence times of a few days, stable operation for a few weeks is required to achieve a single steady slate.

The geometry of the individual reactor sections needs to be modified to optimize the physical separation of liberated pyrite and other insoluble minerals. This separation is caused by a combination of gravity settling and hydrophobic interactions with air bubbles, and would presumably be enhanced in a deeper. narrower vessel. Column flotation of coal may provide some guidelines. although there are significant differences because of the absence of froth. Considerable data exists in the literature both on the effect of Thiobacilias bacteria and the biosurfactants they produce on the flotation process. and on the possibly inhibitory effects of conventional frothers on the bacterial metabolism. However, much of this information is contradictory and no firm conclusions can be dratun at present.

Demisting of the air leaving the process must be improved. The appearance of an acidic mist containing bacteria and coal fines is an environmental problem that could inhibit process development. Also. the ability to maintain a high concentration of viable hackeria at high coal foadings is adversely affected by loss of cells in the mist. In thinking about changes to the shape or size of a slurry reactor, the quantity that must he kept constant (as a first approximation) is the agitation power input per unit slurry volume. This is proportional to the product of the slurry depth (i.e.. the liquid head) and the arrlow rate per unit volume. a product that

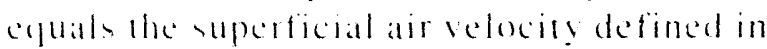
Section 3.2.2. If follow that sealing up the existing process simply by increasing the depth has several advantages. The physical separation of coal from mineral matter can reasonably be expected to improve. Also, the airflow rate, and thus, the mist losses and the air compressor po.ver needed to overcome the pressure drop in the aeration tubes, remain constant while the amount of coal being processed increases. When changing the shape or size of a slurry reactor, the quantity that must be kept constant is the agitation power input per unit volume. This is proportioned to the product of the reacw depth (i.e., the liquid head) and the airflow rate per unit slurry volume, a product that equals the superficial air velocity defined in Section 3.2.2. It follows that scaling up by increasing reactor depth has several advantages. Not only can physical separation be expected to improve. but the airflow rate, the mist losses, and the air compressor energy needed to overcome the pressure drop in the aeration tubes all remain the same while the amount of coal being processed increases.

Coal contains relatively litte pyrite, and the growth yicid of bacteria on pyrite is small. It follows that maintaining a high cell concentration in the system requires active measures to conserve cells. Besides controlling the liquid recycle and solids wastage, and reducing the loss caused by misting requires that the product coal be washed. with the washwater recycled to the process. Future testing would best be done on a coal that has not been cleaned and contains higher levels of pyrite and ash. The fines discarded by many coal preparation plants would be irleal for testing.

Methods are needed to separate and quantify the different classes of microbial activity: iron oxidation. sulfur oxidation. heterotrophic activity that degrades inhibitors of iron and sulfur oxidation (beneficial), and heterotrophic atdivity that solubilizes and oxidizes coal (harmful). The data show that at the highest coal loading studied $(\tau=.3$ days and $w=35 \%$ ). the loss of heating value was reduced but iron oxidation exceeded sulfur oxidation activity. Controlling and halancing these categorice of microbial activity requires that they first he quantifiable in a conal slums. 
Considerable care is needed when applying ASTM procedures to microbial depyritization processes. The preliminary boiling in $\mathrm{HCl}$ will not remove all the nonpyritic iron from a coal that has been in a slurry containing high levels of ferric ion and ferric hydroxysulfate precipitates. It should be preceded by soaking the coal in a large volume of dilute $\mathrm{HCl}$. It must also be noted that the procedure actually measures pyritic iron. and that microbial degradation of coal pyrite does not necessarily proceed stoichiometrically. Pyritic sulfur may be changed to elemental sulfur, which does not show up in the ASTM procedure, but will appear in a total sulfur analysis. 


\section{REFERENCES}

1. L. L. Josephs and D. D. Ferris, "Engineering Development of Advanced Froth Flotation-Pyrite Liberation Study and Round-Rohin Flotation Report," Proceedings $6^{\text {th }}$ Annual Coal Preparation Utilization and Environmental Control Contractors Conference. Pittshurgh. Pennsy/rania. August 1990, p. 298-304.

2. G. F. Andrews, C. J. Stevens, and J. E. Wey, "The Log-Normal Distribution of Pyritic Inclusions in Coal, Consequences for Depyritization," $3^{\text {rd }}$ International Symposium on the Bioprocessing of Coal, DOEIEPRI. Clearw'ater, FL. May 1992.

3. S. McCaughey and M. Mcllwain, Imterim Conceptual Design for a Commercial-Scale Coal Biodesulfurtzation Plant, MSE. Inc., Butte, MT, August 1992.

4. G. F. Andrews, P. R. Dugan, M. E. Mcllwain, and C. J. Stevens, Microbial Desulfurization of Coal, EG\&G-2669, March 1992.

5. G. F. Andrews, P. R. Dugan, and C. J. Stevens, "Combining Physical and Bacterial Treatment forr Romoning Pyritic Sulfur from Coal," In Processing and Utilization of High-Sulfur Corals. Vol. IV, P. R. Dugan, D. Quigley and Y. Attia (eds), New York: Elsevier Publishers, 1991, pp. 515-531.

6. G. F. Andrews, "Mixing Effects in Coal Processing Bioreactors," Resomrces Conservation and Recycling 3, 1990, pp. 137-148.

7. Y. A. Attia. "Feasibility of Selective Biomodification of Pyrite Floatability in Coal Desulfurization by Froth Flotation: Effect of Bacterial Adaption," Proceceding.s. $3^{\text {rd }}$ DOE Bioprocessing of Coals Workshop. Tysomis Comer. VA. August 1988, pp. 199-209.

8. G. Rossi, "Microbial Depyritization of Coal," 3rd International DOE/EPRI Symposium on the Bioprocessing of Coal. Clearwater, FL. May 1992.

9. G. F. Andrews and J. Quintana, "Mixing and Mass Transfer in the Aerated Trough Bioreactor," Proceedings I"International Symposium on the Biological Processing of Coal. Orlando, Florida. EPRI GS6970. 1990. pp. 5-69-5-8.5.

10. G. F. Andrews. M. Darroch. and T. Hanson, "Bacterial Removal of Pyrite from Concentrated Coal Slurries," Biotedmology \& Biongeineering. Vol 32, 1988, pp. 813-820.

11. G. F. Andrews, "An examination of the Kinctics of Coal Pyrite Decomposition." In: Biotechology in Materials and Metal Processing. B. Scheiner. F. Doyle and S. Kawatra (eds). Society of Mining Engineers. 1989. pp. 87-93. 


\section{Appendix A}

Solution To The Ash Removal Equations 
A-2 


\section{Appendix A \\ Solution To The Ash Removal Equations}

Equation (10) can be thought of as the drain strategy equation because it defines the process parameter $\beta$. As written it applies to any section and it can be solved for $D_{i}$ :

$D_{i}=\frac{A_{i} G_{i} \beta}{1-A_{i} \alpha \beta}=B_{i} G_{i} \beta$

where $B$ is defined as $A /(1-\beta \alpha A)$. The first step in the solution is to use this equation to eliminate the six unknown $D$ values from the mass balance Equations (7). (8), and (9). For $3 \leq \mathrm{i} \leq 6$ eliminating $D_{i}$ from the first Equation (7):

$g_{i-1}=g_{1}\left(1+\beta B_{i}\right)$

where

$$
\mathrm{g}_{\mathrm{i}}=\mathrm{G}_{\mathrm{i}} / \mathrm{G}_{\mathrm{f}}
$$

Eliminating $D_{i}$ and $G_{i}$ from the second Equation (7) using (A-1) and (A-2) gives

$$
A_{i-1}=\frac{A_{i}\left(1+\alpha \beta B_{i 1}\right.}{1+B_{i} \beta}=\frac{B_{i}}{1+B_{i} \beta}
$$

where the second equality follows from the definition of $\mathrm{B}$.

For Section 2 the same procedure involving Equations $(A-1)$ and $(8)$ gives:

$$
\begin{aligned}
& g_{1}=g_{2}\left(1+\beta B_{21-1}\right. \\
& g_{1} A_{1}=g_{2} B_{2}-A_{f}
\end{aligned}
$$

Now rake Eyuation (A-1) applied to Section 1 and substitute in the first Equation (9):

$$
\xi_{n=1}-\beta_{g_{1}} B_{1}
$$

$s_{0}=\frac{A_{1}-\alpha A_{1}}{A_{6}-\alpha A_{1}}$

Equations (A-2) 10 (A-7) are now iwelse cyuations in the twelve unknowns $A_{1}, g_{1}$ for $j=1$ through 6. It is actually simpler to specify a desired product quality, $A_{6}$ (along with values of $(\alpha$ and $\beta$ ), and to treat the feed composition $A_{f}$ as an unknown. Equations (A-2) and (A-3) can then be solved for $A_{2}, A_{3}, A_{4}, A_{5}$ and the ratios $g_{5} / g_{6}, g_{4} / g_{5}, g_{3} / g_{4}$. and $g_{2} / g_{3}$, leaving $(A-4)$ to $(A-7)$ as four equations in four unknowns $A_{1}, A_{f}, g_{6}$, and $g_{1}$. Equations (A-4) to (A-7) actually reduce to a quadratic equation for $A_{1}$.

Converting $g_{2}$ in Equation (A-5) with the ratio $b=g_{2} / g_{6}$, and substituting Equation $(A-7)$ for $g_{6}$ yields

$g_{1} A_{1=h} B_{2} \frac{\left(A_{1}-\alpha A_{1}\right)}{\left(A_{6}-\alpha A_{1}\right)}-A_{f}$

Equating Equation (A-6) to (A-7) yields

$g_{1} A_{1}=\frac{\left(A_{6}-A_{f}\right.}{\left(A_{6}-\alpha A_{1}\right)}\left(\frac{1}{\beta}-\left(\mu A_{1}\right)\right.$

Setting Equation (A-8) equal to Equation (A-9) and solving for $A_{1}$ yields

$$
A_{f}=\frac{A_{6} \frac{11}{\beta}-\alpha A_{1}+\alpha A_{1} b B_{2}}{b B_{2}-A_{6}+\frac{1}{\beta}}
$$

Dividing Equation (A-5) by Equation (A-4). substituting Equation (A-7) for go and solving for $A_{i}$ yields

$A_{1}=\frac{a A_{1} \mid b\left(1+b c t a B_{21}-1 \mid+A_{1}\left(A_{11}-b a B_{2}\right.\right.}{A_{1} \mid b\left(1+B B_{21}-a|p h a|+A_{1}-b B_{2}\right.}$

Equating Equation (A-10) with (A-11) and cross multiplying yields

$\alpha A_{1}\left[\frac{b-1}{\beta}+A_{11}\left(1-a / p h(c)+a b B_{2}\right]+\right.$

$\left.\frac{A_{1}}{\beta} \mid A_{n}\left(A_{1}(B)(c)-1\right)+1+a-b\right)-a b B_{3}\left(1+A_{n} b(t a)\right)$

$\frac{A_{1}}{\beta}\left(A_{1}, \cdots, B_{3}\right)=0$

$(\mathrm{A}-12)$

Once $A$ I is solved from Equation (A-12), the feed composition is then found from Equation (A-10). Values of $g$ and $g$ a can then be found from fintittions $(A-7)$ and $(A-4)$ respectively. 


\section{Appendix B}

\section{Raw Data}




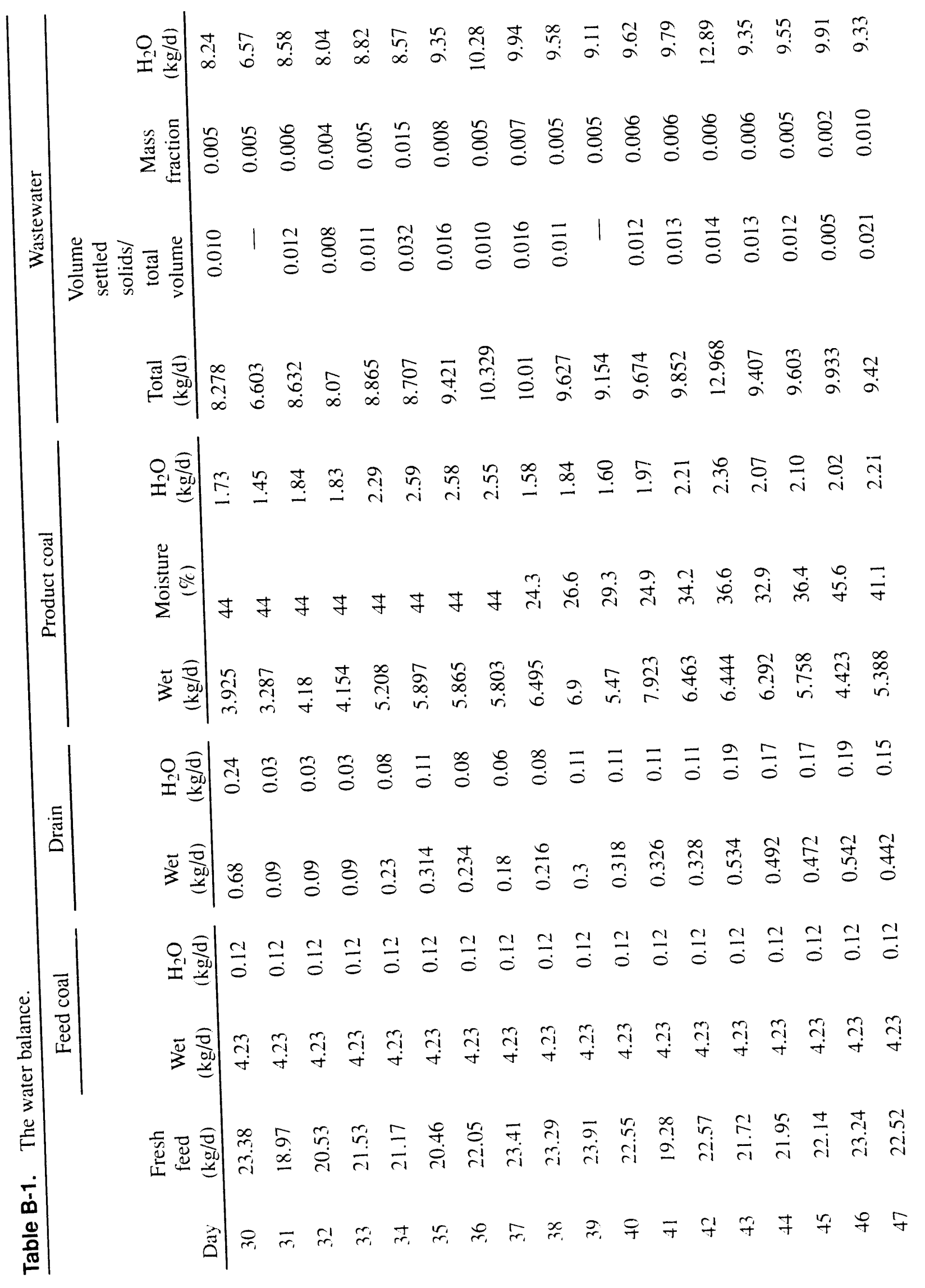




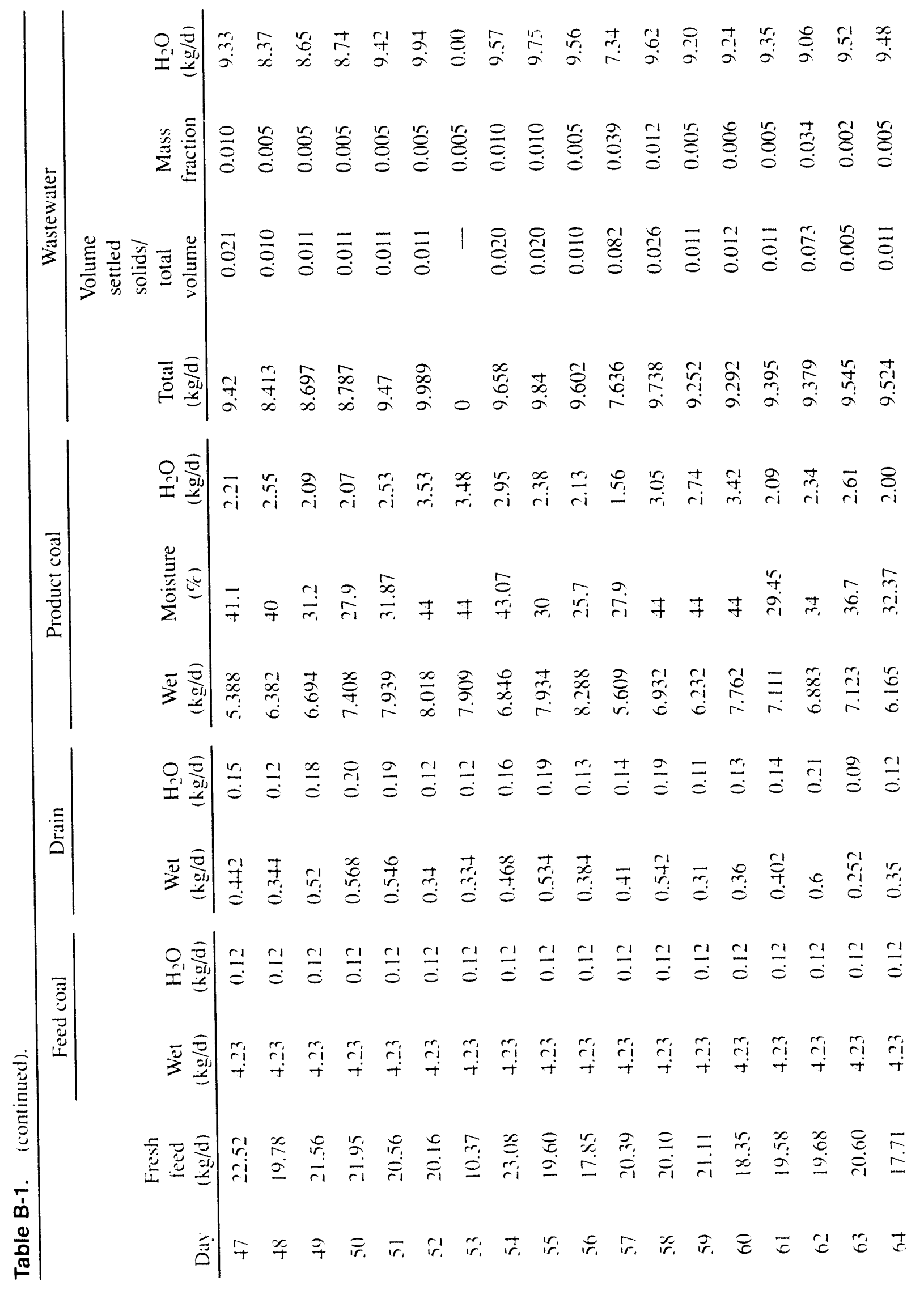




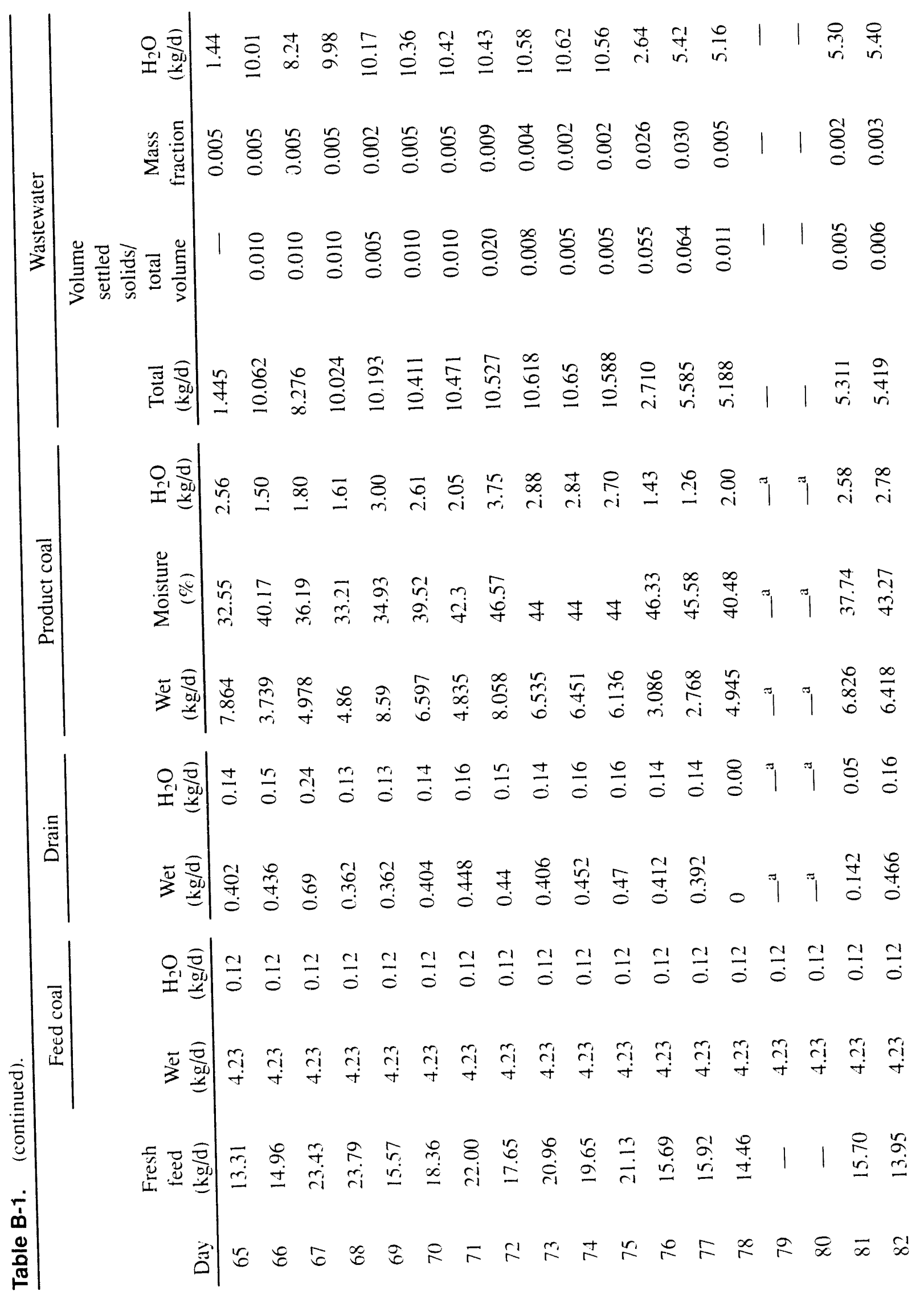




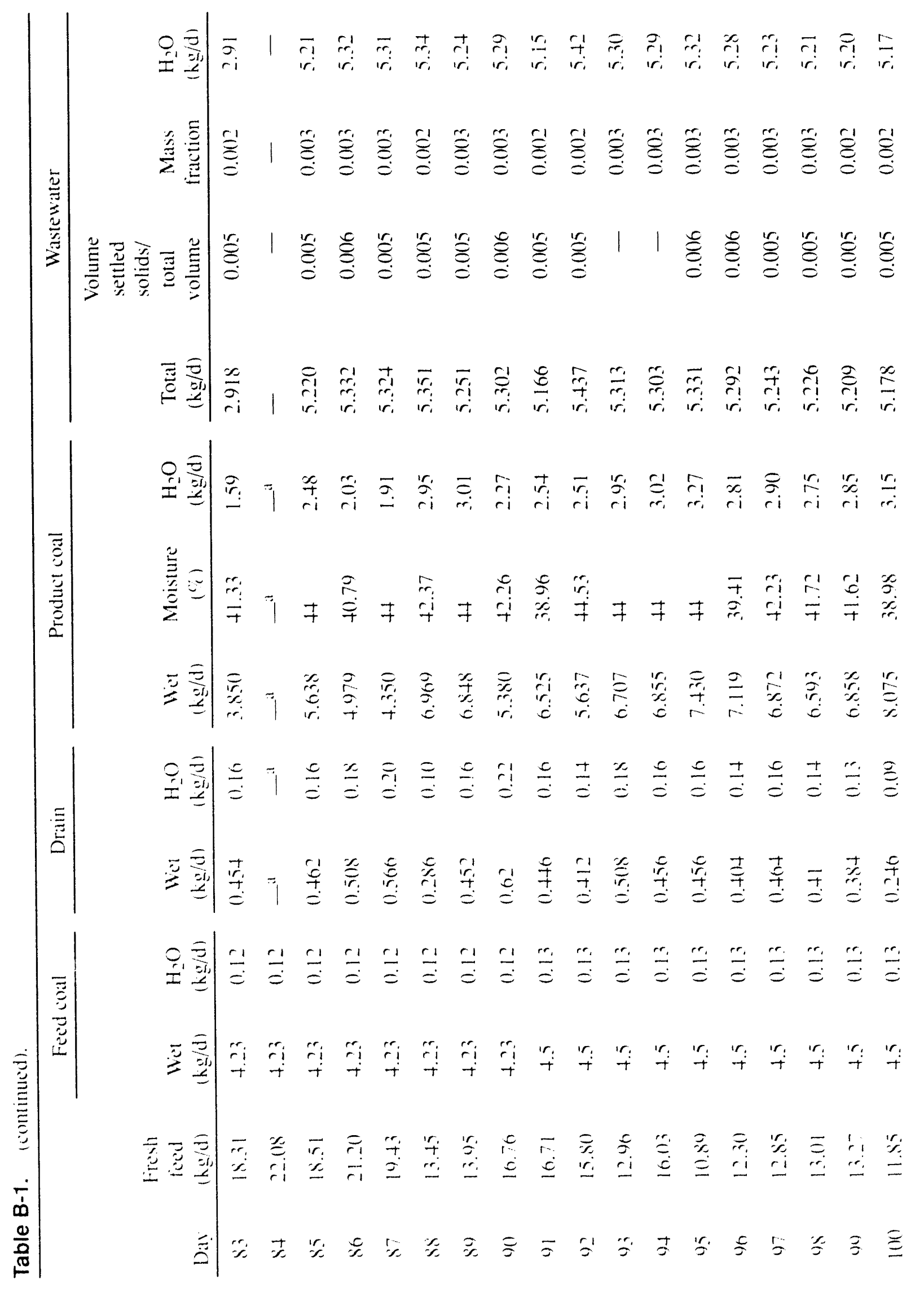




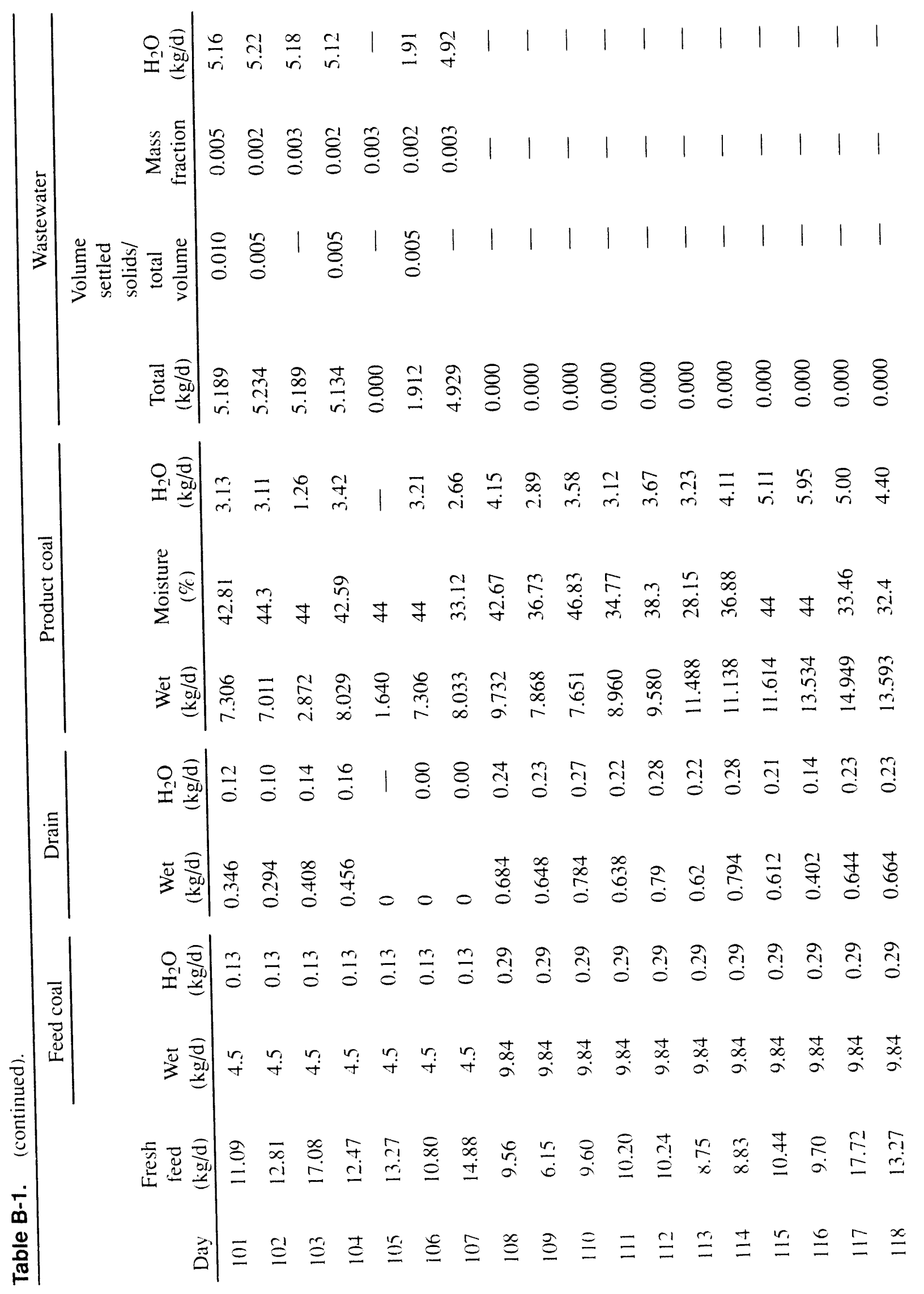




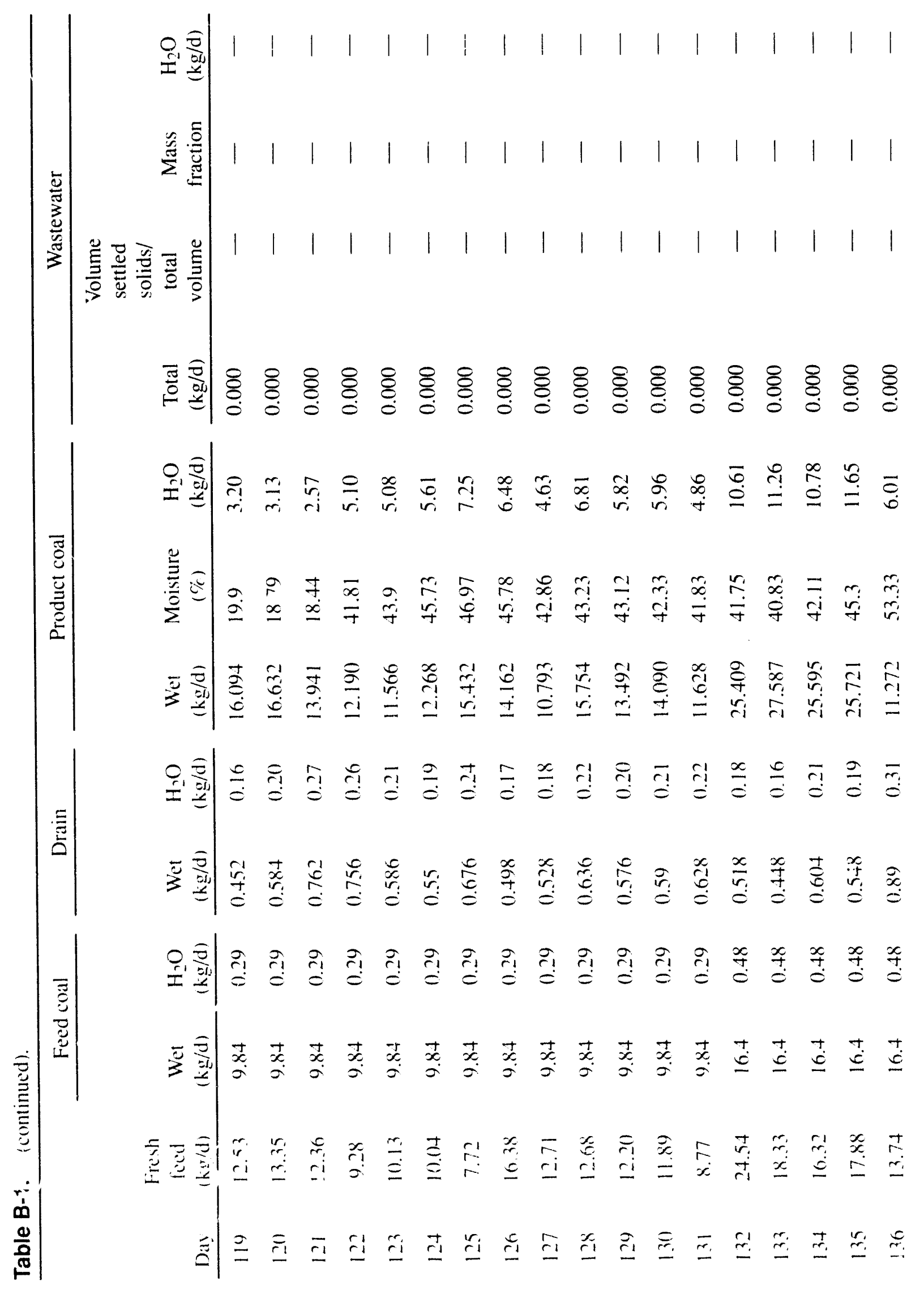




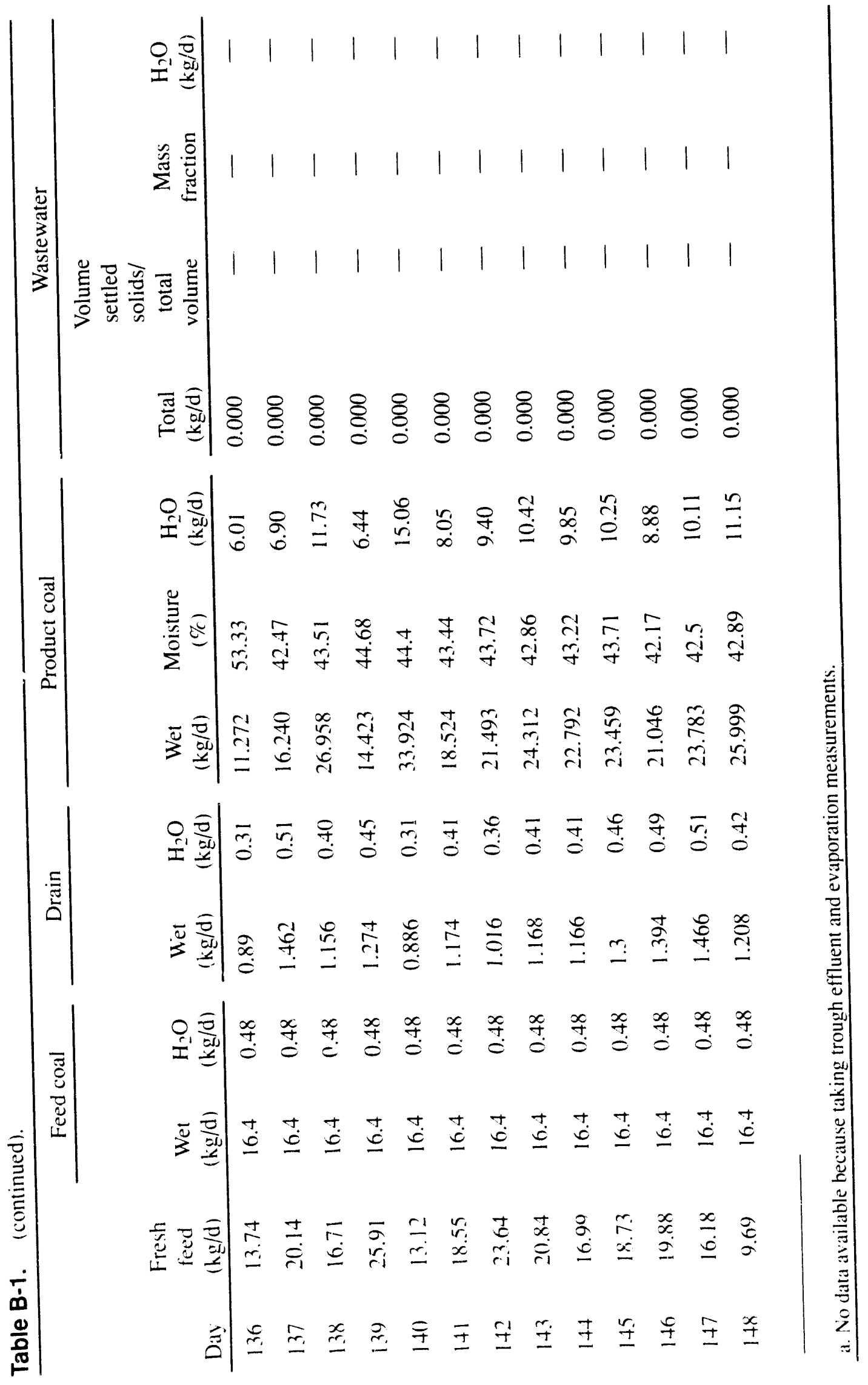




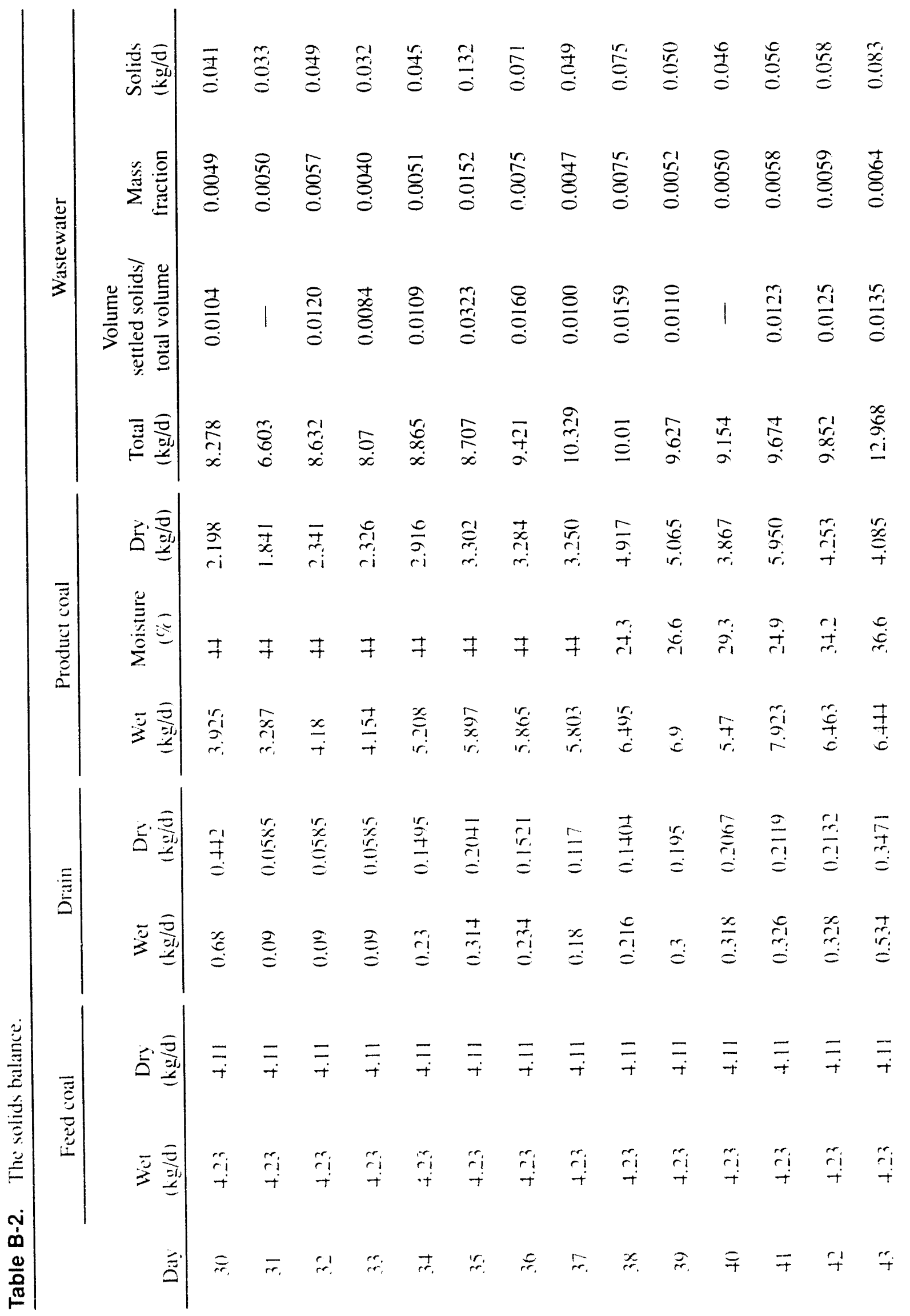




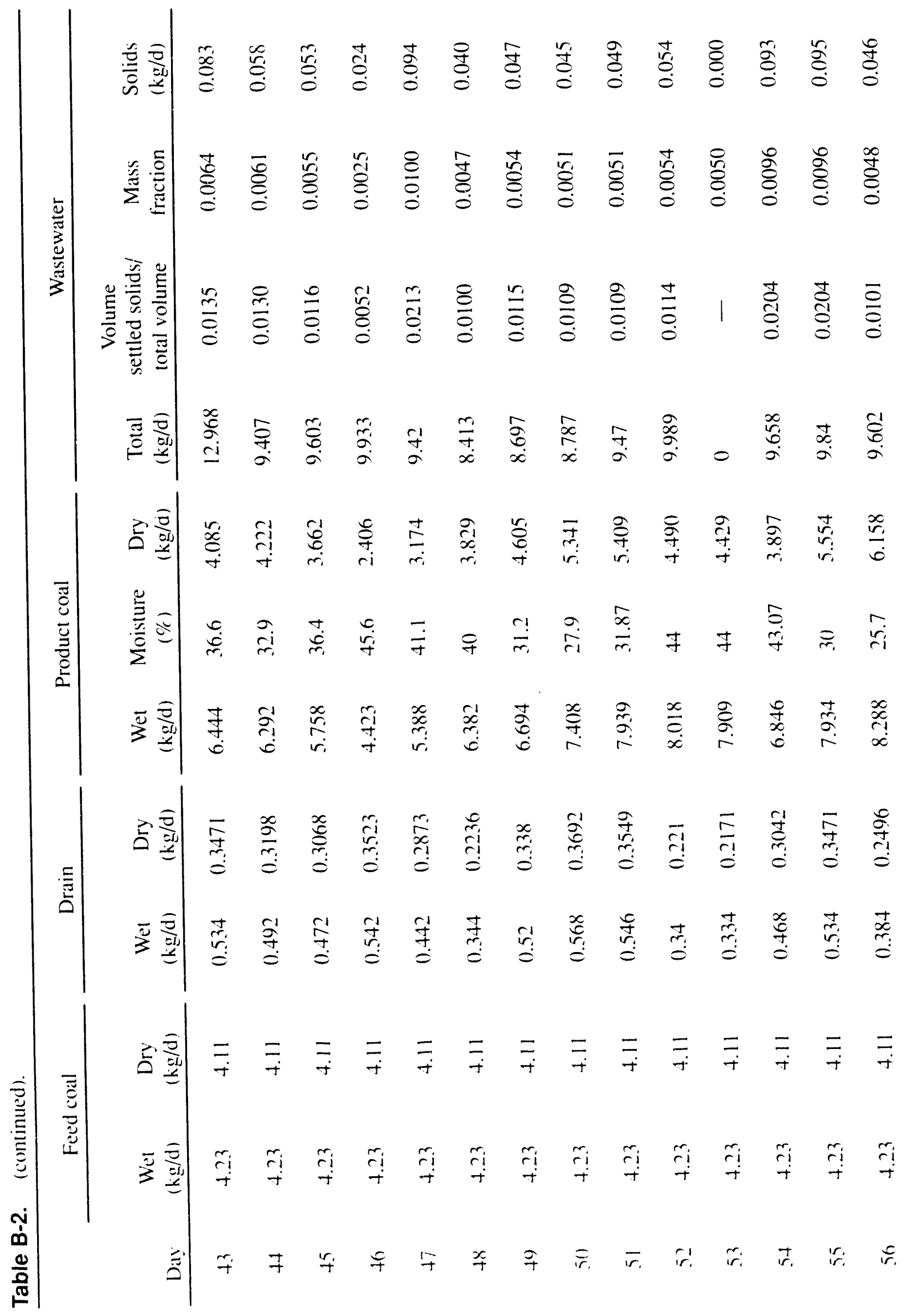




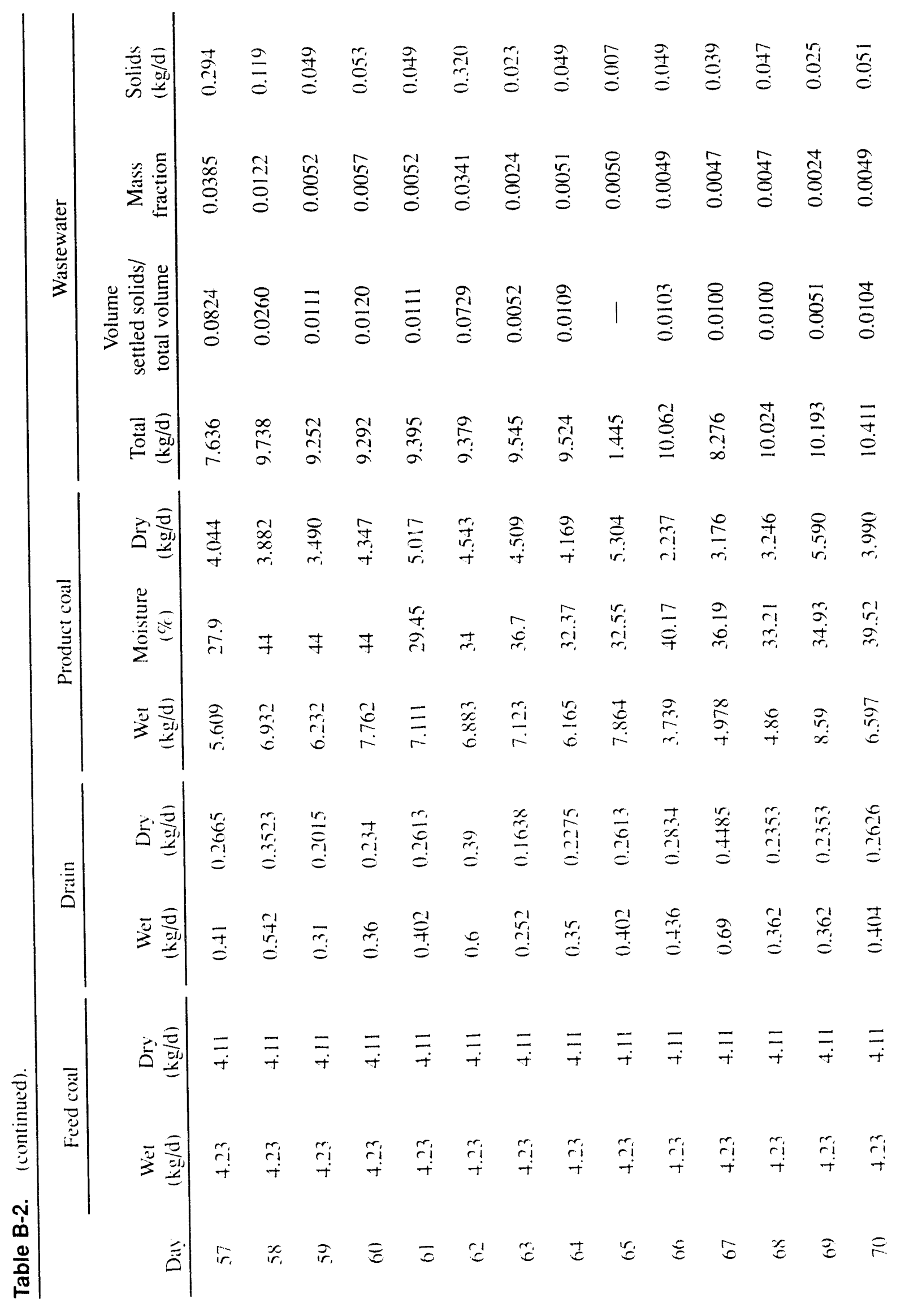




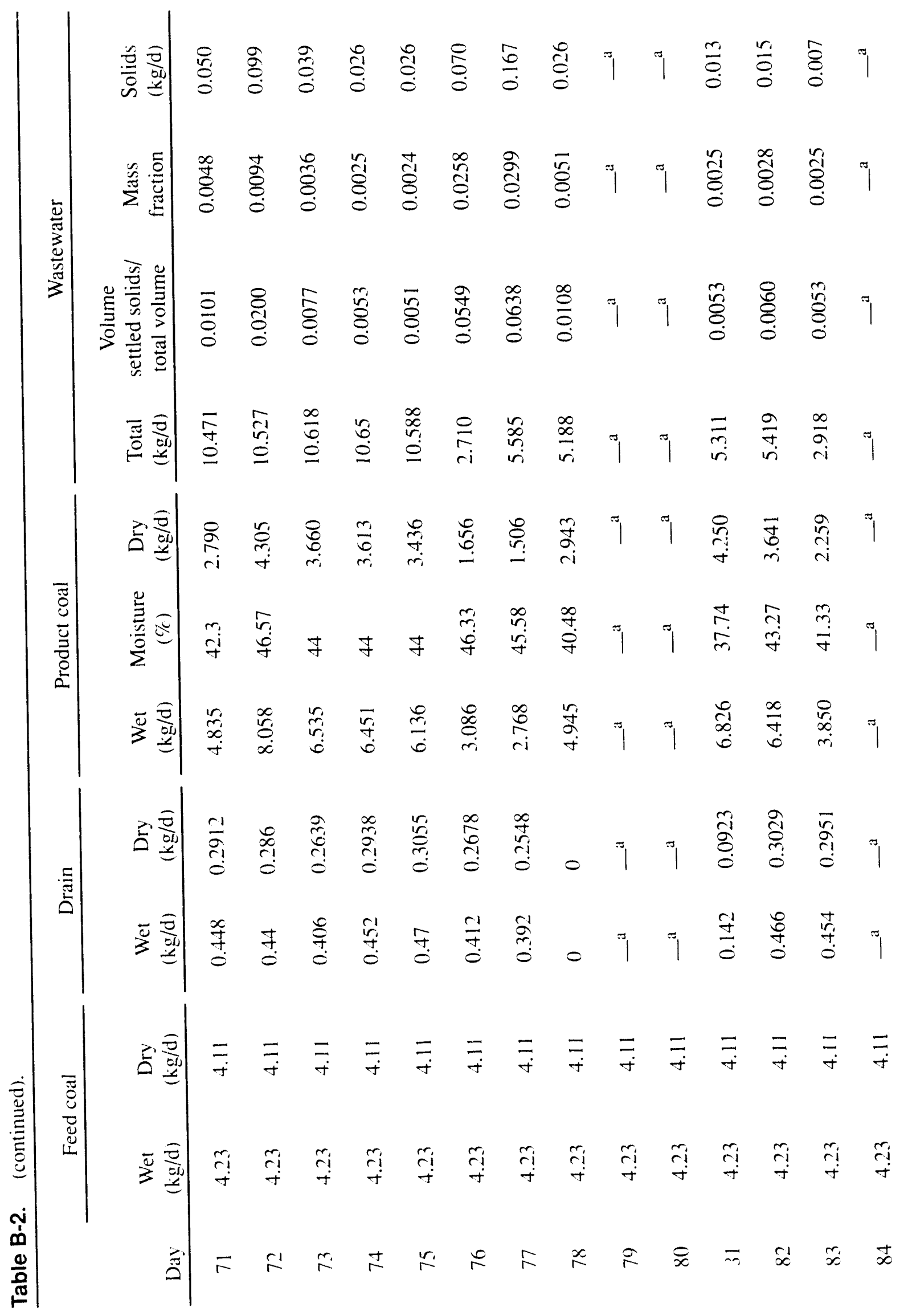




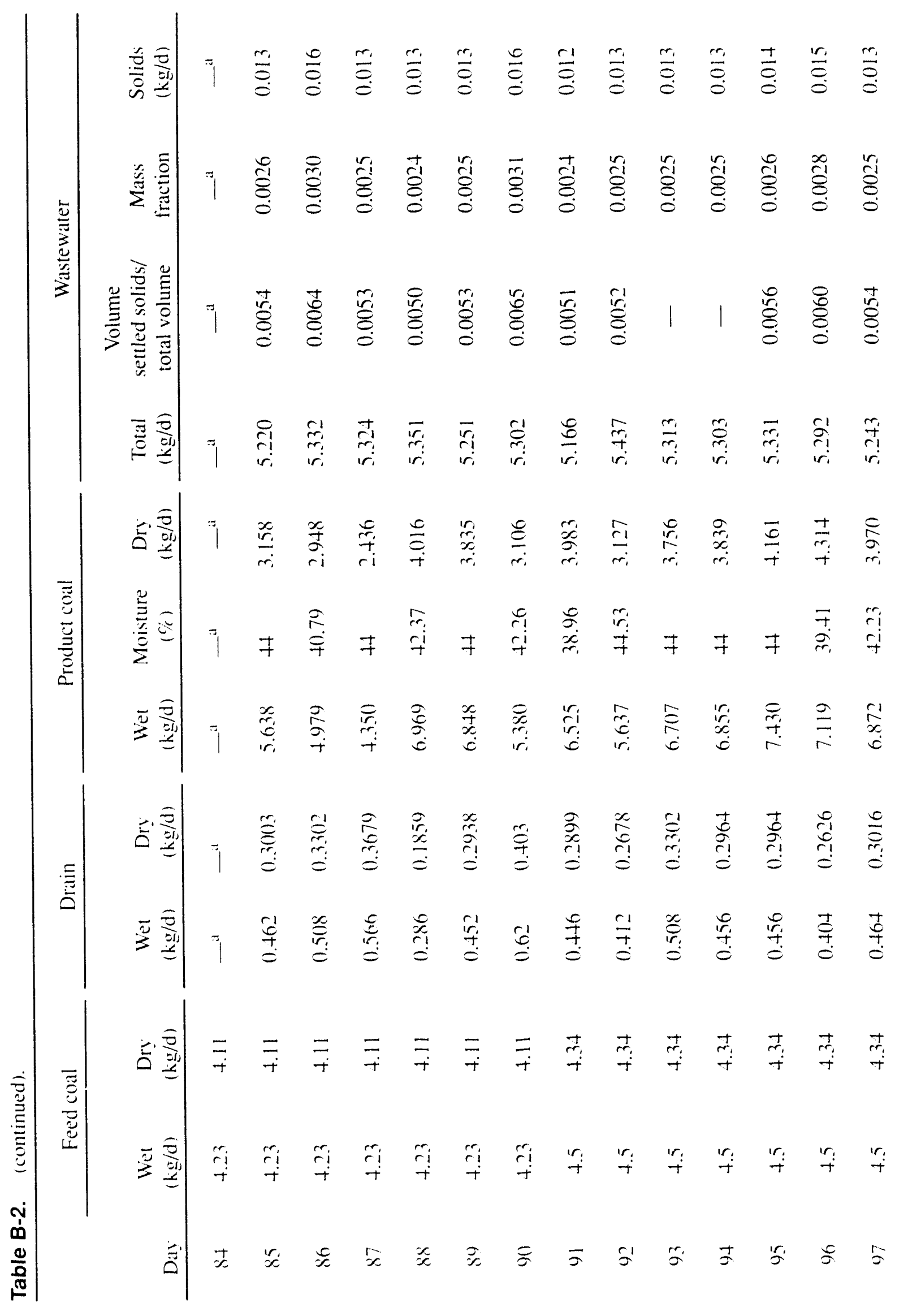




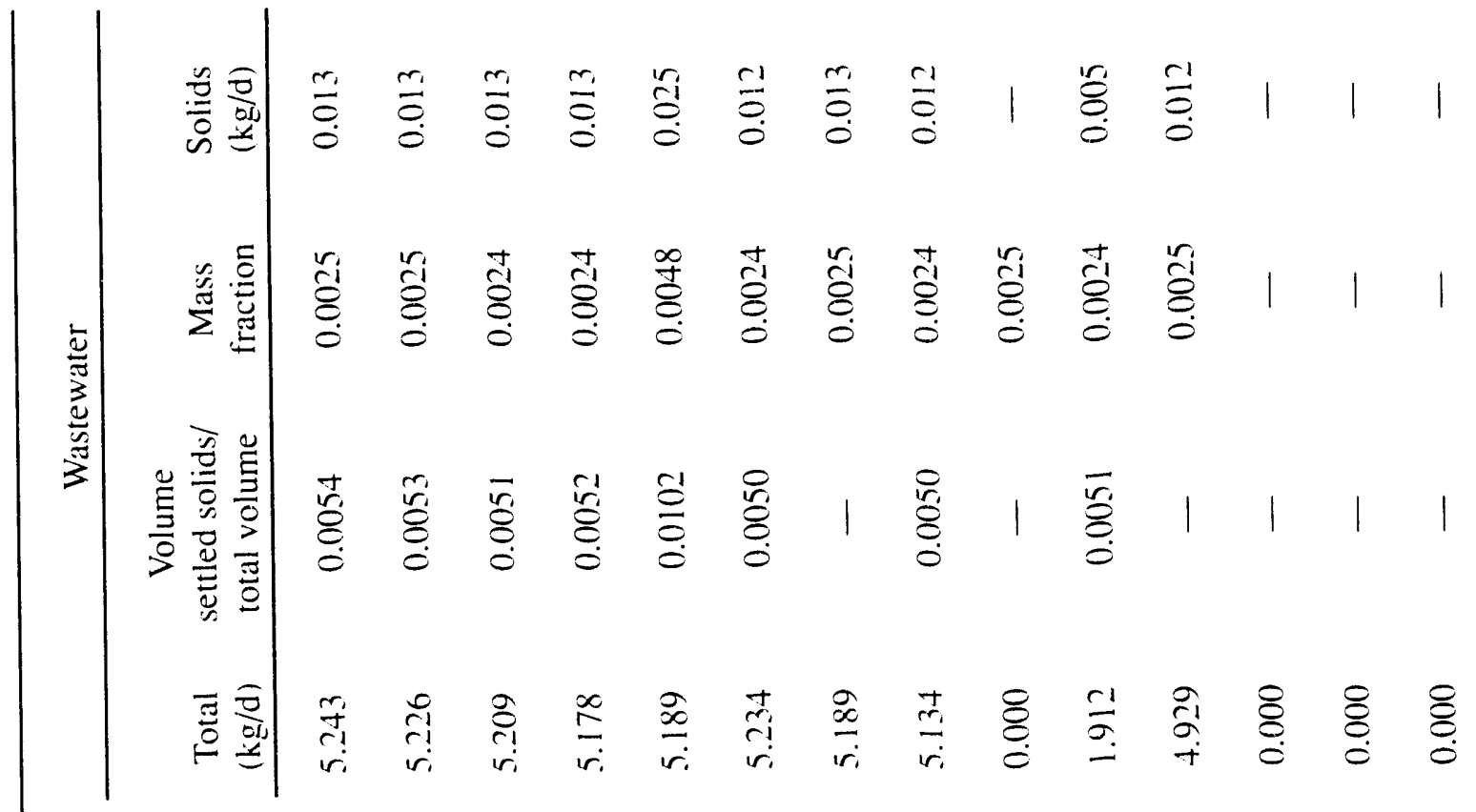

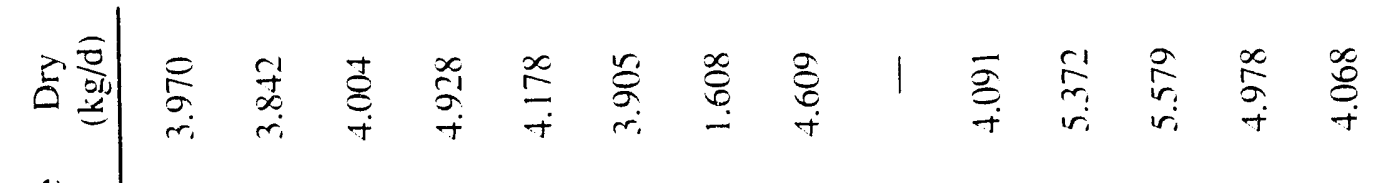

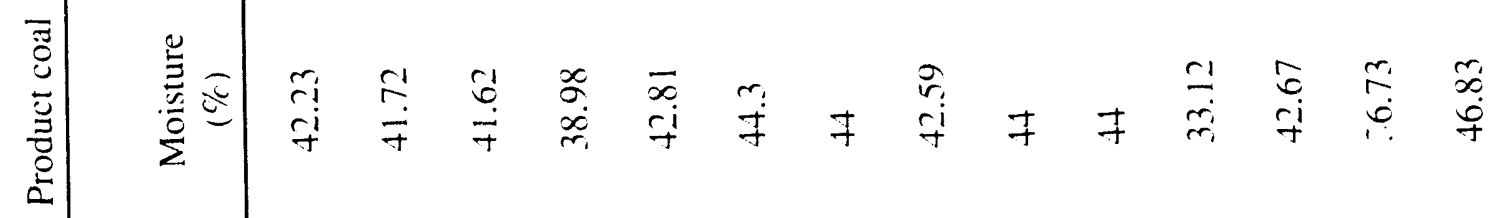

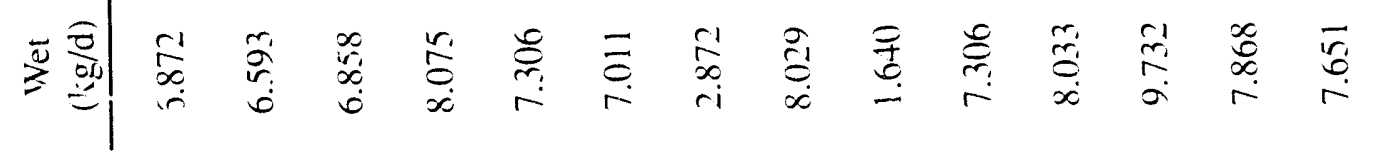

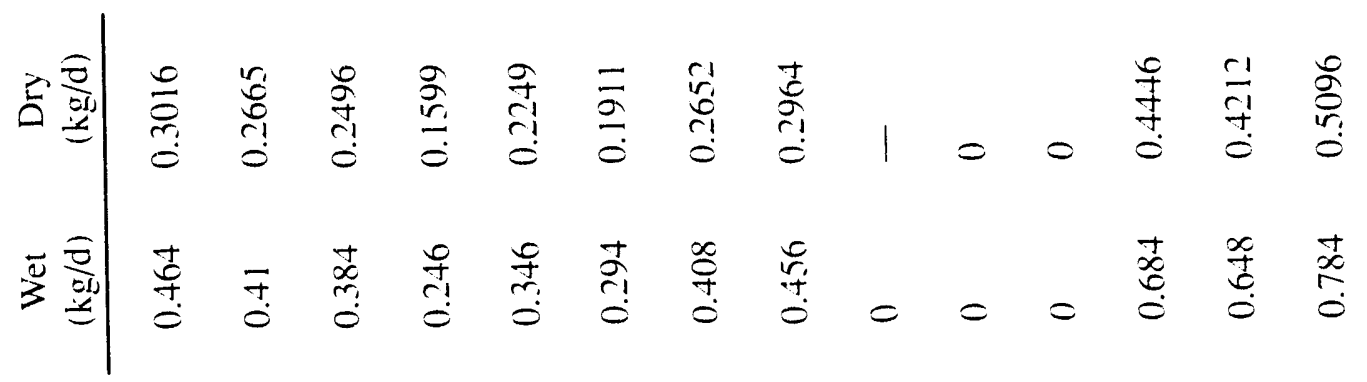

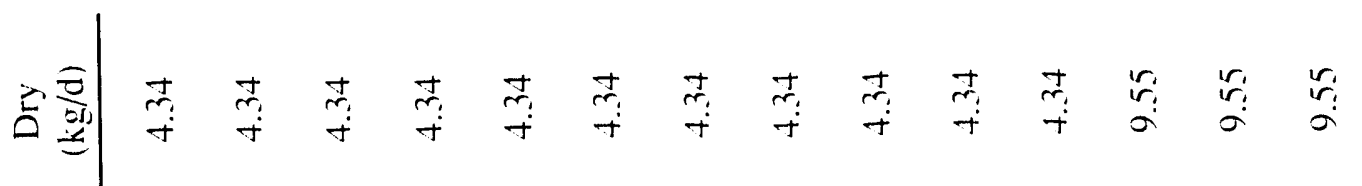

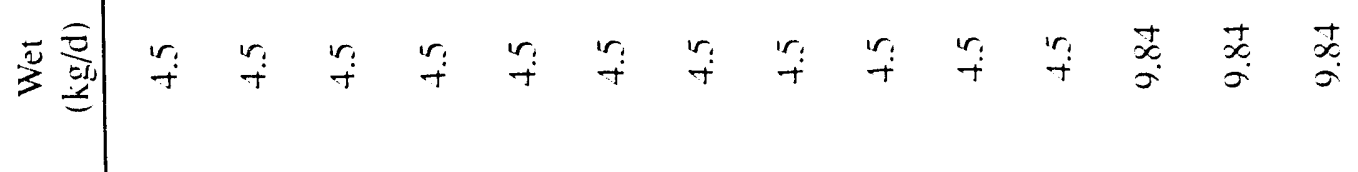

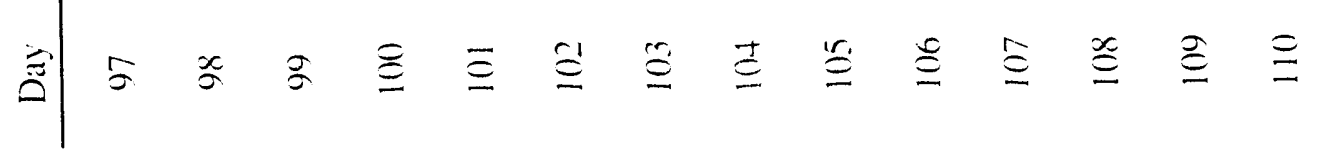




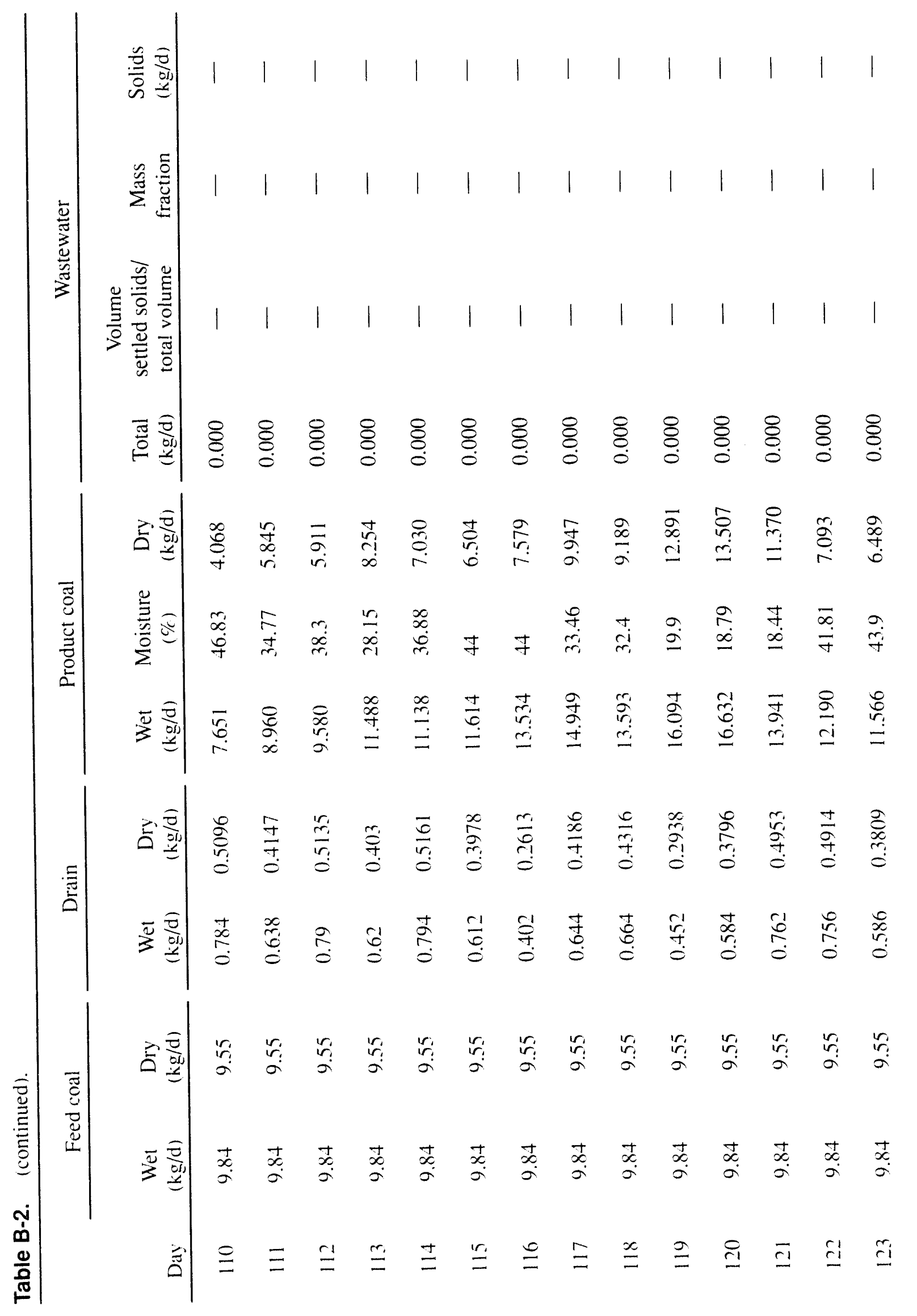




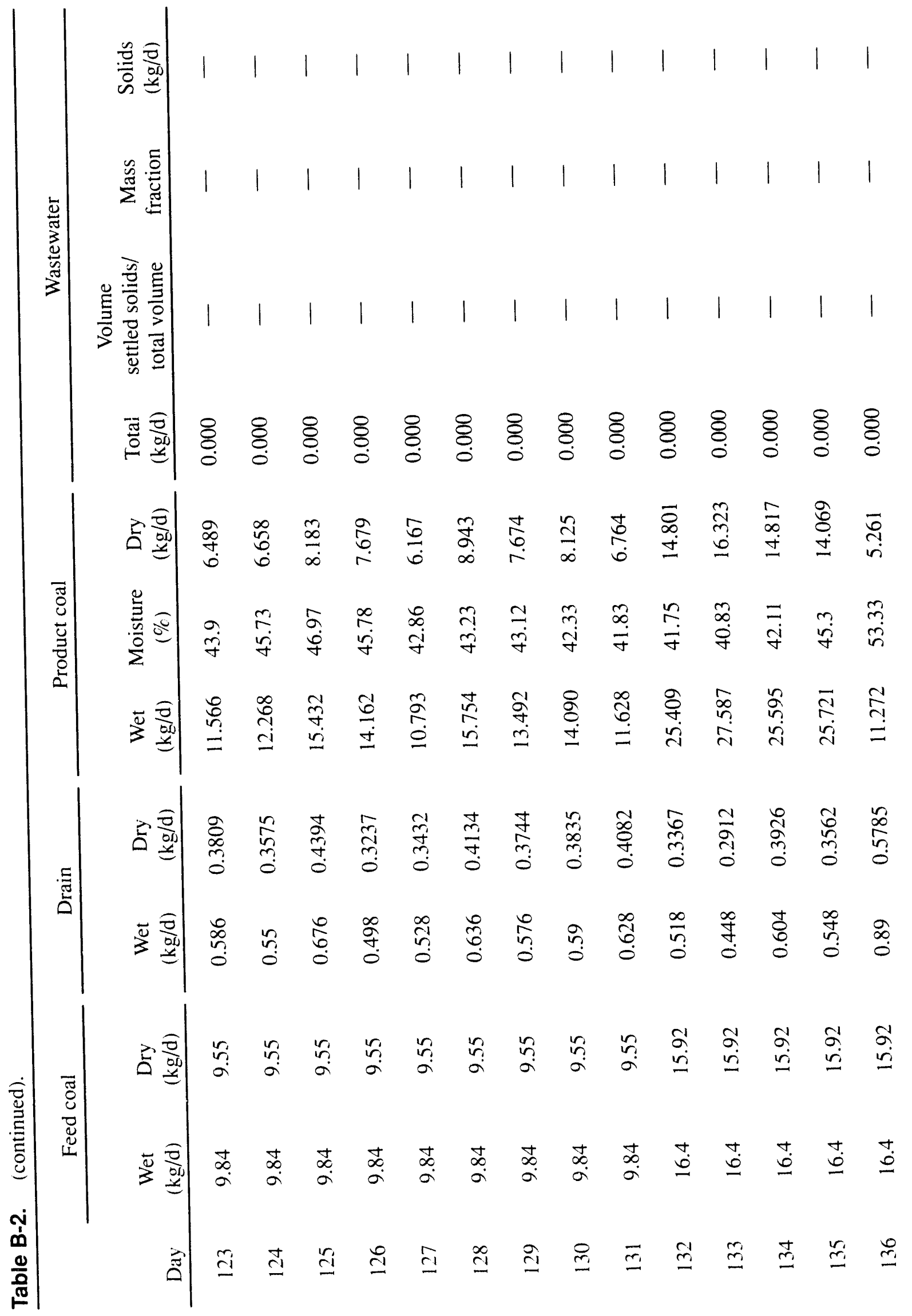




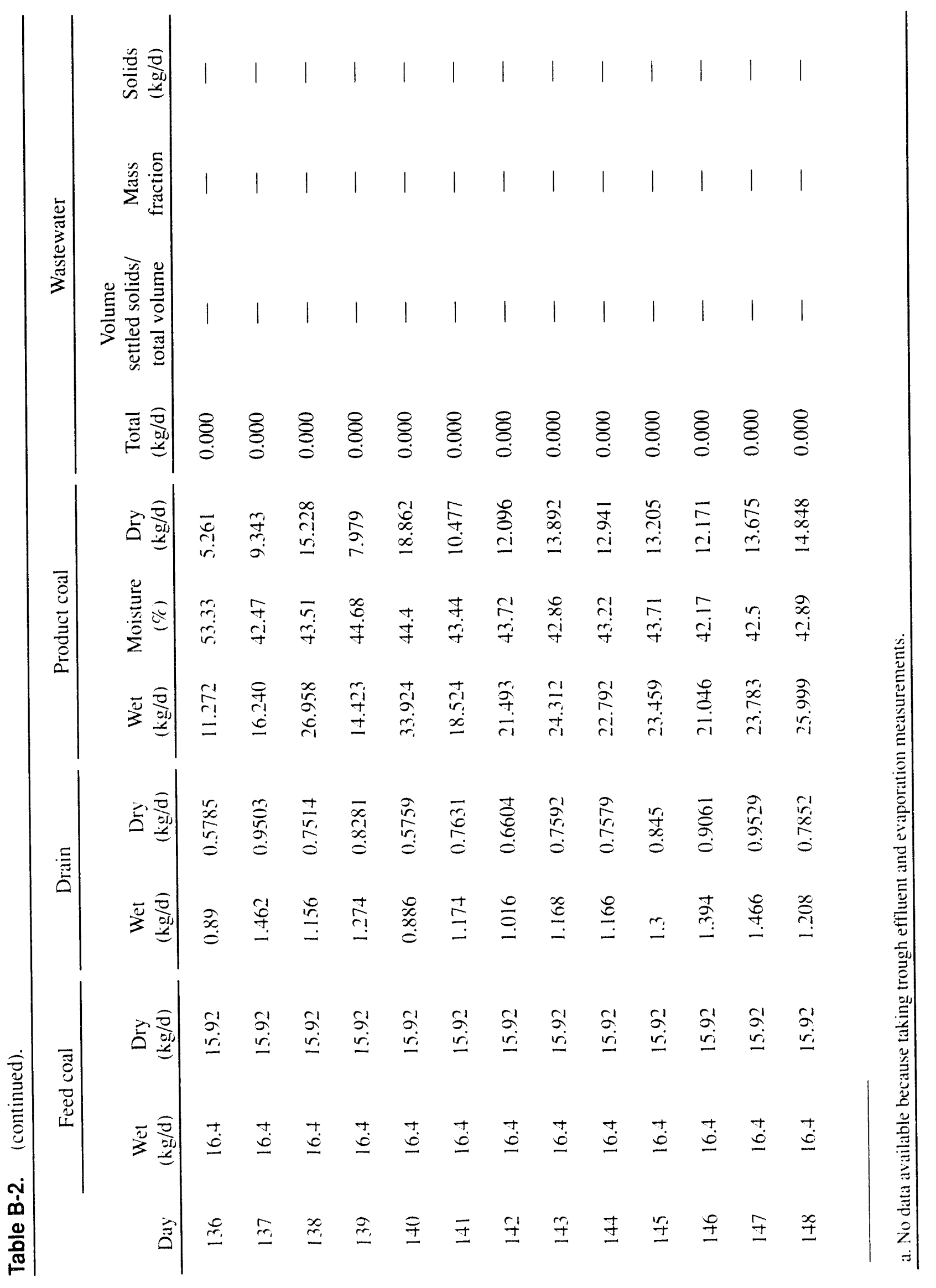




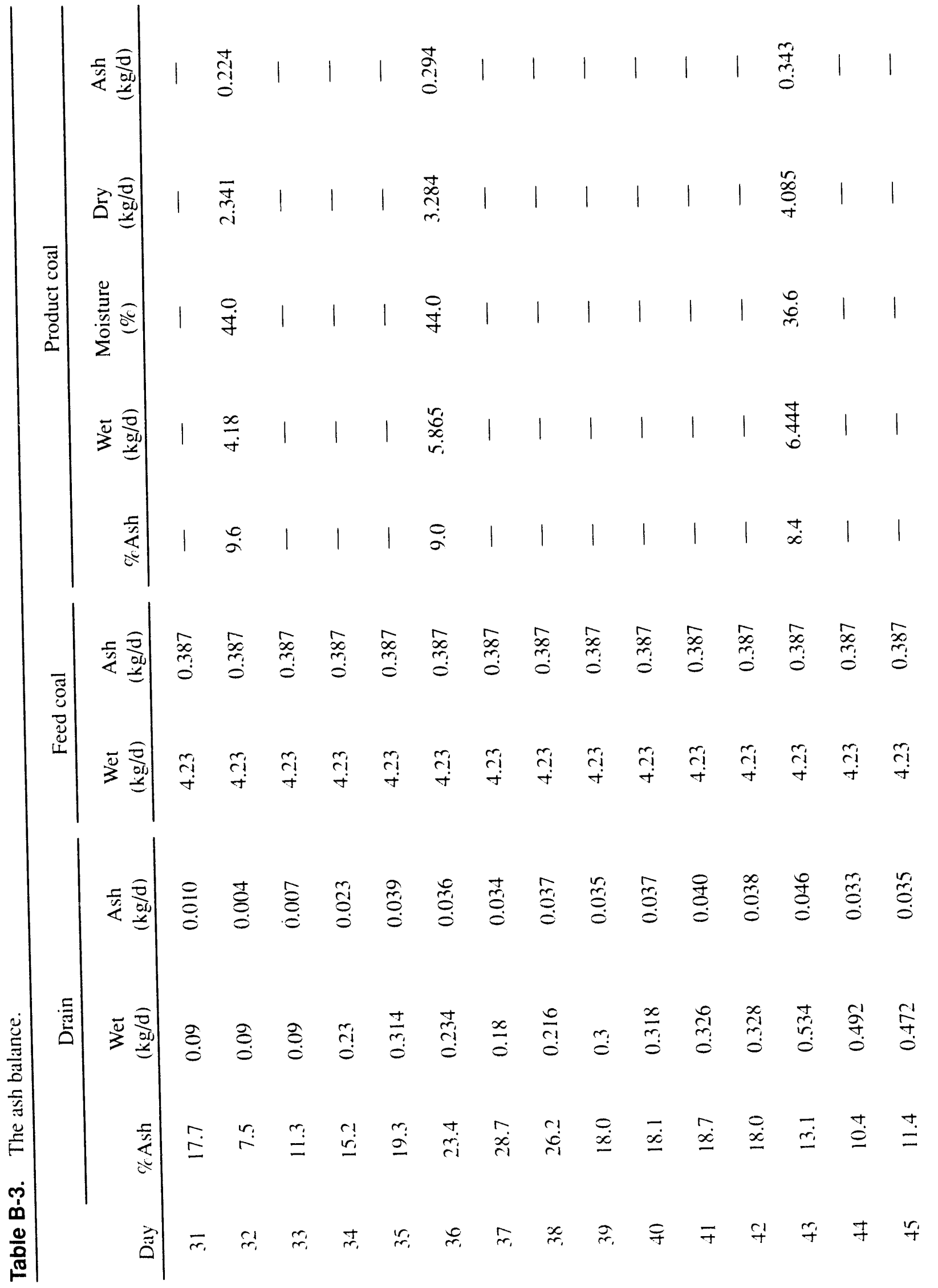




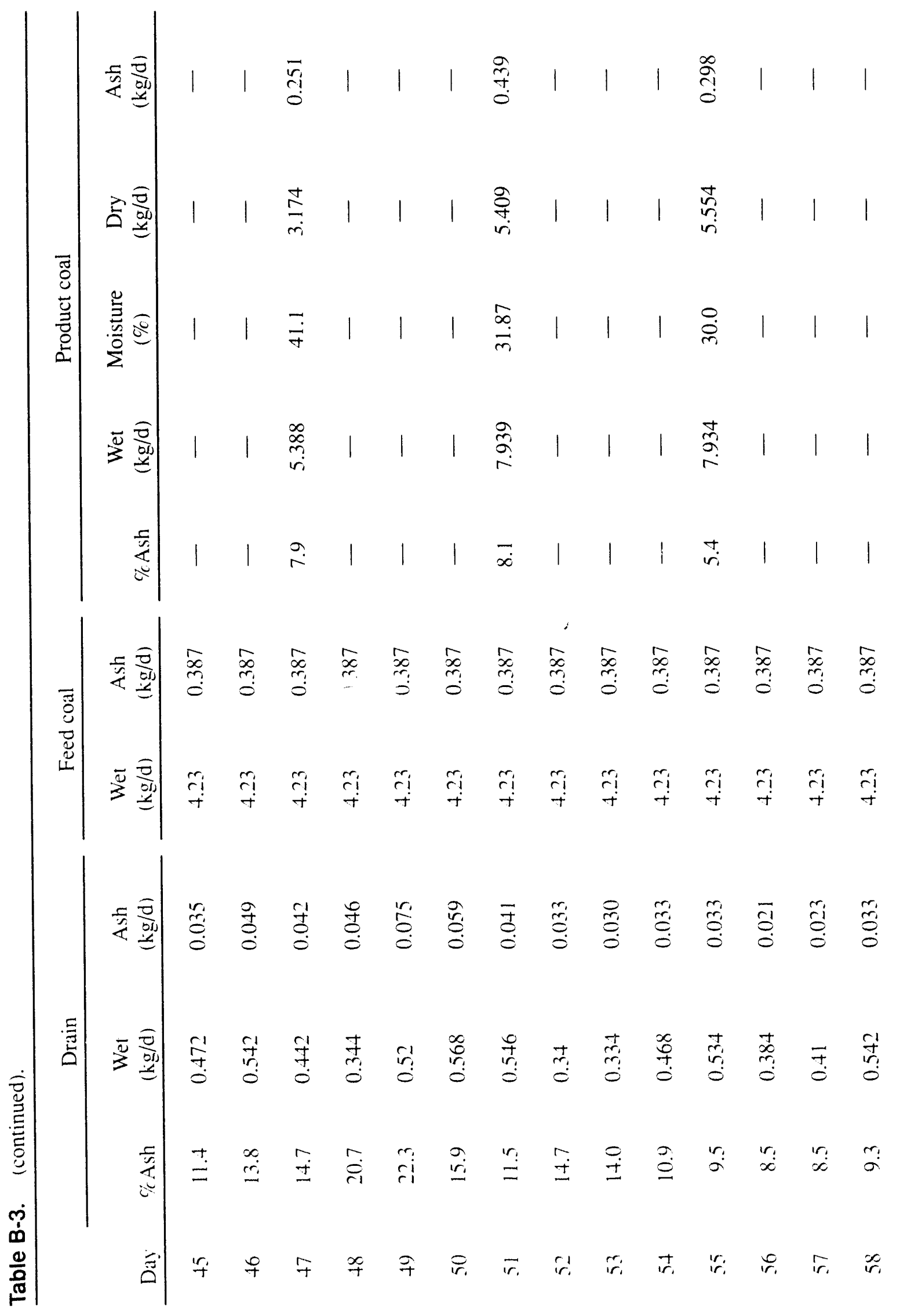




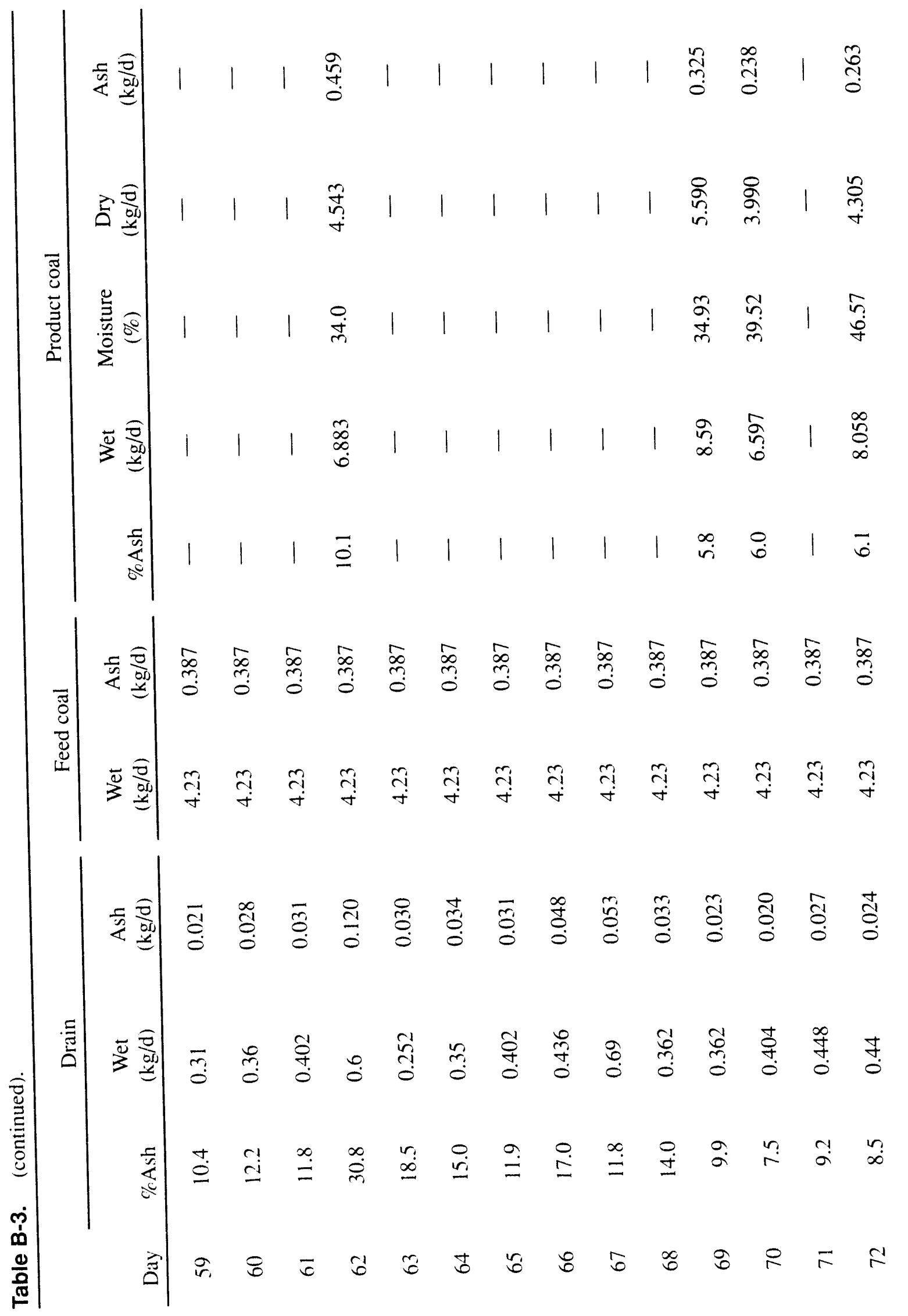




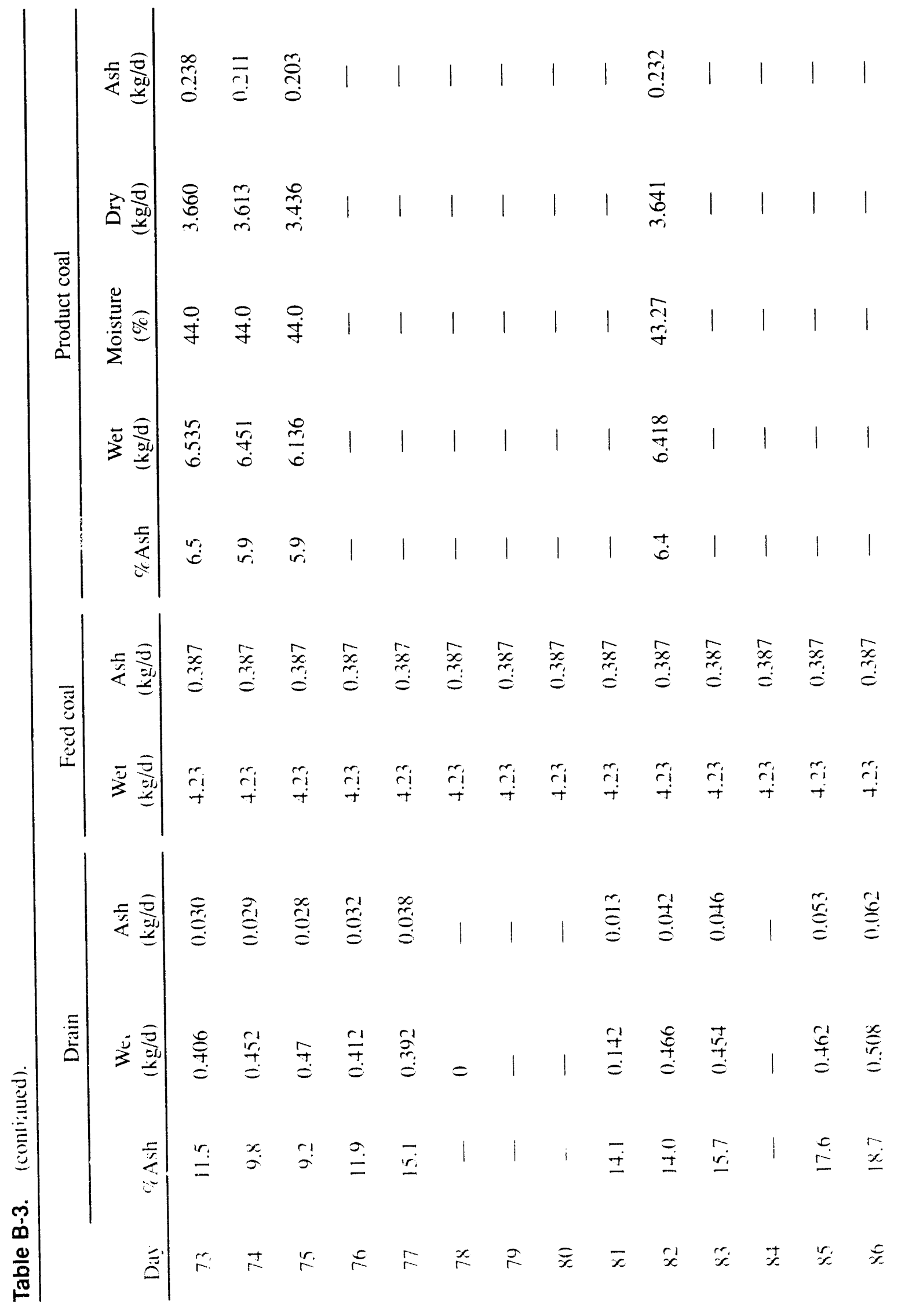




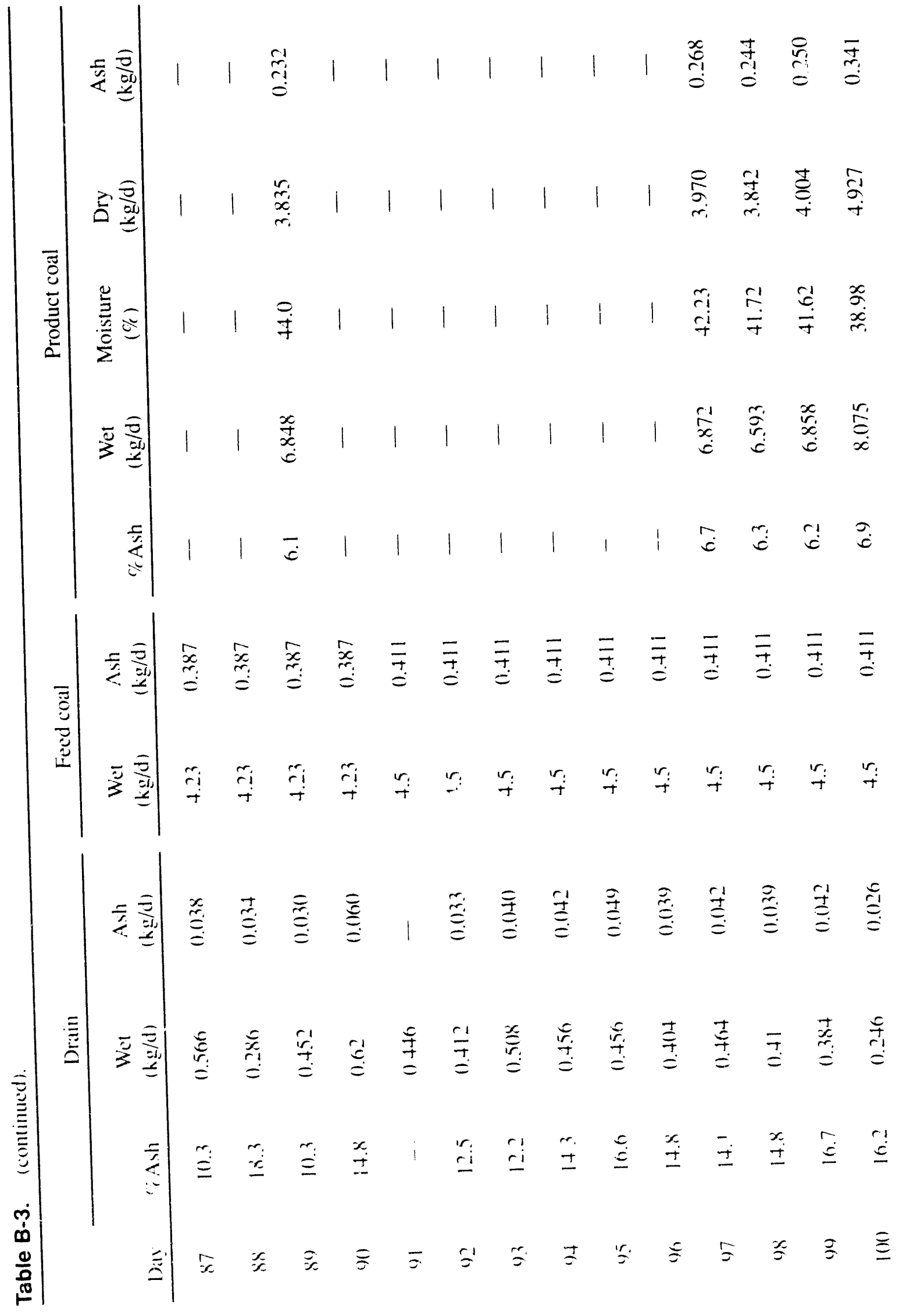




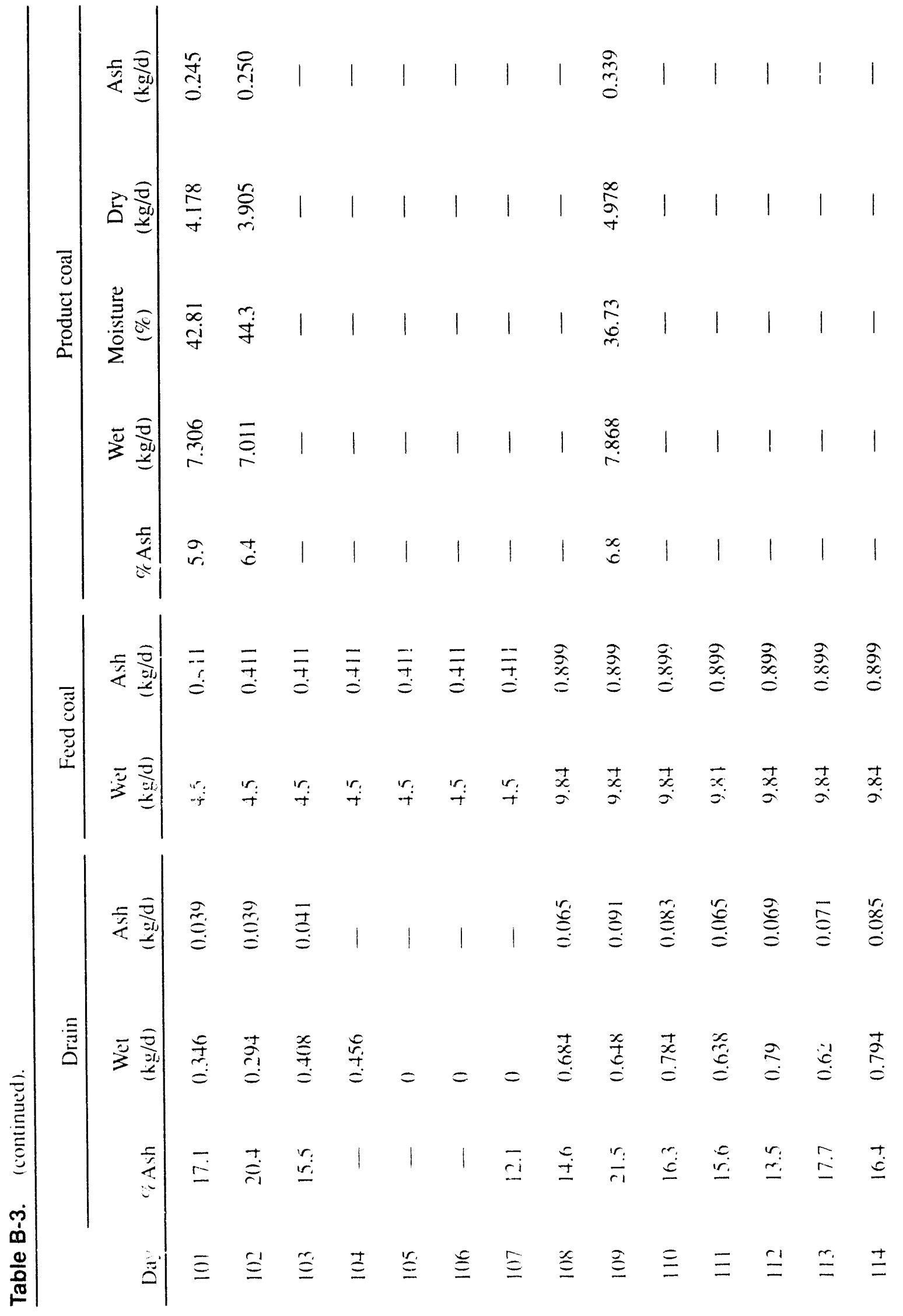




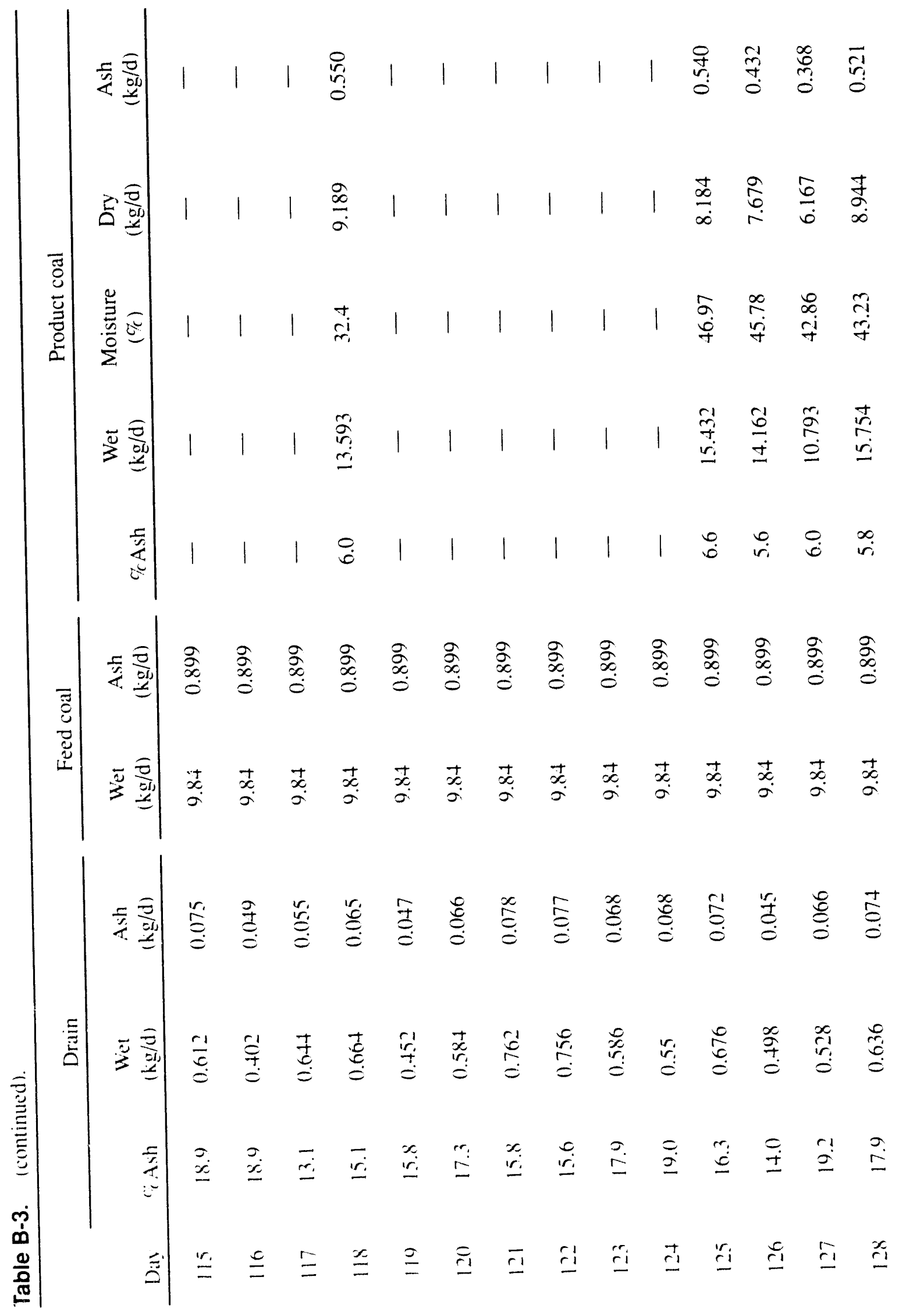




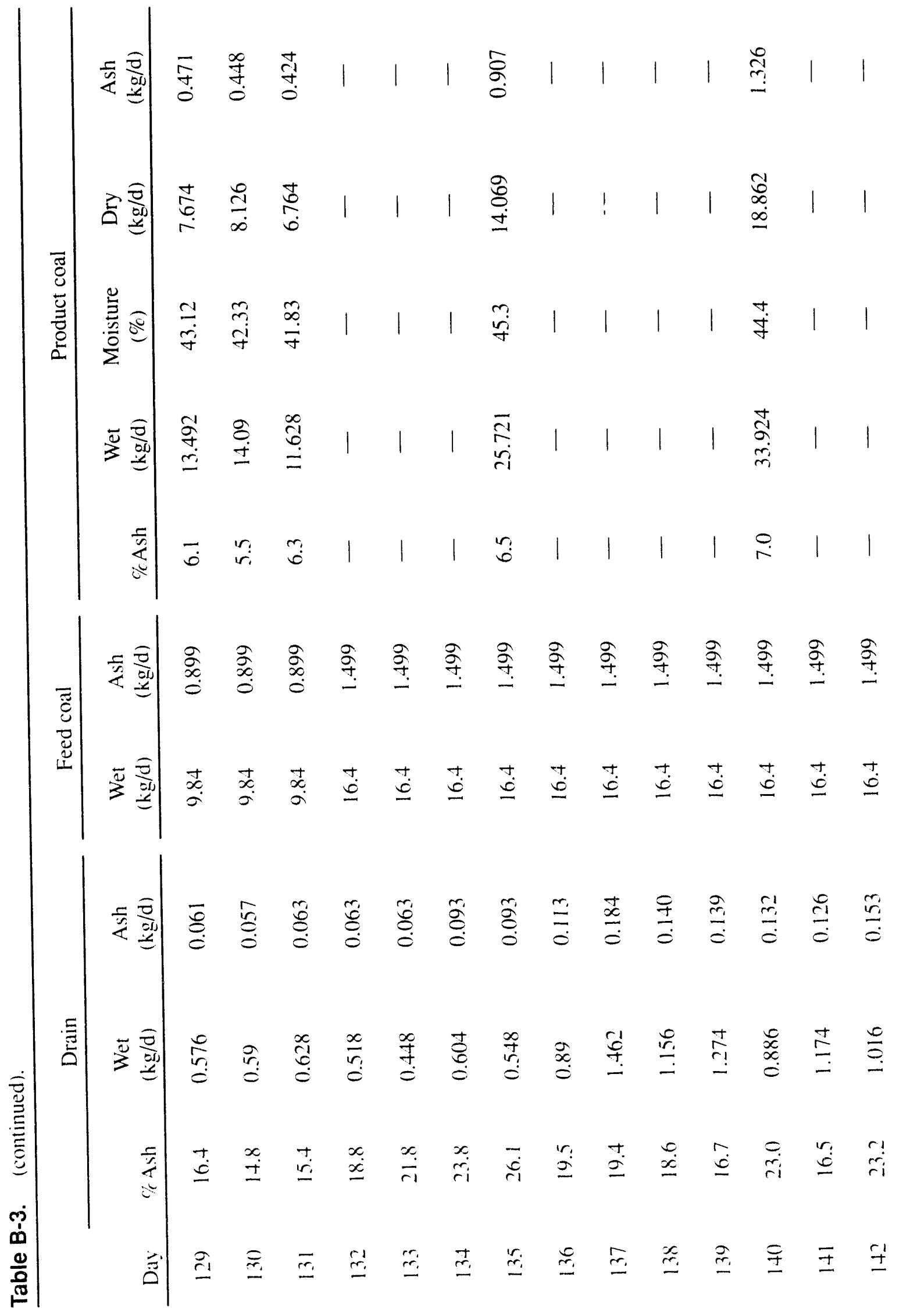




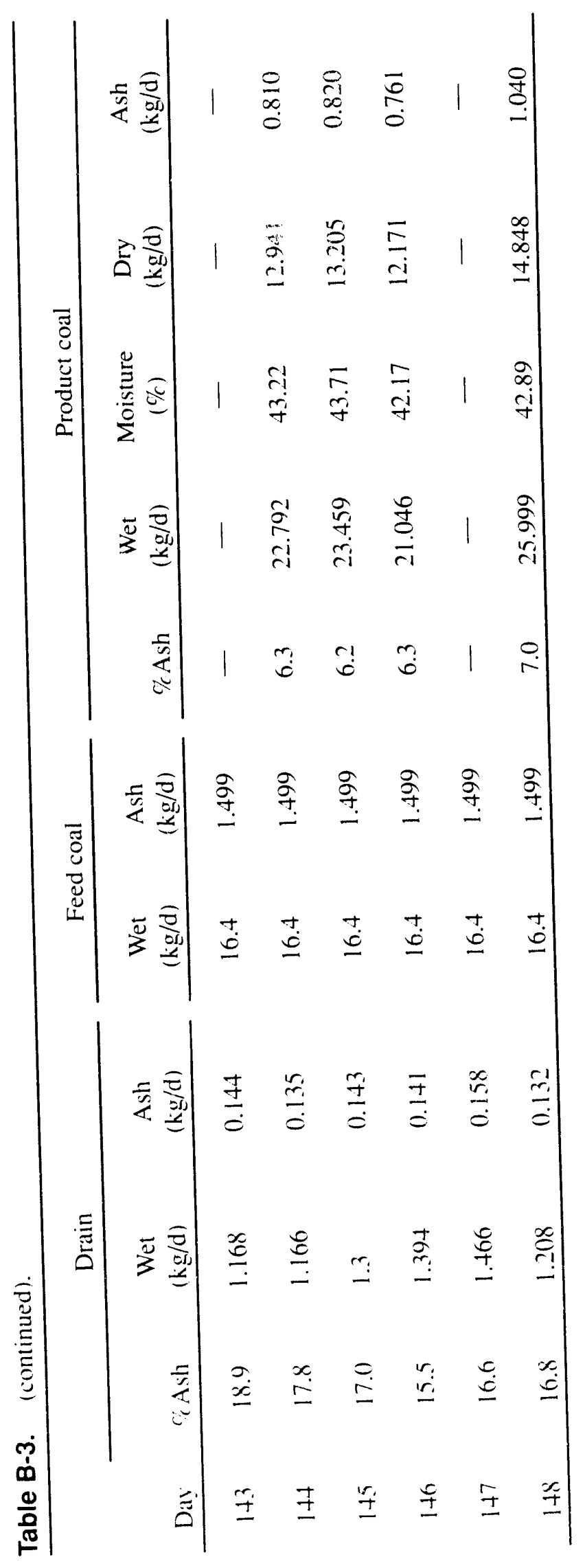

B-2.7 


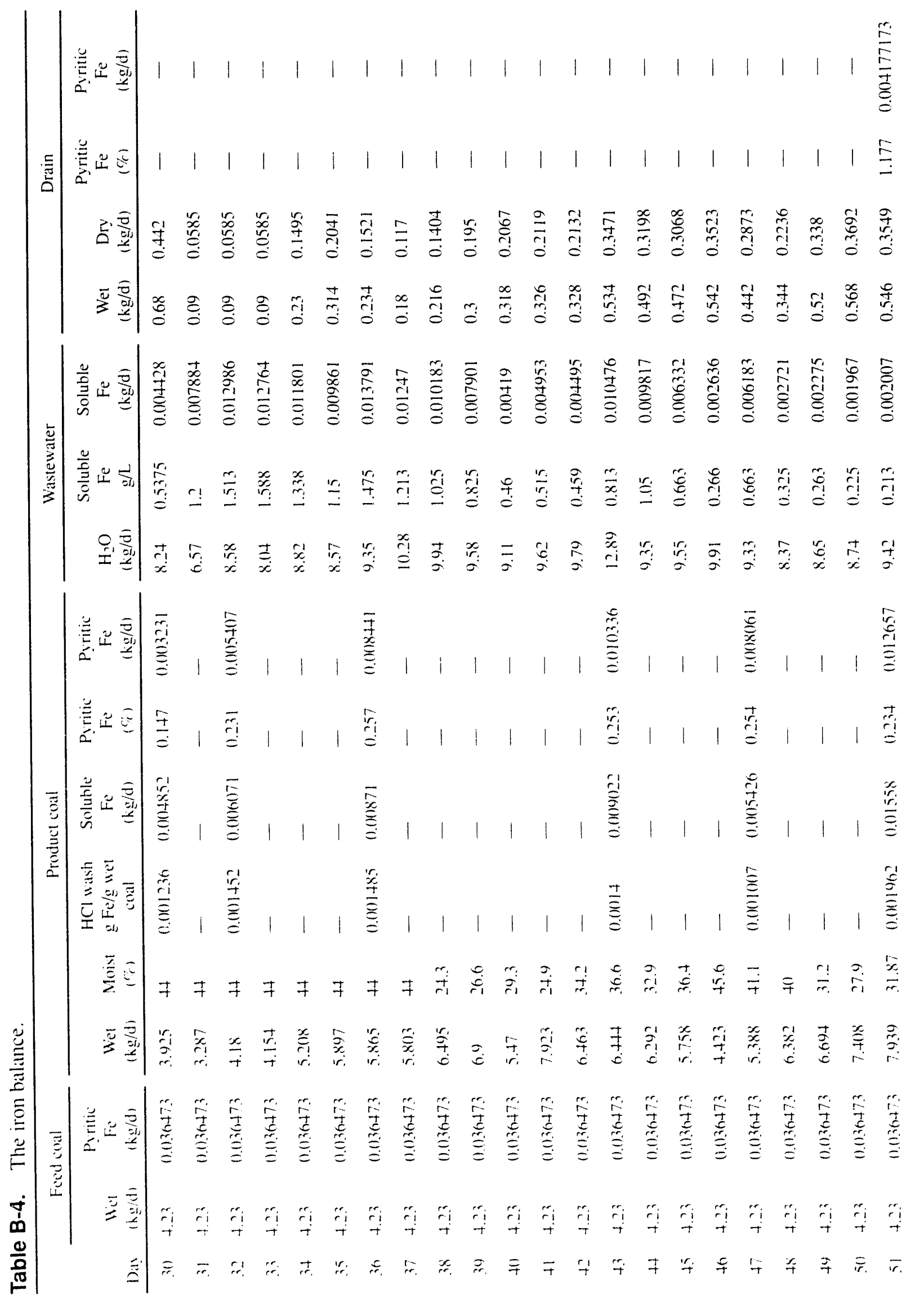




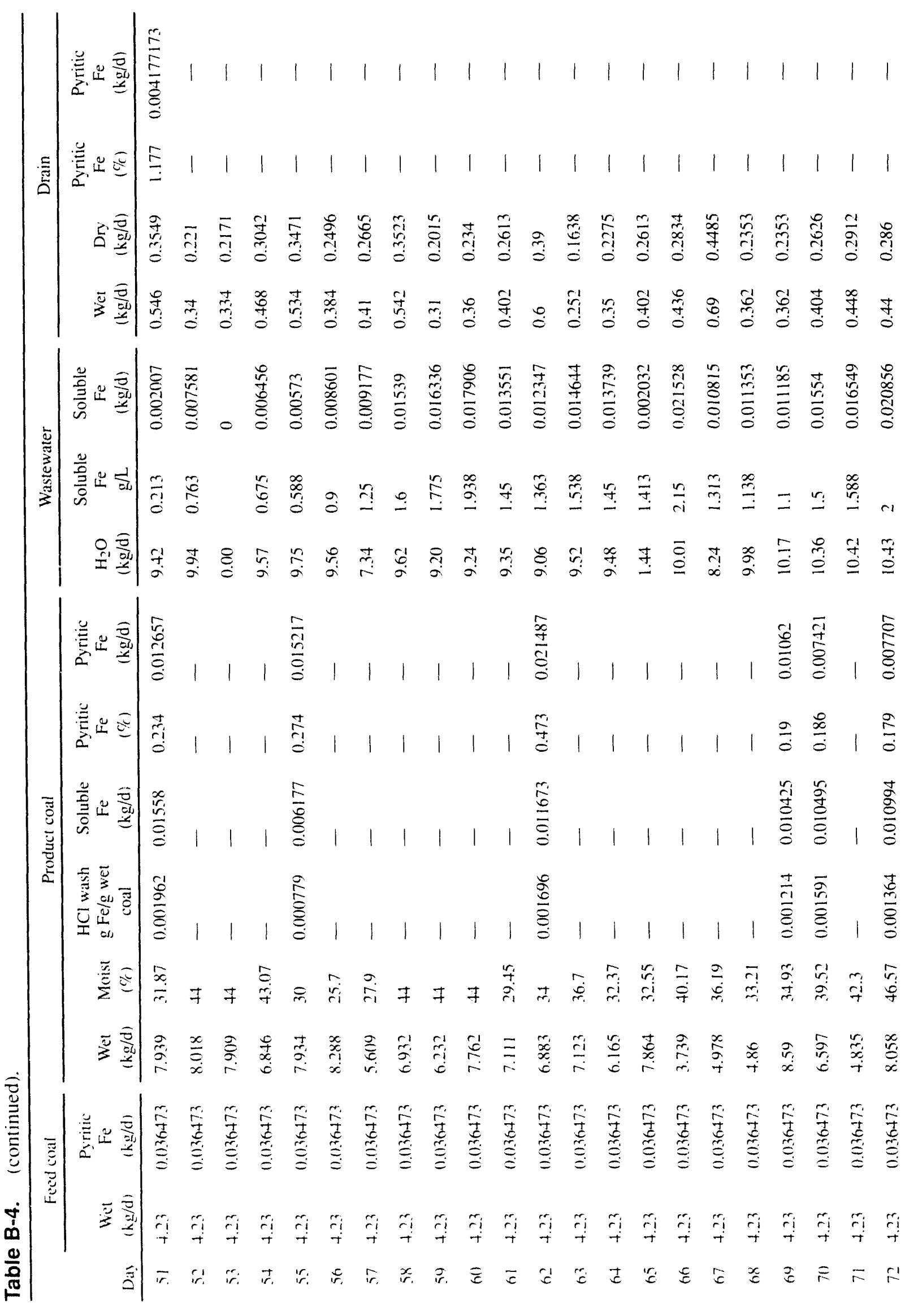




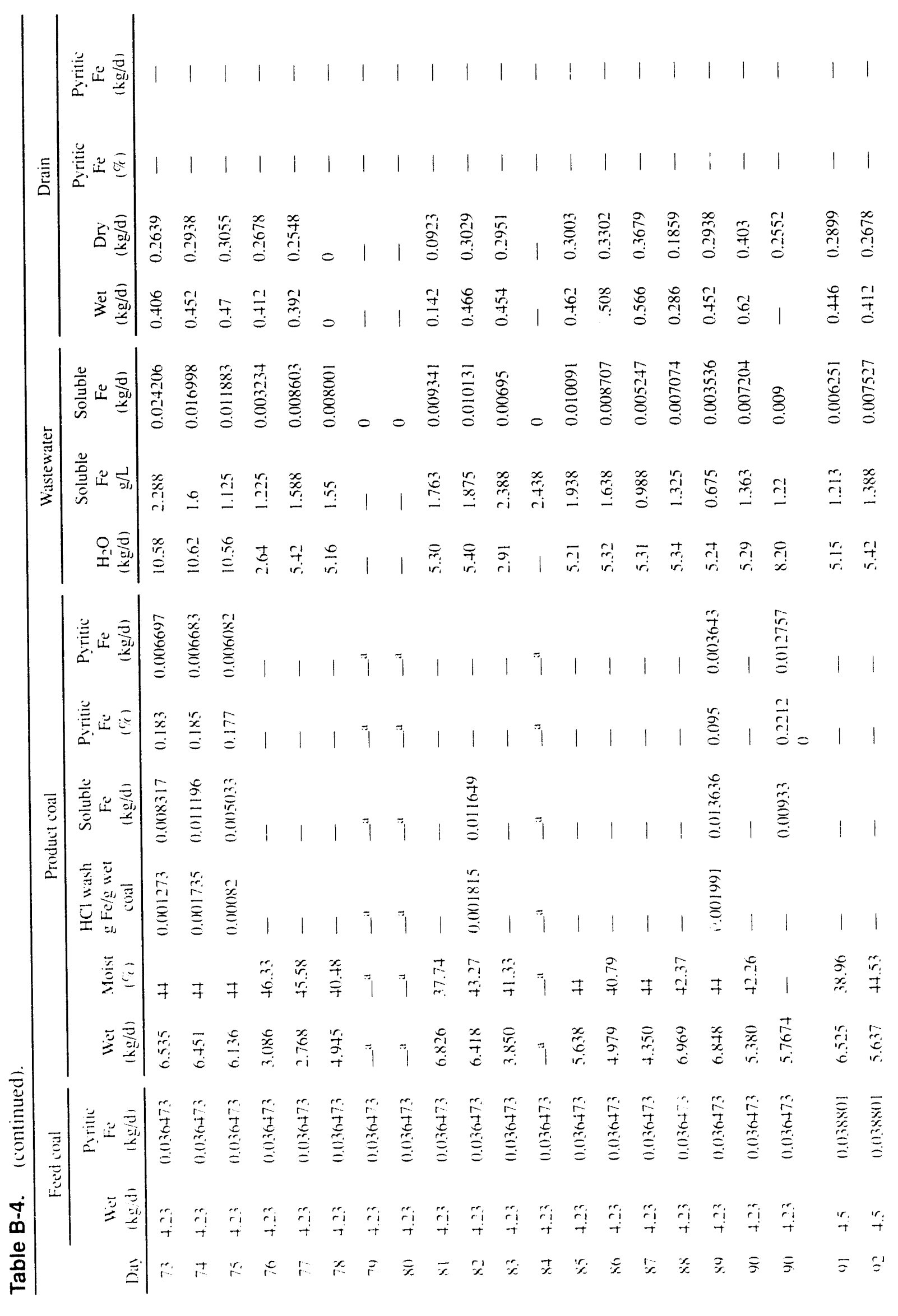




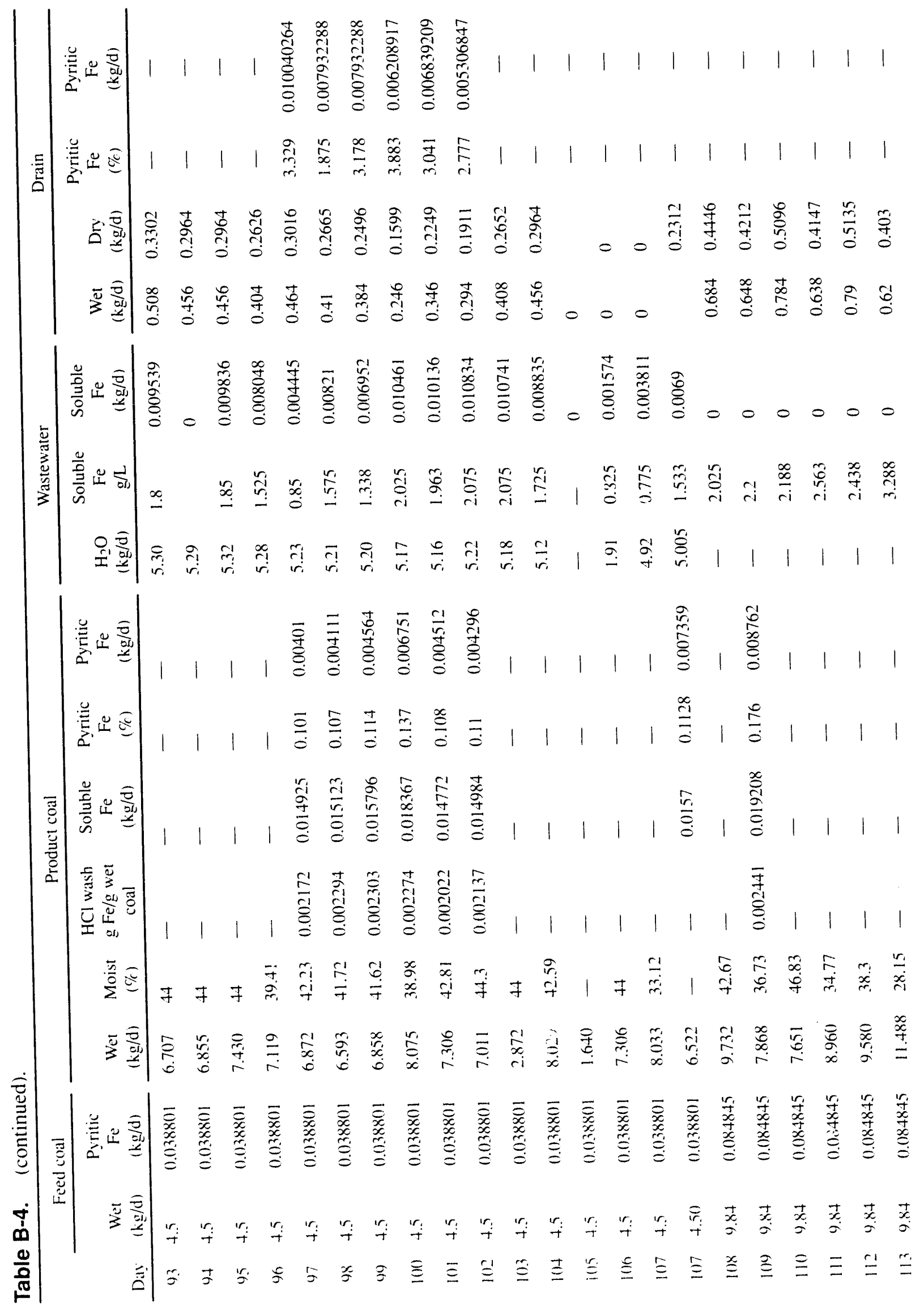




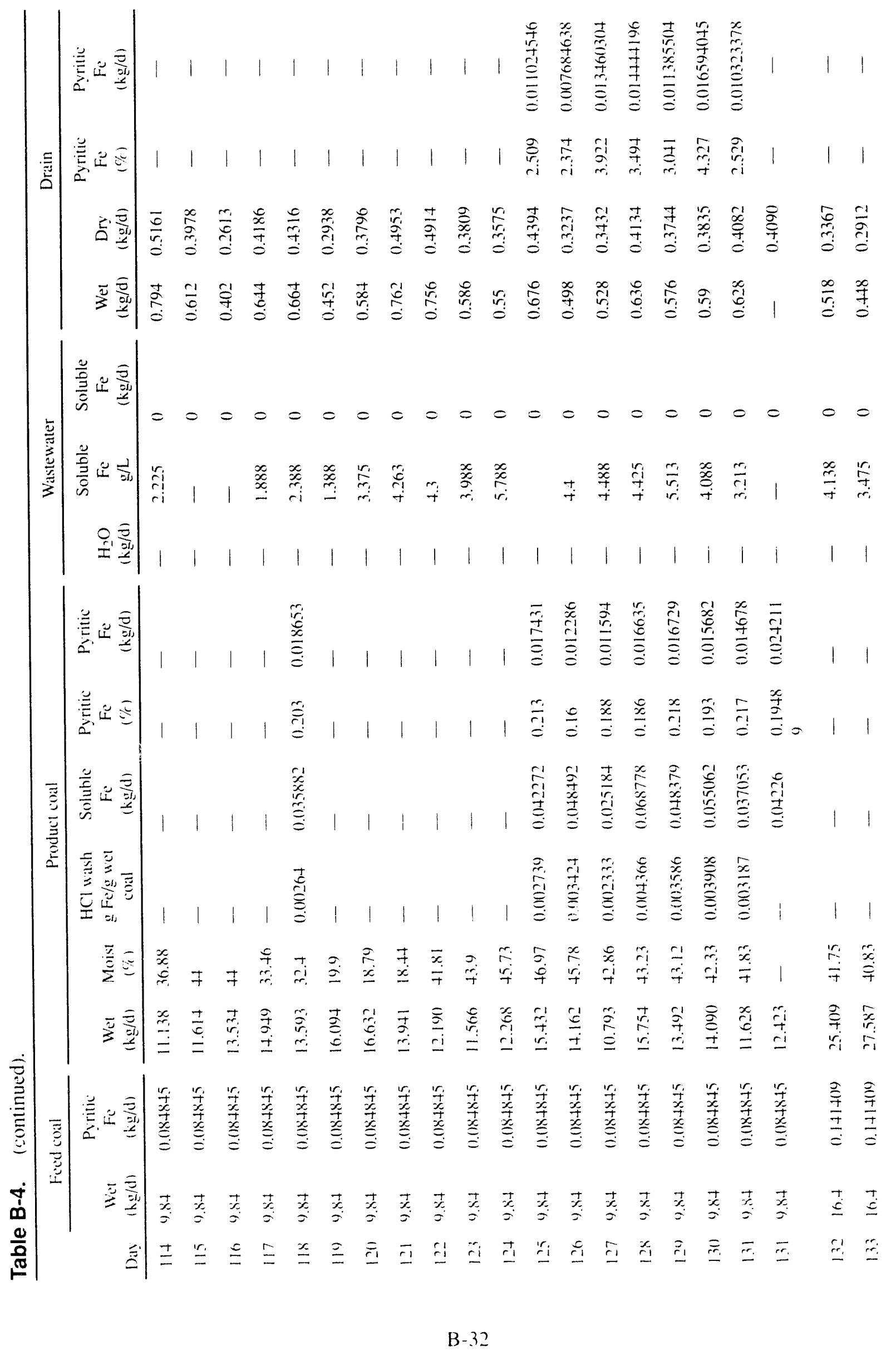




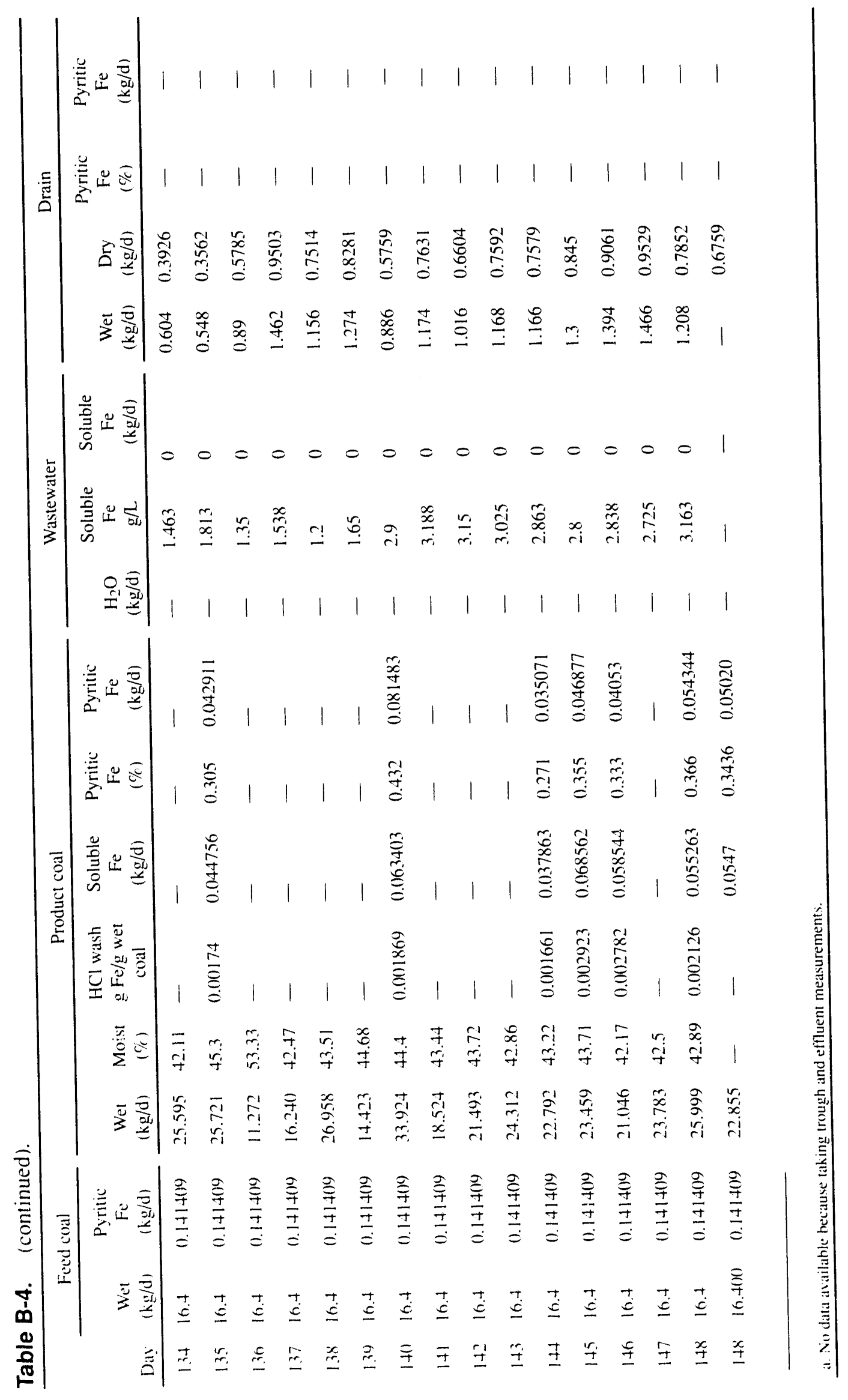



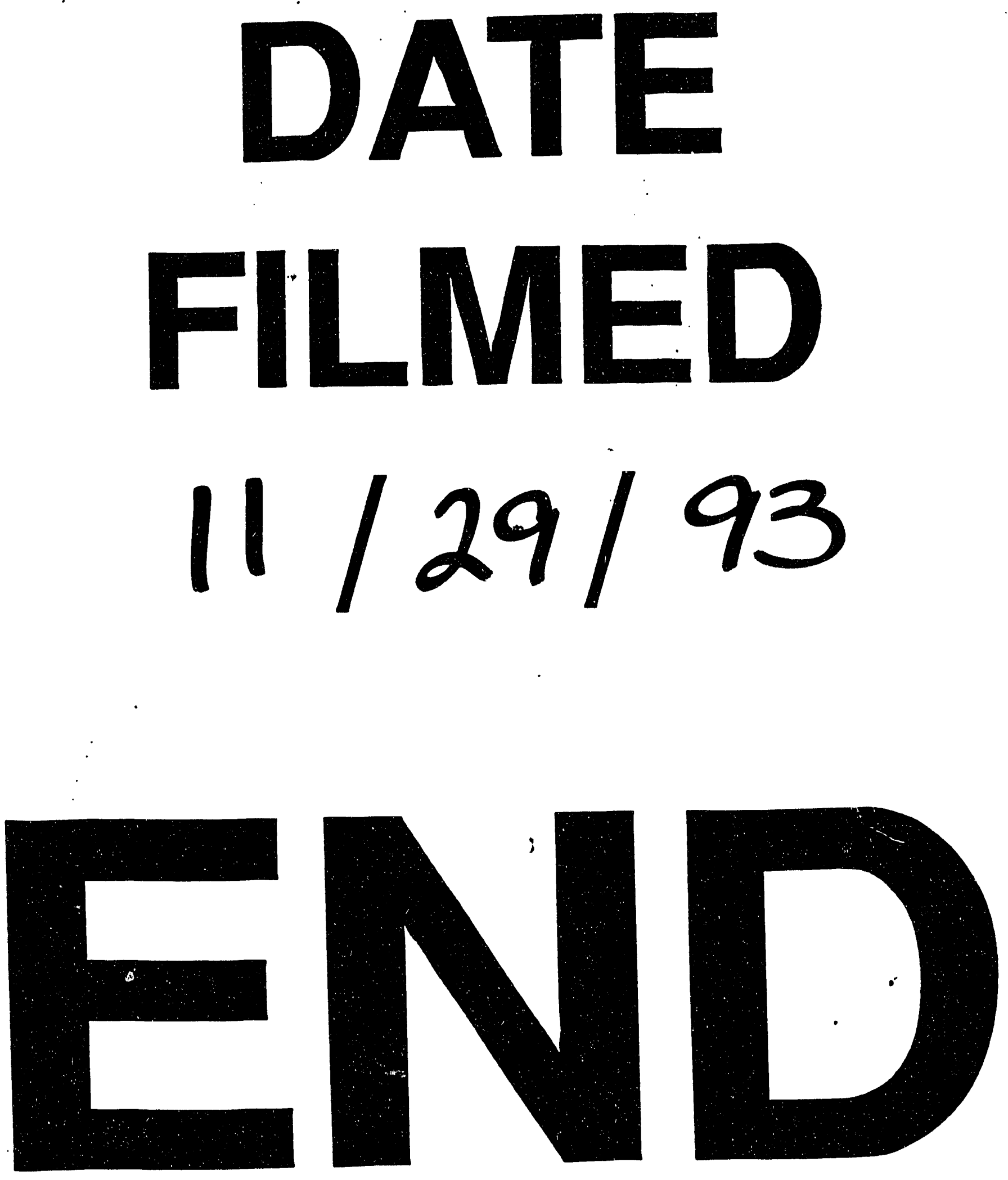
